University of Massachusetts Amherst

ScholarWorks@UMass Amherst

July 2020

\title{
Incorporating Physical Activity in Mental Health Intervention Service Delivery: School Psychologists' Perspectives
}

Scott Greenspan

University of Massachusetts Amherst

Follow this and additional works at: https://scholarworks.umass.edu/dissertations_2

Part of the School Psychology Commons

\section{Recommended Citation}

Greenspan, Scott, "Incorporating Physical Activity in Mental Health Intervention Service Delivery: School Psychologists' Perspectives" (2020). Doctoral Dissertations. 1908.

https://doi.org/10.7275/17148750 https://scholarworks.umass.edu/dissertations_2/1908

This Open Access Dissertation is brought to you for free and open access by the Dissertations and Theses at ScholarWorks@UMass Amherst. It has been accepted for inclusion in Doctoral Dissertations by an authorized administrator of ScholarWorks@UMass Amherst. For more information, please contact scholarworks@library.umass.edu. 
Incorporating Physical Activity in Mental Health Intervention Service Delivery: School Psychologists' Perspectives

A Dissertation Presented

by

SCOTT B. GREENSPAN

Submitted to the Graduate School of the University of Massachusetts Amherst in partial fulfillment of the requirements for the degree of

DOCTOR OF PHILOSOPHY

May 2020

College of Education 
(C) Copyright by Scott B. Greenspan 2020

All Rights Reserved 
Incorporating Physical Activity in Mental Health Intervention Service Delivery: School Psychologists' Perspectives

A Dissertation Presented

By

SCOTT B. GREENSPAN

Approved as to style and content by:

Sara A. Whitcomb, Chair

Sarah Fefer, Member

Laura A. Hayden, Member

Catherine Griffith, Member

Jennifer Randall

Associate Dean of Academic Affairs

College of Education 


\section{DEDICATION}

This dissertation is dedicated to my parents, Sandy and Joe, my family, and my partner, Jonathan. I am forever grateful for your unconditional love and support. 


\section{ACKNOWLEDGMENTS}

This dissertation has been a labor of love, and I am grateful for those who have supported me throughout this process.

To my parents, Sandy and Joe, thank you for your unconditional love and support. I couldn't get through this arduous process without your support along the way and the values that you have instilled in me - humility, sensitivity, and tenacity. Thank you to my siblings for cheering me on and thank you to my nieces and nephews for teaching me and reminding me of the importance of playfulness and perspective.

Jon, you are pretty much a school psychologist by association at this point. I value your love, support, and compassion. I am so grateful for your ability to stay in the moment and find humor in the little things.

Sara, you have helped me grow personally and professionally. Thank you for making this dissertation possible and providing me with opportunities that have allowed for me to engage in research and clinical work that are in line with my career goals. Also, thank you for bringing Buster to some of our meetings.

Cat, thank you for taking me under your wing as your research assistant turned colleague. From presenting to publishing and every academic activity in between, I am forever grateful for your mentorship and trust in me. Sarah, thank you for your mentorship and collaboration over the years. Since working together on a physical activity systematic review during my first semester, you have been a key part of the progression of this research line. Laura, over the past eight years you have been helping me think through the rich intersections between physical activity and social-emotional development. Thank you for your positivity, good vibes, insight, and investment. 
Alexandra, I really appreciate you stepping into the external evaluator role and answering questions throughout. Your expertise has strengthened this study and has developed my skillset as a researcher.

Kelsey, thank you for being an incredible collaborator. You are a key player in this study and your voice and perspectives are embedded in this work. I always looked forward to our research meetings and check-ins. You have a truly bright future ahead in the field of school psychology. Cassidy, thank you for providing edits to this dissertation and for your listening ear regarding the evolvement of my research line over the years.

Jess, I value our friendship, endless communication, and honesty. I would never trade in our endless hours working, laughing, and caffeinating at nearly every coffee shop in Western Mass. Carolyn, thanks for always having a listening ear and meeting me for 6am swims at HAC, 9pm study sessions at the library, and Shelbourne coffee breaks in between.

To my UMass School Psychology family, thank you for providing such a warm and welcoming environment that allows for authenticity and genuineness. From classes to program seminars to holiday parties, I feel so fortunate to be a part of this special community.

Thank you to the donors of the Mary Margaret Whitaker Webster Award and McCormick Doctoral Dissertation Grant for providing funding for this study and for your commitment to contributing to research that enhances positive outcomes for youth, families, and schools. 


\begin{abstract}
INCORPORATING PHYSICAL ACTIVITY IN MENTAL HEALTH INTERVENTION SERVICE DELIVERY: SCHOOL PSYCHOLOGISTS' PERSPECTIVES
\end{abstract}

\author{
MAY 2020 \\ SCOTT B. GREENSPAN \\ B.A., UNIVERSITY OF MASSACHUSETTS BOSTON \\ M.S., UNIVERSITY OF MASSACHUSETTS BOSTON \\ Ph.D., UNIVERSITY OF MASSACHUSETTS AMHERST
}

Directed by: Professor Sara A. Whitcomb

Epidemiological data posits that youth in the United States (US) experience significant mental health concerns. Approximately $10 \%$ of youth meet criteria for Attention Deficit Hyperactivity Disorder (ADHD) diagnoses (Danielson, Bitsko, Ghandour, Holbrook, \& Blumberg, 2018) and approximately 7\% of youth have a behavioral conduct problem or anxiety (Ghandour et al., 2018). Literature continues to suggest that physical activity is a viable modality in supporting the mental health of youth (e.g., Ahn \& Fedewa, 2011; Annesi, 2005; Biddle et al., 2018). While it is recommended that youth achieve one hour of physical activity daily (Physical Activity Guidelines Advisory Committee [PAGC], 2018), nearly $75 \%$ of youth are not meeting these standards. Further, trends suggest that physical education time in school continues to decrease (Physical Activity National Plan Alliance, 2016). In light of school psychologists' professional commitment to supporting the health and wellness of students (National Association of School Psychologists [NASP], 2010; Ysseldyke et al., 2006), coupled with the growing literature base of interventions and models of service delivery 
to promote mental health with physical activity (e.g., Fedewa, Ahn, \& Erwin, 2013; Greenspan, Fefer, Whitcomb, \& Kemp, 2019), such a modality may be well-suited to incorporate in existing school mental health interventions. This study seeks to explore school psychologists' perspectives of using physical activity as a mechanism to support the mental health of students. In doing so, the author conducted a series of focus groups with elementary level school psychologists. Questions centered on processes of implementation to understand facilitators and barriers to physical activity-based interventions (e.g., Bertram, Blasen, \& Fixsen, 2015). Analytically, this study employed a grounded theory approach (e.g., Corbin \& Strauss, 2015) to yield themes that provide insight into the intersection of school psychology and physical activity and further shine light on directions for future intervention development research. Results suggest that when school and district leaders prioritize using physical activity to promote mental health that can then foster the development of systemic and concrete structures, data collection and data-based decision-making efforts, and, in turn effective and targeted interventions and treatment. 


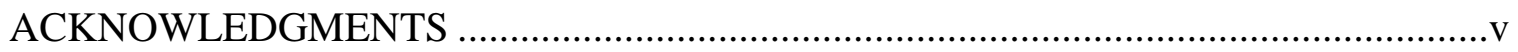

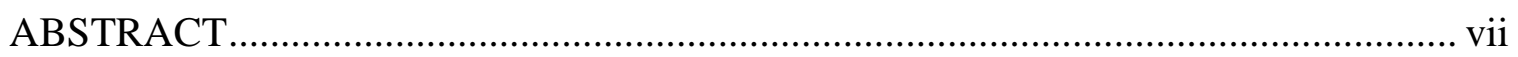

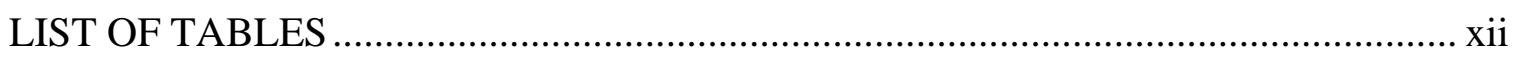

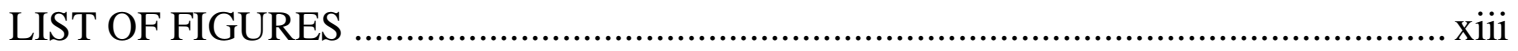

\section{CHAPTER}

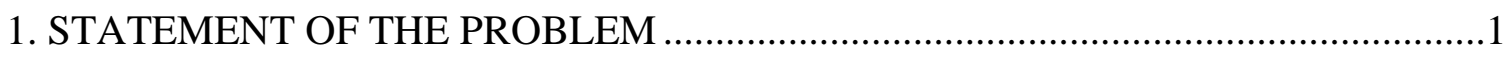

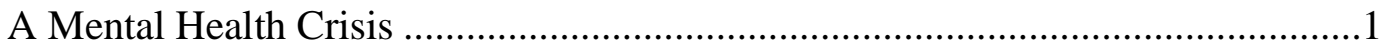

Physical Activity and Mental Health ..................................................................

A Physical Activity Crisis ..................................................................................

Mental Health and Wellness Promotion Efforts in the Schools ..............................

School Psychologists .........................................................................................

Linking Physical Activity and School Psychology Practice ...................................

Current Study ............................................................................................13

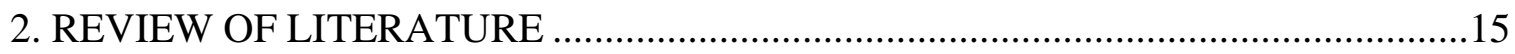

Physical Activity Guidelines for Youth ..........................................................15

Causal Associations of Physical Activity and Mental Health ...............................17

Psychological Mechanisms ..................................................................18

Neurobiological Mechanisms ...............................................................19

Physical Activity Interventions and Mental Health ..........................................21

PAGC $(2018$; 2008) Reviews ...............................................................21

Centers for Disease Control and Prevention (2010) Review .....................22

Classroom Physical Activity ...............................................................22

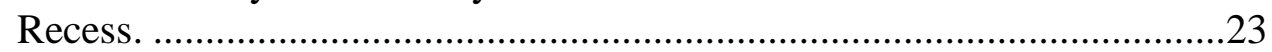

Physical Education .............................................................................24

School-Based Physical Activity Interventions Systematic Review...........24

Meta-Analysis of Physical Activity for Students with ADHD ...................29

Meta-Analysis of Mental Health Outcomes of Physical Activity ..............29

School-Based Conceptualization of Physical Activity ...........................................31

School Psychologists and Physical Activity …………...........................................33

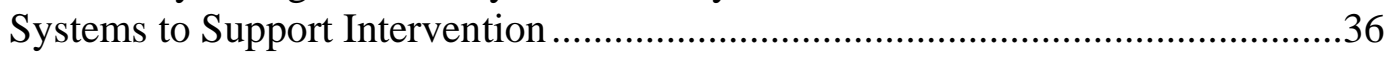

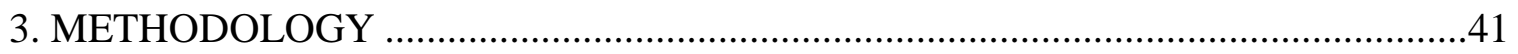




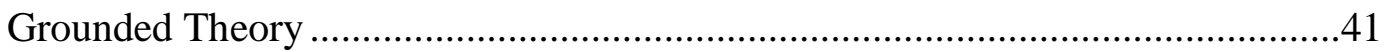

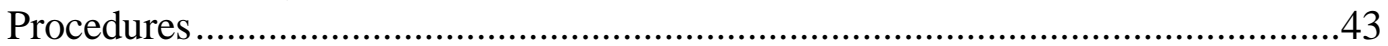

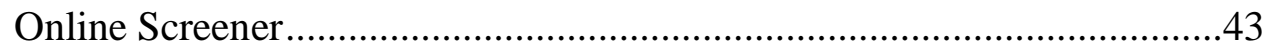

Physical Activity Engagement Questionnaire .......................................44

School Demographics .........................................................................45

Participant Demographics ................................................................45

Focus Group Consent .............................................................................45

Focus Group Procedures ................................................................4

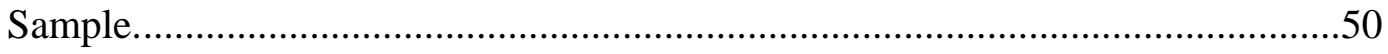

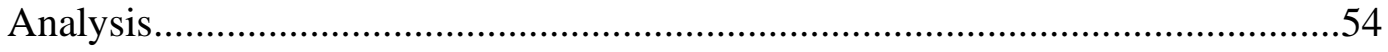

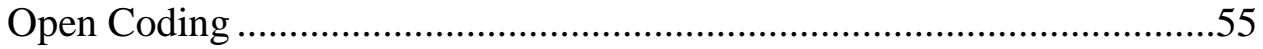

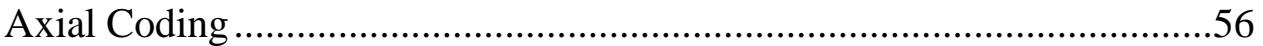

Selective Coding ............................................................................56

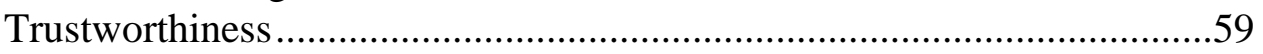

Positionality Statements ......................................................60

4. RESULTS

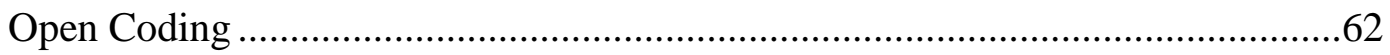

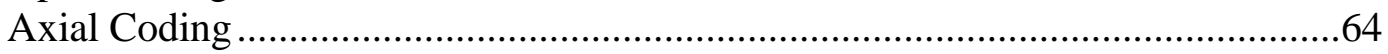

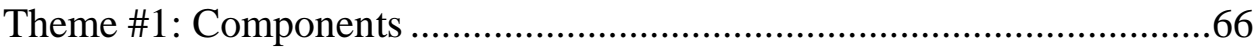

Systemic Components ..........................................................66

Interdisciplinary Team Approach ...................................66

Developmental Appropriateness ....................................71

Inclusivity .............................................................. 72

Whole-Child Perspective ................................................73

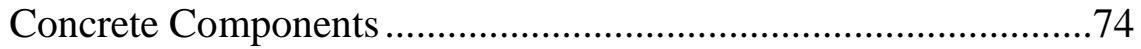

A Multi-Tiered Approach ........................................... 74

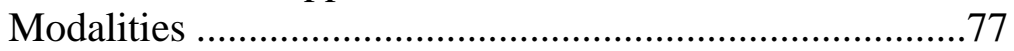

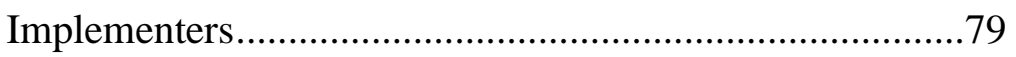

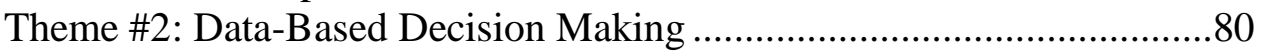

Progress Monitoring.............................................................81

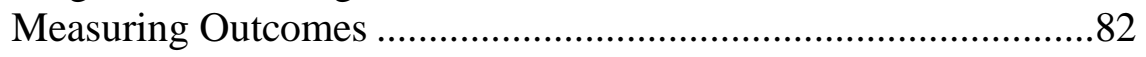

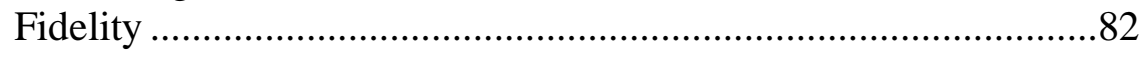

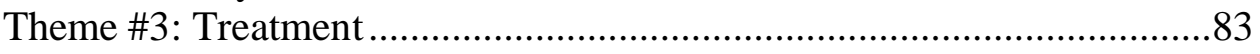

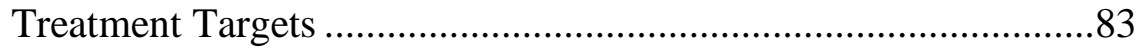

Bi-Directional Teacher-Student Benefit .....................................85

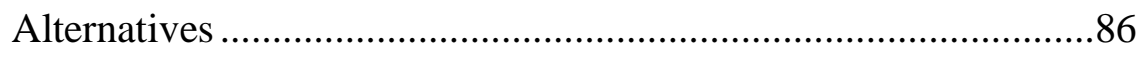

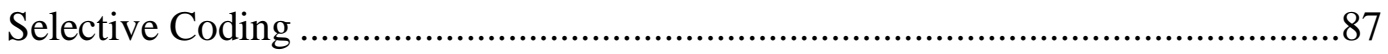

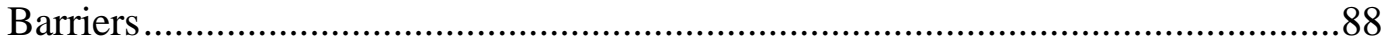

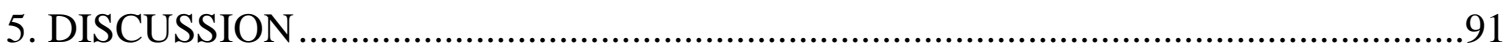

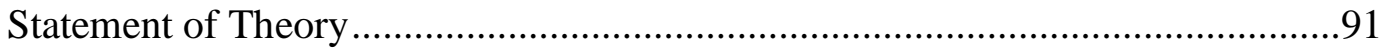

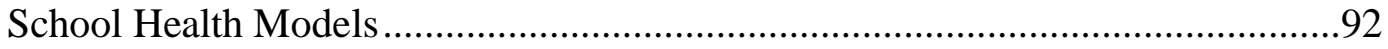

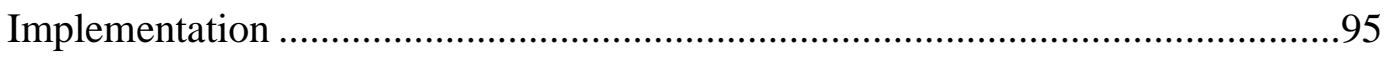




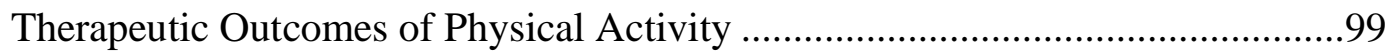

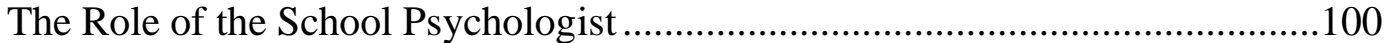

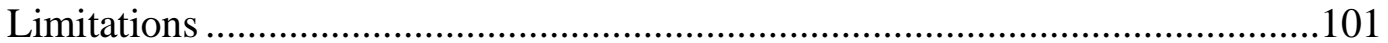

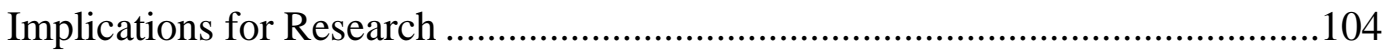

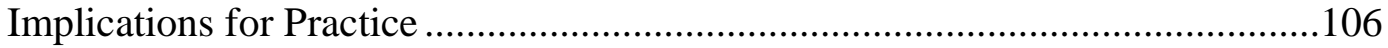

\section{APPENDICES}

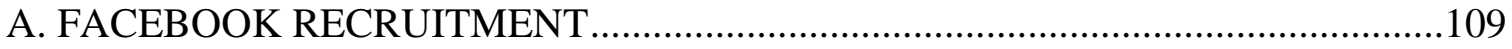

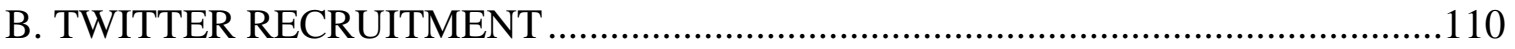

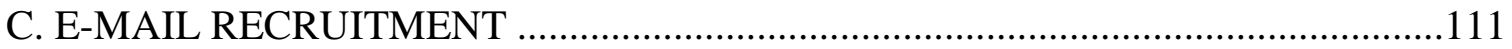

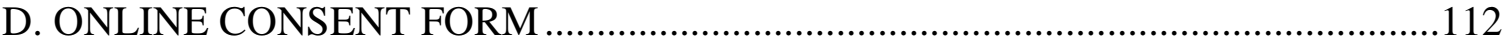

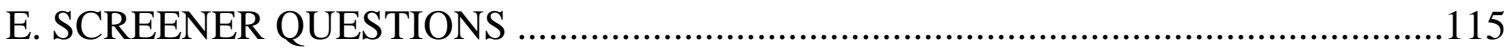

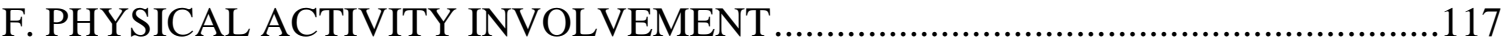

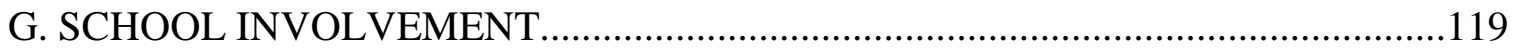

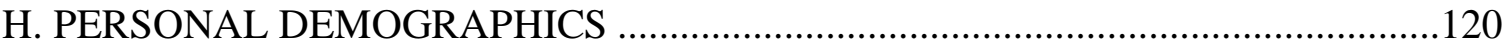

I. FOCUS GROUP CONSENT FORM AND CONFIRMATION ..............................121

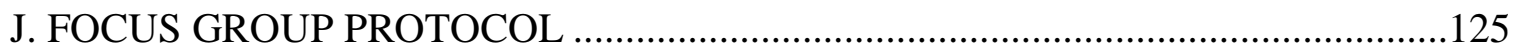

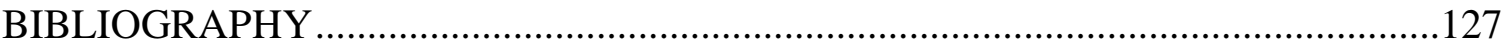




\section{LIST OF TABLES}

Table Page

3.1 Personal Demographics................................................... 51

3.2 School Demographics.................................................. 52

3.3 Physical Activity Engagement of Sample.......................................

4.1. Open Coding ..........................................................63 


\section{LIST OF FIGURES}

Figure $\quad$ Page

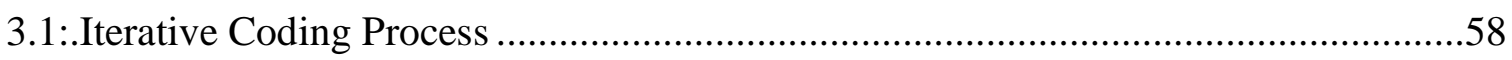

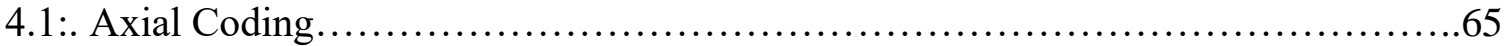

4.2.: Selective Coding .................................................... 87 


\section{CHAPTER 1}

\section{STATEMENT OF THE PROBLEM}

\section{A Mental Health Crisis}

The mental health of youth in the United States (U.S.) remains a critical public health concern. Research suggests that approximately $33 \%$ of youth are expected to meet criteria for a Diagnostic and Statistical Manual of Mental Disorders (DSM) diagnosis (Costello, Mustillo, Erkanli, Keeler, \& Angold, 2003). More specific and recent figures reported by the Centers for Disease Control and Prevention (CDC) indicate that approximately $10 \%$ of youth ages 2 to 17 meet criteria for a diagnosis of Attention Deficit Hyperactivity Disorder (ADHD; Danielson, Bitsko, Ghandour, Holbrook, \& Blumberg, 2016). Of note, nearly $7 \%$ of youth ages 3 to 17 present with behavior disorders or anxiety, and nearly $25 \%$ of youth with anxiety also present with co-morbid depression (Ghandour et al., 2018). The etiology of such mental health concerns is rooted in biological, social, and psychological factors (Mash \& Barkley, 2014).

\section{Physical Activity and Mental Health}

Burgeoning research continues to highlight that physical activity can serve as a viable modality to support the mental health and social-emotional functioning of youth. Notably, youth who engage in aerobic physical activity or aerobic physical activity with resistance exercises have a lesser likelihood of developing symptoms of depression (e.g., Ahn \& Fedewa, 2011; Annesi, 2005; Biddle et al., 2018; Kremer, Elshaug, \& Leslie, 2014; Zahl et al., 2017), anxiety (Biddle et al., 2018), and psychological distress (Ahn \& 
Fedewa, 2011). Youth who engage in physical activity are further likely to exhibit greater self-esteem (Goldfield et al., 2007; Biddle et el., 2018), though direct causal links are not as well substantiated by the literature (Biddle et al., 2018).

\section{A Physical Activity Crisis}

The United States Office of Disease Prevention and Health Promotion Physical Activity Guidelines Advisory Committee (PAGC; 2018) recommends that youth between the ages of 6 to 17 engage in one hour of moderate to vigorous physical activity daily as a mechanism to foster multiple benefits including healthy weight, cardiovascular strength, and cognitive and mental health benefits. Most of this time should involve aerobic activity, and specifically, vigorous aerobic exercises at least three times per week. This report further suggests that youth engage in both muscle strengthening and bone strengthening activities at least three days per week.

In light of the aforementioned recommendations, youth are not obtaining

recommended physical activity levels. Nearly one quarter (23.1\%) of youth ages 6 to 17 engage in one hour of daily physical activity (The Child and Adolescent Health Measurement Initiative, 2018). There are similar figures for adolescents in grades 9 through 12 , with just over one quarter (26.1\%) engaging in physical activity for at least 60 minutes per day (Kann et al., 2018). Researchers highlight that while slightly over $40 \%$ of 6- to 19-year-old young people engage in 60 minutes of physical activity on most days, engagement tends to decrease as young people age into adolescence (Troiano et al., 2008). 
The frequency of physical activity within schools is further declining. Just 3.6\% of elementary schools, $2.4 \%$ of middle schools, and $4 \%$ of high schools provided daily physical education for all students (CDC, 2015). Secondary schools have also decreased time dedicated to physical activity for 14- to 16-year-olds (Youth Sport Trust, 2018). Reports from the Physical Activity National Plan Alliance (2016) suggest that engagement in physical education between the years of 1995 through 2013 was lower than engagement in the early 1990s. Data also indicate that from 1991 to 2013, about $50 \%$ of US youth in grades 9 through 12 did not attend physical education classes during a school week.

\section{Mental Health and Wellness Promotion Efforts in the Schools}

Mental health promotion is a priority for advocacy groups such as the National Association of School Psychologists (NASP), which supports the implementation of mental health interventions within school-based service delivery (NASP, 2015). The CDC advocates for a continuum of mental health assessments and interventions on both individualistic and systemic levels (CDC, 2015) and further endorses the Whole School, Whole Child, Whole Community (WSCC) model, a well-rounded and system-wide approach to supporting student physical and mental health (CDC, 2018). This model specifically considers how schools can serve as a community hub in supporting student wellness across ten domains, which include: (1) physical education and physical activity; (2) nutrition environment and services; (3) health education; (4) social and emotional school climate; (5) physical environment; (6) health services; (7) counseling, psychological, and social services; (8) employee wellness; (9) community involvement; 
and (10) family engagement. Of interest to this paper, the physical education and physical activity aspect of this model involves a comprehensive physical activity program (CDC, 2013). Such a program encompasses systemic and coordinated physical activity that accumulates to one hour throughout the day, which would meet daily recommendations (e.g., PAGC; 2008). This includes: (a) physical education that adheres to standards outlined by SHAPE America (Couturier, Chepko, \& Holt, 2014); (b) before- and afterschool physical activity; and (c) physical activity during the school day. Staff, family, and community involvement and engagement are also important tenants to this approach.

School mental health intervention research suggests that mental health interventions should be delivered within a population-based manner that supports the wellbeing of all students (Adelman \& Taylor, 2010; Doll \& Cummings, 2008; Merrell \& Buchanan, 2006). This underscores the importance of well-sustained frameworks to promote interventions that are linked to targeted needs. Notably, scholars have put forth that "school mental health goals of promoting psychological wellness are not ancillary to student's academic success, but integral to it” (Doll \& Cummings, 2008, p. 2).

A comprehensive approach for systemic intervention, multi-tiered systems of support (MTSS), allows for all students to obtain appropriate support and subsequent skill development. This includes the general population of students, students at-risk, and students who are behind or exemplifying areas of significant concern (Sugai \& Horner, 2009). Further, these approaches draw on data to inform decisions such as those indicating if a student is struggling, which could then lead to the implementation of targeted supports (Doll \& Cummings, 2008; Sugai \& Horner, 2009). Systemic approaches to intervention have been promoted within the field of school psychology 
over the past two decades, coming into documented prominence at the famous 2002 Conference on the Future of School Psychology (Merrell \& Buchanan, 2006).

MTSS involves the provision of intervention supports that match the targeted needs of all students (e.g., Sugai \& Horner, 2009). Response to Intervention (RTI) and Positive Behavioral Interventions and Supports (PBIS) serve as noteworthy examples. RTI was born out of the No Child Left Behind mandate for increased use of academic data (e.g., Newman et al., 2002), involving screening and intervention based upon level of academic need (Speece, Case, \& Molloy, 2003). All students are screened at their academic ability level and data are consistently collected to determine their progress and growth. Students who are not making significant gains are provided more intensive interventions based upon areas of need as indicated by data (Speece, Case, \& Molloy, 2003).

PBIS is a framework focused on safe and prosocial behaviors among all members of a school community (e.g., Sugai \& Horner, 2009). Its three-tiered approach involves a universal level (i.e., preventative interventions for all students), a selected level, (i.e., interventions for students deemed at-risk), and an indicated level (i.e., interventions for students who are struggling and were not successful with selected level intervention). Such a school-wide effort is best sustained through consistency of practices among all members of the school community.

PBIS involves three overarching components including data, systems, and practice (e.g., Horner \& Sugai, 2015). As scholars indicate, data involve information that can be interpreted to support appropriate decision making and measurement of progress; systems broadly refer to the infrastructure that could support and sustain interventions; 
and practices involve the interventions and instruction that are utilized to promote outcomes (Horner \& Sugai, 2015).

The facilitation and sustainability of PBIS involves a diverse group of school community stakeholders that uphold various levels of expertise and roles (e.g., teachers, school psychologists, administrators, specialists) who join together to foster increased school climate initiatives. At the most universal and preventative level of intervention, school PBIS teams develop positively stated expectations and both plan and implement preventative interventions to support all students. School teams also review school data (e.g., office disciplinary referrals) to determine where in the school such supports are warranted. For example, school teams may find that at a certain time of day there are escalated behaviors, and this would provide them with a viable intervention target that could be monitored.

Notably, decisions regarding when a student might need additional support are often determined based upon school data points, such as number of office disciplinary referrals or number of visits to the nurse (e.g., Sugai \& Horner, 2009). PBIS teams also ensure the proper implementation of systems and practices through facilitated discussions and protocols (e.g., Tiered Fidelity Inventory [TFI]; Algozzine et al., 2014).

Research continues to suggest that social and emotional learning (SEL) interventions are well-suited to work alongside existing PBIS structures (Cook et al., 2015). Social-emotional learning fosters students' capacity to learn and exhibit five core competencies, including self-awareness, self-management, responsible decision making, relationship skills, and social awareness (Collaborative for Academic, Social, and Emotional Learning [CASEL], 2017). Learning such skills promotes factors that can 
offset mental health risk and support positive adjustment and coping skills (Greenberg et al., 2003). Such skills are fostered through school-wide practices and curriculum, as well as family and community involvement (CASEL, 2017). Scholars highlight that the use of SEL curricula have been linked with more positive mental health trajectories (Cook et al., 2015; Jones, Greenberg, \& Crowley, 2015) and, specifically, can promote positive behaviors and academic performance, and decrease emotional and conduct problems (Durlak et al., 2011). There are continuous state-level efforts to infuse SEL practices and standards into academic curricula (e.g., Dusenbury \& Weissberg, 2017).

\section{School Psychologists}

School psychologists are uniquely positioned to support the social-emotional, behavioral, and academic wellbeing and capacity of students and school systems. According to NASP's (2010) Model for Comprehensive and Integrated School Psychological Services, school psychologists provide direct and indirect supports to students, families, and school communities to foster positive outcomes across academic, social, and life-skill domains. The model also suggests that school psychologists collaborate with healthcare professionals and consider alterable systemic variables that support the health and wellness for youth.

Authors Castillo et al. (2017) examined facilitators and barriers of integrated school psychological service delivery. Variables making up the construct of integrated school psychological service delivery included problem solving, data-based decision making, collaboration and consultation, school-wide prevention and evaluation, and cultural competence. Castillo and colleagues (2017) found that personal attributes (e.g., 
knowledge and skillsets of school psychologists), stakeholder involvement, resources and support, and school-specific variables were predictive of facilitating comprehensive practice. Of note, these scholars also found consistently across domains that lack of effective resources and support (e.g., professional development, scheduling, supervision) served as barriers to comprehensive practice.

School psychologists are viewed as leaders in supporting the mental health of students (Ysseldyke et al., 2006), with documentation stating that "schools must attend to general health, mental health, and welfare to ensure effective academic development, and school psychologists should provide leadership in these areas" (Ysseldyke et al., 2006, p. 19). Further, school psychologists are positioned to lead initiatives to "design and implement prevention and intervention programs to promote wellness and resiliency" (Ysseldyke et al., 2006 p. 20). Castillo et al. (2016) found that facilitators of integrated practice included personal qualities of school psychologists, access to resources and professional development opportunities, involvement with key stakeholders, and upholding sufficient time with a smaller caseload. In contrast, barriers included having lack of time or a heavy caseload, minimal involvement with key stakeholders, and misalignment of policies or procedures (Castillo et al., 2016).

Survey data suggests that, generally, school psychologists self-identify as transformational leaders, wherein they provide leadership through empowering their school communities, upholding core values and ethical practice, and supporting professional development (Augustyniak, KIlanowski, \& Privitera, 2016). Correlative data highlight positive relationships between transformational leadership of school psychologists and satisfaction of school psychological services among both school 
administrators and teachers (Augustyniak, KIlanowski, \& Privitera, 2016). Notably, key leadership attributes of school psychologists include the ability to support change efforts, uphold competency and vision, and engage in collaboration with the ability to persuade and influence (Shriberg, McArdle, \& James, 2010).

Such leadership skills pave way for engagement in systems change work, including school-wide intervention development and implementation, progress monitoring, and professional development (Machek \& Nelson, 2010). Over half of school psychologists find these types of systems change roles to be desirable or very desirable (Machek \& Nelson, 2010) and would like to spend more time engaging in interventionand professional development-related tasks (Brown, Holcome, Bolen, \& Thomson, 2006).

\section{Linking Physical Activity and School Psychology Practice}

Engagement in physical activity can support mental health and social-emotional outcomes, two areas of youth development of which school psychologists focus their efforts (NASP, 2010). Some literature suggests that school psychologists are well suited to promote physical activity to students, and specifically to assist teachers in incorporating physical activity into their lessons (Fedewa \& Clark, 2010; Greenspan, 2017). Additionally, authors of The Blueprint for Training and Practice in School Psychology (Ysseldyke et al., 2006) specifically discern that health factors must be taken into account for effective learning to take place; they note the importance of addressing prevention, diet, and stress management. 
Other scholars (Dudley, Pearson, Okely, \& Cotton, 2015) indicate necessary overlap between school psychology practice and both physical activity and physical education. They report, "school psychologists and school leadership should be privy to the evidence base regarding the effects of physical education practices in order to advocate for effective systems change that will inevitably promote adaptive outcomes for students, particularly those from culturally diverse backgrounds" (Dudley, Pearson, Okely, \& Cotton, 2015, p. 176). This statement concords with evidence suggesting that certain groups of students feel marginalized within school athletic settings including students with physical disabilities (Goodwin \& Watkinson, 2000), and sexual minority and gender diverse students (Greenspan, Griffith, Hayes, \& Murtagh, 2019; Kosciw, Greytak, Zongrone, Clark, \& Truong, 2018). Further, Dominant gender and racial discourses are embedded within the physical activity context (Azzarito \& Solomon, 2005).

Literature illuminates that physical education is often delivered by teachers who have not obtained skillsets in culturally competent practices to understand the underpinnings of health and physical education from diverse students' worldviews (Barker, 2019). Specifically, researchers suggest that sexual minority youth experience verbal and physical harassment within the confines of physical education with minimal intervention from physical education teachers (Greenspan et al., 2019). While students with physical disabilities report that physical education can provide them with group cohesion and benefit, they also feel socially isolated, question their abilities, and are unable to effectively engage in activities (Goodwin \& Watksinson, 2000). Research (Barros, Silver, \& Stein, 2009) has further suggested through secondary data analysis that 
of a cohort of third graders, those who had no recess or just a minimal recess break were more likely to be students of color and from families of lower income and lower education levels. In light of school psychologists' commitment to social justice (e.g., NASP, 2010; Shriberg, Song, Miranda, \& Radliff, 2013), their involvement in physical activity may support more inclusive and equitable practices.

Scholars Fedewa, Candeleria, Erwin, and Clark (2013) have suggested that physical activity may serve as a viable intervention modality for school psychologists to incorporate into their practice, and further conceptualized the integration of physical activity within a multi-tiered system of support (MTSS). Within this conceptualization, physical activity would be provided to all students (tier 1), and based upon need, more targeted physical activity interventions would be implemented (tier 2 and tier 3 ). For example, at a universal level of intervention service delivery, all students would engage in the recommended 60 minutes of physical activity per day by receiving physical education, recess, and physical activity breaks during class. Students who benefit from higher dosage of physical activity would have increased physical activity breaks, use of physical activity during breaks that would ordinarily be of sedentary nature, and longer bursts of physical activity during the day. This literature, however, did not underscore the specific systems that would substantiate such practices, data that could be used to track student progress, and decision rules to determine if a student warrants an increased level of intervention, and further, what types of interventions would be most appropriate.

Greenspan, Fefer, Whitcomb, and Kemp (2019) engaged in a systematic review of existing physical activity interventions that foster social-emotional-behavioral and academic outcomes. Employing a rigorous coding process, the authors yielded 22 
physical activity intervention studies within a search of 16 select school-focused journals (10 of which were school psychology-specific journals). The articles included interventions that thematically involved yoga $(n=5)$, antecedent exercise $(n=3)$, in-class movement breaks $(n=7)$, and recess interventions $(n=4)$. Three articles were categorized as "other," as the scope of those physical activity modalities were unrelated to the general themes yielded from the results of the other studies.

Notably, these 22 studies were pooled within a multi-tiered framework to match the intervention with the level of student need. However, most of these studies did not explore in detail the degree to which school psychologists could have involvement and what their role could entail. This highlights a research-to-practice deficit, as many of these studies are published within school psychology journals, but do not outline the ways in which school psychologists can use their unique skillset to support the implementation of physical activity within interventions. Greenspan et al. (2019) suggest that school psychologists can specifically incorporate physical activity within interventions through teacher consultation, data-based decision making, and infusing such work in their direct service interventions (e.g., counseling). However, the voices of school psychologists will provide further data pertaining to their belief systems and perceptions of facilitators and barriers, as they pertain to physical activity interventions to support mental health.

Further, authors (Greenspan et al., 2019) call for future research to both explore school psychologists' roles in physical activity promotion and consider how physical activity can be embedded within existing intervention frameworks. In light of these research directions, a critical next research step involves developing an understanding of 
school psychologists' perspectives when considering a shifting role toward physical activity intervention, and specifically, facilitators and barriers of implementation. Indeed, school psychologists are change agents who are well-equipped with skills to provide data-based supports for student wellness through empirically supported interventions (NASP, 2010; Ysseldyke et al., 2006).

\section{Current Study}

This study seeks to develop an empirically rooted understanding of elementary level school psychologists' belief systems and perspectives of implementation factors related to using physical activity within mental health interventions. Such an understanding adds to the knowledge base focused on the intersection between school psychological interventions and physical activity. The overarching research question is: What are elementary level school psychologists' perspectives of implementing physical activity to support students' mental health? The elementary level was specifically chosen as a means to focus in on one sub-population of students to consider developmentally appropriate practices. Further, providing youth with physical activity at a younger age could off-set risks of developing depression (e.g., Ahn \& Fedewa, 2011; Annesi, 2005; Biddle et al., 2018; Kremer, Elshaug, \& Leslie, 2014; Zahl et al., 2017), anxiety (Biddle et al., 2018), and experiencing psychological distress (Ahn \& Fedewa, 2011).

This study employed focus groups with school psychologists. The author and a research team developed questions rooted in an implementation science heuristic (i.e., Bertram, Blasé, \& Fixen, 2015) to understand processes of implementation and sustainment of physical activity interventions. Using a grounded theory methodological 
approach (e.g., Corbin \& Strauss, 2015), data gleaned from the focus groups were analyzed and results highlight ways in which physical activity can be incorporated within school psychological services to systematically target mental health functioning. 


\section{CHAPTER 2}

\section{REVIEW OF LITERATURE}

\section{Physical Activity Guidelines for Youth}

Physical activity, like other facets of child development, is embedded within an ecological framework (Brofenbrenner, 1979). While youth engagement in physical activity is informed by proximal factors, such as individual motivation and family and school values toward wellness (e.g., WSCC; CDC, 2013), distal factors, such as policies and cultural beliefs also influence such practices. One such systemic factor is public health guidelines, many of which in the U.S. are created by government-funded entities (e.g., U.S. Department of Health and Human Services, CDC) and are disseminated to the public to highlight best practices and recommendations. Such guidance can influence initiatives in community contexts (e.g., WSCC), which can, in turn shape individual values and belief systems.

Public health guidelines indicate that youth between the ages of 3 and 17 should engage in one hour of moderate to vigorous physical activity daily. This includes three days per week of vigorous exercise and three days per week of strengthening activities (PAGC, 2008). This specific guidance indicates:

- Aerobic: Most of the 60 or more minutes per day should be either moderate- or vigorous-intensity aerobic physical activity, and should include vigorousintensity physical activity at least three days per week.

- Muscle-Strengthening: As part of their 60 or more minutes of daily physical activity, children and adolescents should include muscle-strengthening physical activity on at least three days of the week. 
- Bone-Strengthening: As part of their 60 or more minutes of daily physical activity, children and adolescents should include bone-strengthening physical activity on at least three days of the week (PAGC, 2008, pg. vii).

These guidelines note that "the documented health benefits include increased physical fitness (both cardiorespiratory fitness and muscular strength), reduced body fatness, favorable cardiovascular and metabolic disease risk profiles, enhanced bone health, and reduced symptoms of depression and anxiety" (PAGC, 2008, pg. G9-20).

These guidelines suggest that while literature has found significant inverse relationships between physical activity and depression and anxiety symptoms, and has found positive relationships among physical activity and self-esteem and self-concept, there remains minimal literature to provide converging data to substantiate these findings (PAGC, 2008). Indeed, increased literature to further underscore these relationships would bring forth more targeted and robust guidelines. Additionally, the dosage of physical activity in order to improve health outcomes remains unclear (PAGC, 2008). Further, measuring the response to physical activity remains complex, as developmental maturation can confound intervention effects (PAGC, 2008).

In 2018, a follow-up iteration of the PAGC guidelines was disseminated. Within the 10-year span, there was little change pertaining to the state of mental health outcomes of physical activity. The guidance reiterated that that there is insufficient evidence to make conclusions about the relationships between physical activity engagement and depressive and anxiety symptoms for youth (PAGC, 2018). 


\section{Causal Associations of Physical Activity and Mental Health}

Burgeoning literature from neurobiological and psychosocial disciplines continues to illuminate several causal, mediating, and moderating associations among physical activity and mental health outcomes. Biddle, Ciaccioni, Thomas, and Vergeer (2018) engaged in a systematic review of meta-analytic studies to understand causal associations between physical activity and mental health functioning. The authors identified four themes from this review: Anxiety $(n=0$; no reviews focused solely on anxiety), cognitive functioning $(n=20)$, depression $(n=8)$, self-esteem $(n=5)$, and mixed $(n=9)$. To parse out causal factors, the authors focused on (a) strength of the relationship between physical activity and the specific mental health variables; (b) consistency of the evidence across diverse samples and locations; (c) temporal sequencing; (d) plausibility in light of current biological and mental health knowledge;

(e) dose-response associations; and (f) evidence of experimental interventions.

Depression was rated as having partial support for causality; self-esteem was rated as not having support for causality; and cognitive function was rated positively for having support for causality. Lubans et al. (2016) proposed a model indicating that physical activity engagement is influenced by individual characteristics (e.g., sex, age, weight, fitness, physical activity history). However, the topography of the engagement (e.g., frequency, magnitude, length, modality) moderated neurobiological, psychosocial, and behavior mechanisms. Such mechanisms are explored below. 


\section{Psychological Mechanisms}

There are various theories and perspectives delineating the psychological processes that mediate the positive outcomes of physical activity. Firstly, research suggests that exercise can serve as a coping skill that can distract people from negative thought processes (e.g., Stathapolou et al., 2006; Craft \& Perna, 2004). Janson and Rholeder (2017) suggest that distraction coping can foster decline in cortisol levels that can sustain up to one hour after a stressful situation. This concords with a cognitivebehavioral and skills-focused approach of employing strategies and techniques to foster targeted coping (e.g., Zahl, Steinsbekk, \& Wichstrøm, 2016; Hilt \& Pollak, 2012).

Literature also indicates the utility of physical activity in fostering self-efficacy (e.g., bringing forth meaningful experiences in which people feel they are achieving mastery; e.g., Craft \& Perna, 2004). Key attributes of self-efficacy in physical activity involve cognitive appraisal (e.g., belief in ability to engage in a task), action (e.g., engaging in the task), power to choose physical activity in the face of barriers, and adjusting to changes in self-efficacy (Zahl, Steinsbekk, \& Wichstrøm, 2016; Voskuil \& Robbins, 2015). Authors (Strong et al., 2005) underscore that the benefits of physical activity on self-concept may be mediated by the type of physical activity (i.e., aerobic physical activity mixed with strength or flexibility exercises) in addition to cognitivebehavioral interventions to foster physical activity engagement. Other scholars suggest that the causality between decreased depression risk and youth engagement in physical activity and sport (e.g., Kremer et al., 2014) could be mediated by healthy activity or social connectivity (e.g., Ianotti, Kogan, Jannsen, \& Boyce, 2009; Paluska \& Schwen, 2000). 


\section{Neurobiological Mechanisms}

Scholars have theorized and examined neurobiological mechanisms that mediate physical activity outcomes (Morgan, 1999). Firstly, the thermogenic hypothesis indicates that during exercise engagement, the rise in brain stem temperature can promote relaxation and relieve muscular tension while further supporting changes in neuronal functions (e.g., deVries, 1981). This theory is underpinned by the anxiolytic and musclerelieving impact of warmth on the body (deVries, Beckman, Huber, \& Dieckmeir 1968; Kuusinen \& Heinonen, 1972; see Morgan, 1987 for a review). A seminal study found that an increase in whole body temperature impacts neuronal activity in animal models (von Euler \& Sodber, 1957). Scholars further posit that heating of the body can increase endorphin levels, which can bring forth anxiolytic effects (von Euler \& Sodber, 1957). With this noted, research indicates that this hypothesis is generally unsupported (DeBoer, Powers, Utschig, Otto, \& Smits, 2012; Morgan, 1997).

The endorphin hypothesis indicates that exercise promotes the release of endorphins and increase in $\beta$-endorphin levels, which can support a positive mood and sense of well-being (Hosker et al., 2019; Wildman, Kruger, Schmole, Niemann, \& Matthaei, 1986). In a study published over 30 years ago, researchers found that an increase in endorphin levels was correlated with feelings of pleasantness post-running (Wildman, Kruger, Schmole, Neiman, \& Matthei, 1986). However, reactions to this literature remain mixed, especially as the effects have not always been reversible by naloxone, an opioid antagonist (McGowan et al., 1993). Further, there have been inconsistent effects when researchers have blocked endorphin levels (Dishman \&

O’Connor, 2009). There is also inconsistency in the dose-response to exercise and a 
general uncertainty pertaining to the neurological systems involved with and impacted by physical activity and its effect on mental health (Dishman \& O'Connor, 2009).

The monoamine hypothesis indicates that exercising leads to an increase in serotonin, dopamine, and norepinephrine. Authors (Helmich et al., 2010) suggest that exercise produces similar norepinephric and serotoninergic effects as antidepressant medication. For example, exercise promotes the modulation of monoamines, including the neurotransmitters serotonin, dopamine, and norepinephrine, while further supporting neurogenesis, synaptogenesis, angiogenesis, and increased myelination (Hosker et al., 2019). The dopaminergic effect of exercise has been linked to positive impacts on motivation and symptoms of anhedonia (Dunlop \& Nemeroff, 2007), while the increased availability of serotonin and endogenous opioids post-exercise further underscores a decrease in depressive symptoms (e.g., Wipfli, Lander, \& Ringenbasch, 2011; Stathapolou et al., 2016).

Research has discussed the role of exercise in promoting Brain-Derived Neurotrophic Factor (BDNF), which facilitates increased neuronal growth and survival, as well as synaptic plasticity (e.g., O’Callaghan, Ohle, \& Kelly, 2007). Some theories suggest that a decrease of BDNF, particularly in mid-brain regions, can lead to an increase in ADHD symptoms, while increasing BDNF may be a viable treatment for ADHD symptomatology (Tsai, 2017). However, this link is not consistently substantiated (Rommell et al., 2013). 


\section{Physical Activity Interventions and Mental Health}

Burgeoning intervention research explores physical activity as a means to support youth mental health outcomes across various settings in which youth are present (e.g., school, home clinic). Existing documentation of these interventions allows for both reliable implementation and outcomes and systematic assessment of effectiveness by researchers and evaluators. Subsequent sections synthesize a number of meta analyses and systematic reviews focused on such interventions.

\section{PAGC (2018; 2008) Reviews}

As indicated previously, the PAGC $(2018 ; 2008)$ reviewed a host of literature underscoring the connection between physical activity and mental health among elementary aged youth. The relevant literature in these guidelines focused on depressive symptomatology and quality of life indices.

Brown, Pearson, Braithwaite, Brown, and Biddle (2013) engaged in a metaanalysis of nine physical activity interventions. Inclusion criteria were stringent and involved studies that employed physical activity-based interventions for depression symptomatology for young people ages 9 through 15 . These studies found that 45 -minute yoga and guided meditation sessions four times per week for fourth and fifth grade students produced small and positive effects ( $g=-.131$; Mendelsohn et al., 2010). Other literature describes that a sample of fourth-grade Hispanic youth who engaged in aerobic physical activity (heart rate beats per minute $[\mathrm{BPM}]=160$ ) for 20 minutes at the frequency of three times per week demonstrated promising post-test differences for depression (effect size $=-2.4)$ and self-esteem (effect size $=.39$; Melnyk et al., 2009). 
Another related study indicated in the guidelines report included work conducted by DeBate and Thompson (2005), who evaluated the impact of the Girls on the Run program for 377 participants over 28 sites (322 participated in the post-test). The authors specifically focused on post-test differences in self-esteem, body size satisfaction, and eating attitudes and behaviors. The 12-week (two one-hour sessions per week) intervention for girls ages 8 through 12 infused running with activities that promote social-emotional and life-skills development. Results indicated strong positive effects for self-esteem ( $g=.70)$ and weak positive effects for eating attitudes and behaviors overall $(g=.26)$, and specifically, weak effects for dieting behavior $(g=.22)$, preoccupation with weight $(g=.11)$, and pressure from others related to eating $(g=.15)$. There was also a weak positive effect for body dissatisfaction $(g=.23)$.

\section{Centers for Disease Control and Prevention (2010) Review}

The CDC (2010) published a review of literature focused on the relationships between school-based physical activity and health outcomes. Many of these outcomes, as subsequently discussed, were related to mental health. These studies are categorized by their mode of service delivery (i.e., classroom physical activity, recess, or physical education).

\section{Classroom Physical Activity}

Authors Mahar, Murphy, Rowe, Golden, Shields, and Raedeke (2006) found that students in kindergarten through fourth grade who participated in short bursts of physical activity during class time demonstrated greater on-task behavior for the general 
population of students (effect size $=.60$ ) and students who were least on-task at baseline (effect size $=2.20)$. Similarly, authors Lowden, Powney, Davidson, and James (2001) evaluated an in-classroom movement break program (10- to 15-minute exercise breaks) in 15 classrooms serving children ages 5 through 12 across Scotland and Wales, finding that students enrolled in the program exhibited increased concentration, preparedness, calmness, and social skills development (e.g., working with others).

\section{Recess}

Barros, Silver, and Stein (2009) employed a secondary data analysis (using the Early Childhood Longitudinal Study's kindergarten class of 1998-1999) to compare teachers' perceived behaviors of students who engaged in daily recess for 15 minutes or more versus students who engaged in less than 15 minutes of daily recess. The analysis involved between 10,301 and 11,624 students. Teachers rated behavior on a five-point scale $(1=$ misbehaves very frequently; $5=$ behaves exceptionally well $)$, and results indicated a significant difference between the "no or minimal" recess group $(\mathrm{M}=3.44)$ and the "some" recess group $(\mathrm{M}=3.60)$. Other researchers (Jarrett, Maxwell, Hoge, Dickerson, Hoge, Davies, \& Yetley, 1998) revealed converging results, in that 15 to 20 minutes of recess promoted on-task behavior, as well as less fidgeting and less disinterest among fourth-grade students. Of note, students exhibited significantly more on-task work and significantly less fidgeting behavior on recess days versus non-recess days.

Descriptively, on non-recess days, students were on-task $85 \%$ of the time and were fidgeting $16 \%$ of the time. Comparatively, on recess days, students were on-task $90 \%$ of the time and fidgeting $7 \%$ of the time. 


\section{Physical Education}

Ericsson (2008) engaged in a three-year study that compared attention and impulse control between groups of students ages 7 through 9 who received either combined physical education and as-needed motor-skills training five or six times per week, or students who had physical education for two lessons per week. Conners' Abbreviated Questionnaire (Conners, 1998) was administered to teachers (every year of the project) and parents (at the beginning and end of the project) to gain perspectives about students' attentional functioning and impulse control. Per teacher report, students exhibited greater attention outcomes after the first and second years. However, the results did not sustain in the third year of the study. Students with motor skills issues exhibited positive attentional outcomes in the second and third years, from both parent and teacher perspectives.

\section{School-Based Physical Activity Interventions Systematic Review}

Greenspan and colleagues (2019) focused on physical activity intervention studies published within the field of school psychology and related journals. The authors reviewed 22 studies that met criteria, 17 of which reported on mental health, socialemotional, or behavioral variables, and themed the interventions by modality, which included yoga, antecedent exercise interventions, in-class movement breaks, recess interventions, and other.

Yoga interventions (i.e., Bray et al., 2012; Felver et al., 2015; Frank et al., 2014; Napoli et al., 2015; Peck et al., 2005) involved a full class of students or a small group (homogenously-grouped students with asthma and anxiety or behavioral concerns) 
engaging in a structured yoga class led either by a certified instructor or a video.

Participants were elementary aged (Peck et al., 2005; Napoli et al., 2015; Bray et al., 2012), middle school-aged (Bray et al., 2012), and high school-aged (Frank et al., 2014; Felver et al., 2015).

Effect sizes for group design studies revealed moderate to large outcomes for variables such as anger $(d=.24)$, depression, $(d=.24)$, and fatigue (.48; Felver et al., 2015), as well as revenge motivation $(d=.80)$, hostility $(d=.30)$, and involuntary stress response ( $d=.89$; Frank et al., 2014), and also selective attention $(\mathrm{d}=.6)$, ADHD behaviors ( $d=.49)$, and reduced test anxiety ( $d=.39$; Napoli et al., 2005). Similarly, Bray et al. (2012) found that, in a sample of three students, two of three students that engaged in a yoga intervention to alleviate symptoms of anxiety had medium (.58) and small (.39) effect sizes. While effect sizes were not reported, quality of life and happiness generally improved post-intervention for the three participants (Bray et al., 2012). The Peck, et al. (2005) single case study garnered large effect sizes for on-task behavior, with the average ranging from 1.51 to 2.72 post-intervention, and $.77-1.95$ at follow-up.

Antecedent exercise interventions (i.e., Canella-Malone, Tullis, \& Kazee, 2011; Folino et al., 2014; Nicholson et al., 2011) involved students with behavioral challenges (Folino et al., 2014; Canella-Malone, Tullia, \& Kazee, 2011; Nicholson et al., 2010), with two studies focusing on students with intellectual disabilities (Canella-Malone, Tullis, \& Kazee, 2011) and autism spectrum disorders (Nicholson et al., 2010). Participants were elementary aged (Canella-Malone et al., 2011; Folino et al., 2014; Nicholson et al., 2010) and middle school-aged (Folino et al., 2014). The exercise routine in these studies involved mostly aerobic physical activity (Canella-Malone et al., 2011; Folino et al., 
2014; Nicholson et al., 2014) with two studies also mentioning the incorporation of yoga poses (Canella-Malone et al., 2014) or stretching (Nicholson et al., 2010). Results of antecedent exercise interventions highlight immediate effects (Canella-Malone et al., 2014; Folino et al., 2014; Nicholson et al., 2010) specifically for disruptive behaviors (Canella-Malone et al., 2014; Folino et al., 2014), prosocial behaviors (Folino et al., 2014), compliance (Folino et al., 2014), and academic engagement (Nicholson et al., 2010). The positive results were sustained at follow-up (Canella-Malone et al., 2014), while others upheld less consistent sustainment (Folino et al., 2014; Nicholson et al., 2010).

In-class movement breaks (e.g., Harvey et al., 2018; Melnyk et al., 2015; Melnyk et al., 2009; Ronsley et al., 2013) involved engagement of physical activity during class time. These studies generally encompassed one of two modalities: 1) physical activity implementation within course content, such as movement breaks that were linked to the content of the class (Harvey et al., 2018); or 2) physical activity implementation within curricula, such as a health curriculum with a physical activity component (Melnyk et al., 2015; Melnyk et al., 2009; Ronsley et al., 2013). Participants were elementary aged (Harvey et al., 2018), high school-aged (Melnyk et al., 2015; Melnyk et al., 2009), and kindergarten through twelfth grade broadly (Ronsley et al., 2013). Studies focused on mental health variables, including positive classroom behaviors (e.g., Harvey et al., 2018), internalizing (Melnyk et al., 2015; Melnyk et al., 2009) and externalizing (Melnyk et al., 2009) symptoms, and self-esteem and healthy body image (Ronsley et al., 2013). The studies described positive results for increased behavioral engagement for secondand third-graders with learning and behavioral challenges $(d=.81$; Harvey et al., 2018), 
reduction in anxiety symptoms for adolescents that were overweight $(d=-.56$; Melnyk et al., 2009), decreased depressive symptoms for adolescent students $(d=2.12$; Melnyk et al., 2015), and increased knowledge of healthy living and self-esteem for kindergarten through twelfth-grade aboriginal students $(\mathrm{p}=.005$ when measuring the interaction between time and group; Ronsley et al., 2013).

Recess interventions (e.g., London et al., 2014; Madsen et al., 2010; Mayfield et al., 2017) focused on using facilitated and guided recess time to foster increased feelings of safety and belongingness in school (London et al., 2014), as well as prosocial behaviors (Mayfield et al., 2017) and perceived safety, as well as both external (e.g., school connectedness, caring adults) and internal assets (e.g., empathy, problem solving, goals; Madsen et al., 2010). The three studies evaluated the impact of specific programs, including Playworks (e.g., London et al., 2014; Madsen et al., 2011) and Peaceful Playgrounds (e.g., Mayfield et al., 2010) and all centered on the elementary school context. Promisingly, the interventions fostered increased physical safety $(\mathrm{p}<.05)$, emotional safety $(\mathrm{p}<.05)$, school connectedness $(\mathrm{p}<.05)$, and belongingness $(\mathrm{p}<.01$; London et al., 2015), as well as participation $(\beta=.024)$, problem solving skills $(\beta=.028)$, and goals and aspirations $(\beta=.007)$, in addition to a decrease in verbal conflicts $(\mathrm{p}<$ $0.05)$.

The other two studies (Käll, Malmgrem, Olsson, Linden, \& Nillson, 2015; Twemlow et al., 2008) explored by Greenspan and colleagues (2019) were categorically different and did not fit into the established themes. One study (Käll, Malmgrem, Olsson, Linden, \& Nillson, 2015) assessed the impact of providing structured physical activity two times weekly (30-45 minutes two times per week) for pre-school students through 
sixth grade students in Sweden. Students also participated in their originally scheduled 2 hours of physical education weekly. Through a broad screening measure, the authors measured variables including psychological well-being, peers and social support, and school environment. The other study (Twemlow et al., 2008) focused on effectiveness of a martial arts intervention in fostering more adaptive bystander behavior and less aggressiveness for elementary aged youth (third, fourth, and fifth grades).

Käll and colleagues' (2015) results indicated that students in the control group had more likelihood to experience conduct problems ( $\mathrm{p}<0.05$ ), and girls in the intervention group had lower levels of hyperactivity than girls in the control group ( $\mathrm{p}<$ 0.05). Twemlow et al. (2008) also produced promising results, in that the intervention reduced aggression $(\beta=.31)$ and improved bystander behavior $(\beta=.15)$, but only for male students.

An additional review of reviews conducted by Dale, Vanderloo, Moore, and Faulkner (2018) focused on physical activity and its effect on depression, anxiety, and self-esteem for youth. Of the 26 reviews that were explored, most studies focused on depression $(n=16)$, followed by self-esteem $(n=14)$ and anxiety $(n=2)$. The authors found that approximately $70 \%$ of the depression studies indicated associations with symptom reduction, with the largest effects on clinical levels of depressive symptoms. In light of the small number of studies, the relationship was not well documented. For selfesteem variables, there were weak to moderate effects, as just $50 \%$ of the reviews indicated positive findings. 


\section{Meta-Analysis of Physical Activity for Students with ADHD}

Authors Cornelius, Fedewa, and Ahn (2017) conducted a meta-analysis of the application of physical activity for students with ADHD. The authors found that physical activity brought forth statistically significant findings across outcomes when comparing treatment to control groups $(t(20.9)=2.88, \mathrm{p}=.009)$. When focused on particular variables, the effect was significant on just emotionality and mood problems $(t(8.68)=$ $-2.67, \mathrm{p}=.02)$, and specifically internalizing problems $(t(6.75)=-3.29, \mathrm{p}=.01)$. Aerobic physical activity was the only modality that brought forth effects $(t(13)=2.94, \mathrm{p}=.01)$. Physical activity also brought forth significant effects for those children that were unmedicated $(\bar{g}=1.79, S E=0.55,95 \%$ CI $[0.06,3.53])$. Of note, the dosage of physical activity did not impact effects.

\section{Meta-Analysis of Mental Health Outcomes of Physical Activity}

Ahn and Fedewa (2011) engaged in a meta-analysis of 73 studies focused on mental health outcomes of physical activity for youth ages 3 through 12 . The authors differentiated results for randomized controlled trial (RCT) and non-RCT designs. RCT studies $(n=30)$ produced generally strong results in reducing depression $(\mathrm{d}=-.41)$, anxiety $(d=-.35)$, psychological distress and PTSD $(d=-.61)$, and emotional disturbance $(d=-.33)$, while also promoting self-esteem $(\mathrm{d}=.29)$ and self-concept $(d=.16)$. In terms of modality, circuit training $(d=-.72)$ brought forth the largest effect size, followed by combined approach $(d=-.57)$. Physical activity incorporated within the context of a classroom $(d=-.45)$ indicated significant reductions. Further, interventions that were more than 33 hours showed a significant reduction $(d=-.55)$, followed by those that were 
20 to 33 hours $(d=-.28)$. Of note, use of the physical education teacher as the interventionist gleaned more positive outcomes $(d=1.02)$, followed by classroom teachers $(d=-.36)$ and researchers $(d=-.20)$.

Non-RCT studies $(n=24)$ indicated significant mental health outcomes related to self-esteem $(d=.78)$ and showed that sport participation $(d=1.06)$ was an effective modality. This cluster of studies further illuminates the association between moderateintensity physical activity and mental health symptomology reduction $(d=1.89)$. Of note, individual physical activity generated strong and significant reductions in mental health symptoms, followed by small group service delivery $(d=-.50)$. In terms of time, intervention effects were indicated with less than 20 hours $(d=-1.84)$, with slightly higher involvement showing a smaller effect $(d=-.28)$. Relatedly, an intervention once per week indicated strong significant reductions $(d=-.81)$. For non-RCT studies, a researcher was the most impactful interventionist $(d=-1.71)$, followed by a classroom teacher $(d=-.76)$. For correlational and cross-sectional studies, there were relationships between physical activity engagement and depression $(r=-.14)$ and self-concept $(r=-$ $.14)$.

Strong et al. (2005) has delineated that while cross-sectional study designs yield generally weak effects of physical activity and anxiety, quasi-experimental designs bring forth generally strong associations. For self-concept, specifically, it is noteworthy that cross-sectional studies yielded moderately positive relationships between physical activity and physical self-concept, although associations were weaker for global, social, and academic self-concept. For quasi-experimental studies, however, there were strong 
effects for both sport competence and global self-competence, though weaker effects for social and academic self-concept.

\section{School-Based Conceptualization of Physical Activity}

School health models are rooted in rich history. In a seminal article, Allensworth and Kolbe (1987) indicate that schools are a prime location to support youth in living "healthier, more satisfying, more productive lives" (pg. 409) and further underscore that collaboration among school health professionals could support the comprehensiveness of health programs in schools. The Whole School, Whole Community, Whole Child Model, as discussed, involves core health principles that are infused within the school climate. This includes physical education and physical activity; nutrition environment and services; health services; counseling, psychological, and social services; social and emotional climate; physical environment; employee wellness; family engagement; community engagement; and health education (CDC, 2013). WSCC literature suggests incorporating a Comprehensive School Physical Activity Program (CSPAP; CDC, 2013), which involves obtaining 60 minutes of physical activity per day through before-school physical activity, after-school physical activity, and movement breaks. Staff, family, and community involvement and engagement and also important tenants to this approach.

Fedewa, Candelaria, Erwin, and Clark (2013) conceptualized a multi-tiered model of physical activity interventions. Within tier 1, all students are provided up to one hour of daily physical activity through classroom movement breaks, recess, and physical education. Tier 2 interventions for students needing additional physical activity (for a host of reasons, including academic, mental health, and socio-economic issues) involve 
before- or after-school programs, and additional physical activity breaks that might be implemented during transition times that do not typically engage students in movement. For tier 3 supports, students may benefit from individualized instruction with a physical education teacher to foster cardiovascular or strength and resistance exercise.

Alternatively, a student could use a stability ball or walk to a separate area of the classroom to obtain a quick session of physical activity. It is suggested that tier 3 supports are also infused in the home setting as well.

Of importance, the environment in which physical activity is delivered is pivotal to fostering engagement (Choy, McGurk, Tamashiro, Nett, \& Maddock 2008; Durant et al., 2009). Choy and colleagues (2008) overviewed a pilot project in which a high school signed a joint use agreement to better facilitate physical activity in the building. In doing so, researchers surveyed the school and community about their physical activity preferences and offered youth (teenagers) a selection of adult exercise classes. Most participants (75\%) were satisfied with the classes. Slightly over half of participants were confident in their ability to exercise for 30 minutes per day on most days (52.2\%), felt that they had a safe place to exercise (61.6\%), and felt that the program helped them exercise more $(59.4 \%)$

Durant et al. (2009) determined that adolescent students that had physical education and access to school fields engaged in more physical activity (.236 semi-partial correlation coefficient, .186 semi-partial correlation coefficient, respectively). However, when these individual factors were analyzed within a multivariate regression model, just weekly physical education was significant $(\beta=0.264, \mathrm{p}=.007)$. 
The updated national physical activity guidelines discuss promoting physical activity across spheres of ecological influence, particularly school settings (PAGC; 2018). At the community level, multi-component school interventions and those that have successfully revised the structure of physical education classes are effective in promoting increased school-based physical activity in children and adolescents (PAGC, 2018, pg. D28). A Midcourse Report by the PAGC (Lavizzo- Mourey et al., 2012) focused on interventions that can increase physical activity engagement within schools and other community settings, and illuminated that there is sufficient evidence supporting a multicomponent approach involving classroom activity breaks, engagement in moderate to vigorous physical activity, before- and after-school activities, adequate activity spaces and equipment, and the development of behavioral skills to foster the implementation of physical activity into students' lives.

\section{School Psychologists and Physical Activity}

In a seminal paper published in American Psychologist, Kolbe, Collins, and Cortese (1997) called for psychologists to support the health and well-being of youth and intervene against problematic health outcomes, including lack of physical activity, through coordinated school health programs. The authors request assistance from psychologists to address this need, and specifically note that school mental health professionals are "indispensable members of the school health team" (pg. 263).

There is a growing body of research underscoring school psychologists' involvement in physical activity promotion. School Psychologists may have some personal connections to physical activity as research from unpublished data (Greenspan, 
Whitcomb, Fefer, \& Hayden, 2017) suggests that school mental health professionals engage in an average of 34.5 minutes of physical activity per day. Additionally, $57.1 \%$ of school mental health professionals were high school athletes or frequent participants in fitness activities while $39.3 \%$ were college athletes or frequent participants in fitness activities.

Fedewa and Clark (2010) identified school psychologists as change agents who can incorporate physical activity within school-wide practices to support a host of student outcomes by advocating across classroom, school, and district levels. Authors Savina, Garrity, Keny, and Doerr (2016) echo these sentiments, stating "school psychologists can play an active role in educating policymakers, school personnel, youth, and parents regarding the benefits of movement, and create a school culture that celebrates an active lifestyle" (Savina et al., 2016, pg.282). These authors highlight the growing body of literature depicting the link between physical activity and well-being as an important component to the field of school psychology.

Savina and colleagues (2016) discuss that at a universal level, school psychologists can provide professional development to staff about the benefits of physical activity, provide consultation to teachers about incorporating physical activity in the classroom, and engage in collaboration with physical education teachers and occupational therapists to culminate a list of developmentally-appropriate physical activities. More targeted initiatives involving school psychologists can promote access to physical activity for students with various needs, including motor coordination issues and anxiety. Also, school psychologists can provide support to enhance children's motivation and perceived competence in physical activity. 
School psychologists are well positioned to lead the promotion and implementation of physical activity-based interventions. For example, Folino, Ducharme, and Greenwald (2014) discuss that school psychologists could be promoters of physical activity as an effective modality that is safe and feasible to enact, specifically for students exhibiting externalizing behaviors. Frank et al. (2014) suggest that school psychologists working within alternative school settings utilize yoga-based interventions to foster social-emotional skills development and reduce risky behaviors. Napoli, Krech, and Holley (2005) propose that school psychologists become credentialed to facilitate a mindfulness program that incorporates movement in order to improve attention and reduce test anxiety among participants. Greenspan, Fefer, Whitcomb, \& Kemp (2019) encourage school psychologists to consult and collaborate with teachers so they can incorporate physical activity within their work, engage in progress monitoring of interventions, and consider how to integrate and implement such work within their schools. School psychologists are cautioned to first pilot such initiatives to obtain data that would inform larger-scale rollouts (Greenspan, Fefer, Whitcomb, \& Kemp, 2019).

Motta, McWilliams, Schwartz, and Cavera (2012) discuss the utility of using exercise in schools to support children with Post Traumatic Stress Disorder (PTSD), anxiety, and depression. The authors underscore that collaboration between school psychologists and physical education teachers would necessarily bridge this work, while highlighting that exercise interventions may be met with less resistance than therapeutic interventions.

Researchers (Hosker, Elkins, \& Potter, 2019) encourage clinicians to prescribe physical activity to promote positive mental health outcomes for youth. These scholars 
have recommended a list of questions for clinicians to ask parents in order to assess youth physical activity, including inquiry about the type of physical activity in which a child engages in, as well as the amount of time, preferences, and barriers. Clinicians are encouraged to use motivational interviewing to understand the physical activity values and interests of children and consider developmentally appropriate activities. Hosker, Elinks, and Potter (2019) provide clinical considerations and list developmentally appropriate activities while within a positive psychology perspective that considers positive emotion, engagement, relationships, meaning, and accomplishments around physical activity.

\section{Systems to Support Intervention}

Implementation science research is regarded as the "scientific study of methods to promote the systematic uptake of research findings and other evidence-based practices into routine practice, and, hence, to improve the quality and effectiveness of health services" (Eccles \& Mittman, 2006, pg. 1). Implementation science scholars (Fixsen, Naoom, Blase, Friedman, \& Wallace, 2005) assert that implementation is a multi-year process that requires carefully enacted steps to produce positive outcomes. These scholars denote stages of the intervention implementation process: exploration, installation, initial implementation, and full implementation. The first stage, exploration, refers to assessing needs, considering the match of the intervention with the target population, identifying facilitators and barriers (e.g., resources, personnel) that could promote or hinder implementation, and ensuring feasibility of the intervention. Installation refers to obtaining resources and preparing the organization at hand for the new intervention. In 
this stage, the focus is on identifying and ensuring drivers for implementation both on personnel and a systemic or organizational level, and on developing procedures pertaining to data systems, staff training, and policy. The third stage, initial implementation, involves rolling out an intervention while iteratively adjusting the drivers of implementation and navigating concerns of stakeholders. Lastly, full implementation requires that the intervention is rolled out with strong data systems and implementation drivers that foster desired effects and sustainability.

Although there is generally scant empirical and outcome-based research on these stages of implementation (National Implementation Research Network [NIRN], n.d.), there are converging data that highlight the importance of fostering sustainability in systematic interventions. For example, a review of the literature conducted by NIRN suggests that agencies that pay careful attention to exploration can think carefully about perceived risks and determine if adoption of an intervention is warranted (McCormick, Steckler, \& McLeroy 1995). Further, engaging in initial implementation and understanding the perceptions of consumers can positively impact fidelity and sustainment (Panzano et al., 2004), thus indicating the importance of pre-planning. Further, engaging in progress monitoring, upholding organizational capacity to problem solve, having access to technical assistance, and believing in the program all can support the full implementation stage (Panzano et al., 2004).

Fixsen et al. (2005) delineated the degrees of implementation which include a) Paper implementation (e.g., putting forth new procedures and policies), b) Process implementation (e.g., providing professional development) and c) Performance implementation (e.g., that policies and procedures are put forth with effort and fosters 
benefit to clients). Fixsen and colleagues (2015) conceptualized components that serve as building blocks of implementation. These include a) a source or program that is intended to be implemented, b) a destination that involves the person or entity that will oversee the program, c) a communication link or individual that represents the program and engages in efforts to support its fidelity, d) consistent feedback about the program, and e) its influence on the individual or systemic level.

Rogers (1983) highlights the concept of diffusion which refers to "the process by which an innovation is communicated through certain channels over time among the members of a social system" (pg. 5). With this said, stakeholders go through an attitudinal process before deciding whether they accept or reject a particular innovation. This process involves a) knowledge (e.g., understanding the purpose and use of a particular product or idea), b) persuasion (e.g., shaping positive attitudes of individuals toward the product of idea), c) decision (e.g., the individual has become dedicated to the product or idea), d) implementation (e.g., the individual experiences the routine positive benefit of the product or idea), and e) confirmation (e.g., the individual is further committed to the product or idea based upon the positive benefits that they receive; Rogers, 1983). Rogers highlights the unique rates among which individuals adopt an intervention (e.g., ranging from "innovators" who are said to be risk-takers to "laggards" who are said to be more traditional. The theory also delineates the necessity of communication within a social network to foster messaging about the product or idea as well as time to support decision-making and adoption.

Sugai and Horner (2006), in a seminal paper on PBIS implementation, discussed that schools often implement an intervention or initiative and then move on to another 
area of focus, leading to concerns around successfully sustaining the intervention. The authors noted "inaccurate and narrow programmatic adoption, reduced program outcomes, and limited sustained or expanded use" (Sugai \& Horner, 2006, pg. 249) as consequences. It is noteworthy that Adelman and Taylor (1999) encourage coordinated intervention efforts in schools in contrast to fragmented models of care. Stakeholders are encouraged to consider the availability of interventions and then match them with the needs of the system and students that they are working with to strengthen the scope of intervention. Interventions are well sustained when they are embedded within a framework of support (e.g., Adelman \& Taylor, 2014; Adelman \& Taylor, 1999; Sugai, \& Horner 1996).

Adelman and Taylor (1999) consider physical activity as a preventative and primary modality of mental health support that can be infused between school (e.g., general health education and social and emotional learning programs) and home (e.g., recreation and enrichment programming and public health and safety programming) contexts. For significant systemic change and sustainment to occur, new policies must be translated into appropriate daily practice with readiness for systemic change, intentional mechanisms for implementation, and linkages with other school and community resources (Adelman \& Taylor, 1999). Coordinated efforts involve stakeholders with training in understanding systemic psychosocial, maturational, and cultural factors that can promote positive development (Sugai \& Horner, 2006).

It is apparent that linkages exist between physical activity and mental health functioning. Interventions that use physical activity may be beneficial in schools to support student outcomes. In light of school psychologists' skill and desire to engage in 
system-level initiatives, coupled with their professional commitment to social-emotional, behavioral, academic, and health and wellness outcomes, these stakeholders are well positioned to spearhead or participate in initiatives that merge physical activity with mental health supports.

\section{CHAPTER 3}




\section{METHODOLOGY}

\section{Grounded Theory}

This study employed a grounded theory methodological approach (Corbin \& Strauss, 2015) to obtain a comprehensive understanding of elementary-level school psychologists' perspectives on the utility of their role and skillset in supporting the implementation of physical activity within mental health service delivery. Broadly, grounded theory seeks to understand a concept or phenomena by systematically and iteratively reviewing data indicating experiences, perceptions, and beliefs. Through this

process, higher-order and sub-categories are derived from data and shed light on a theory or theoretical framework (Corbin \& Strauss, 2015).

Grounded theory has underpinnings in both pragmatism and interactionism (e.g., see Dewey, 1917; Mead, 1917), suggesting that thoughts are representations of reality and that perspectives and thoughts reciprocally interact with societal notions, respectively. Sociologists Glaser and Strauss (1967), in their original work on grounded theory, highlight that grounded theory uses the data to guide the development of a specific theory rather than "[using] theory generated by logical deduction from a priori assumptions" (Glaser \& Strauss, 1967, pg. 3). Corbin and Strauss (2015) explain that raw data can form categories that serve as themes, which culminate to generate an overarching theory. Grounded theory, given its ability to underscore a theory on a concept or concepts, is well-suited when exploring a content area with minimal research and can reveal rich data encompassed by participant perspectives (e.g. Corbin \& Strauss, 2015). 
Grounded theory methodology is referred to as part of the Experience and Formation Theory (EFT) cluster of qualitative research, which considers how experiences relate to the conceptualization of a theory (Flynn, Korcuska, Brady, \& Hays, 2019). Other EFT approaches include phenomenology, consensual qualitative research (CQR), and heuristic inquiry.

In line with a Straussian perspective of grounded theory, the epistemology stands that "reality is developed socially and experientially" (Flynn, Korcuska, Brady, \& Hays, 2019, pg. 4). While approaches like CQR (e.g., Hill, 1997) share similarities with grounded theory, a major difference is that grounded theory emphasizes themes through the breadth of content and magnitude of meaning, rather than driving consensus through frequency of codes. Further, CQR often samples individuals who are knowledgeable about the topic of research, while grounded theory seeks to obtain a sample that embodies the construct of study. Phenomenology seeks to understanding lived experiences of participants (e.g., Flynn, Korcuska, Brady, \& Hays, 2019), while this current study seeks to underscore broad perspectives of the participants. Similarly, using heuristic inquiry would not support the scope of this study as questions center around the experience of a particular phenomenon and have autobiographical underpinnings (Moustaka, 1990). Grounded theory is an appropriate methodological choice for this study in light of its deductive approach to highlighting a core theory through analyzing the depth and magnitude of the data. 


\section{Procedures}

A purposeful sample of elementary-level (kindergarten through fifth grade) school psychologists practicing in the US were recruited via social media and email (Appendix A: Facebook Recruitment Materials; Appendix B: Twitter Recruitment Materials; Appendix C: Email Recruitment Materials) to participate in a focus group study. Within recruitment materials, participants were informed about the scope of the

study, were informed that they would receive an incentive upon completion of the study (i.e., a \$35 Amazon gift card), and were provided with a link to a Qualtrics survey. This survey encompassed four components: 1) an online screener; 2) a physical activity engagement questionnaire; 3) a school demographic questionnaire; and 4) a personal demographic questionnaire. Eligible participants were invited to partake in an online focus group. Data were analyzed in a systematic manner.

\section{Online Screener}

Prospective participants who clicked on the Qualtrics link were provided with a screener consent form and subsequent screener questionnaire (Appendix D, Appendix E, respectively) to ensure their eligibility in the study. Specifically, inclusion criteria involved elementary school psychologists who may serve traditional kindergarten through fifth grade elementary schools, and could also work in elementary schools that include pre-school, pre-kindergarten, sixth grade, seventh grade, and/or eighth grade. Inclusion criteria further entailed that participants engage in systems-level change work, such as school-wide data collection and analysis efforts, MTSS, and/or PBIS. Exclusion criteria involved individuals who were not elementary school psychologists (e.g., school 
counselors, school social workers), not working in a public school (e.g., private school), not serving the elementary school level, and not engaging in systems change work (e.g., only engaging in psychoeducational evaluations).

\section{Physical Activity Engagement Questionnaire}

Participants who met inclusion criteria were directed to a physical activity engagement questionnaire (Appendix F) to provide information about their exercise behaviors. Such data were collected to underscore where personal value systems of physical activity might intersect with the scope of the study. Participants first responded to two questions: 1) "Were you a high school athlete or frequent participant in fitness activities?"; and 2) Were you a college athlete or frequent participant in fitness activities?"

Following, participants engaged in the Brunel Lifestyle Physical Activity Questionnaire Planned Exercise Sub-Test (Karageorghis, Vancato, Chatzisarantis \& Carron, 2005), which measures the frequency and intensity of planned physical activity

engagement among participants $(1=$ no engagement or not relevant; $5=$ high ranking of frequency or intensity; see appendix F for measure). This measure is made up of two scales, which were determined through a Confirmatory Factor Analysis (CFA): 1) planned physical activity, and 2) unplanned physical activity (Karageorghis, Vancato, Chatzisarantis \& Carron, 2005). Based upon pilot sample data, the planned physical activity sub-scale upholds greater internal consistency $(\alpha=.90)$ than the unplanned physical activity sub-scale $(\alpha=.68$; Karageorghis, Vancato, Chatzisarantis \& Carron, 
2005). In light of the scope of the study and the stronger reliability of the planned physical activity sub-scale, just the planned physical activity sub-scale was used.

\section{School Demographics}

Participants were then provided with a school demographics questionnaire (Appendix G), which asked about the grades housed in their school, type of location (i.e.,

rural, suburban, urban), percentage of students receiving free or reduced lunch, minutes per week of physical education, and minutes per week of recess. These data elucidated the general demographic make-up of the schools in which participants worked.

\section{Participant Demographics}

Participants further responded to a demographic questionnaire (Appendix $\mathrm{H}$ ), which asked for their state of employment, racial and ethnic identification, gender identity, highest degree, and years working as a school psychologist within their current district and overall. Of note, the questions about gender and transgender status were developed by the Human Rights Campaign (2016). The questions about racial and ethnic identity were developed by BrckaLorenz, Zilvinskis, and Haeger (2014) and used within the National Survey of Student Engagement (e.g., http://nsse.indiana.edu/).

\section{Focus Group Consent}

Following, participants were provided with a focus group consent sheet (Appendix D) where they indicated if they "agree" or "disagree" to participate in the study or indicated that they were "not sure." If participants indicated "not sure," the 
Primary Investigator (PI) contacted them to answer any questions. If the prospective participant indicated "disagree," the PI did not contact them. If the prospective participants clicked "agree," the PI contacted them to schedule a time to attend a focus group. These eligible and consenting participants received an email from the PI with an attached focus group consent form for their records, as well as a list of available times for focus groups. Prospective participants were also sent a hyperlink to a SignUp Genius (i.e., www.signupgenius.com) page that provided them with a list of focus groups they could sign up for.

SignUp Genius was configured to allow for a maximum of seven people per group. There were eight group offerings, and participants could sign up for only one group. When a time was selected, participants were sent an automatic confirmation email from the SignUp Genius service. The PI also confirmed the time with participants and sent a Zoom.com video chat link. If participants did not sign up for a time using the SignUp Genius service, the PI sent a maximum of three follow-up emails.

The PI intended to form participants into groups of five to six participants, with no more than seven participants in a focus group. These numbers stand in accordance with literature suggesting a minimum number five or six participants and at most between seven to ten participants (Carey \& Asbury, 2012; Morgan, 1997).

It was intended that the total number of participants would be dependent upon data saturation, or informational redundancy, wherein themes and codes are repeated and new rich information is scant (Baum, 1998; Corbin \& Strauss, 2015; Fusch \& Ness, 2015; Glaser \& Strauss, 1967; MacDougall \& Fudge, 2001). However, for logistical purposes, that PI aimed to glean a sample of approximately 30 participants, based on 
consultation with qualitative research experts who hypothesized that data would saturate at that number.

\section{Focus Group Procedures}

Focus groups were held in June 2019. There was a total of 20 participants. Participants entered the focus group through the link received in their email. Online synchronous focus groups using video chat was selected as a feasible and inexpensive method to collect data from participants located in various geographic locations (e.g., Kenny, 2005). Of note, there is some academic literature focused on the promise of both asynchronous and synchronous focus groups using email or chatroom formats (Kenny, 2005; Stewart \& William, 2005; Williams, Clausen, Robertson, Peacock, \& McPherson, 2012), with newer literature highlighting the promise in collecting rich data from online video focus groups conducted in real time (e.g., Han, Torok, Gale, Wong, WernerSeidler, Hetrick, \& Christensen, 2019; Tuttas, 2015; Kite \& Phongsavan, 2017). Further, focus groups would allow participants to build off of one another's perspectives to further support the development of a theory. Stewart and Williams (2005) underscored that "[focus groups] are distinguished by their explicit use of group interaction to produce data. Therefore, synchronous focus groups using video chat adds to this literature and serves as a potential rigorous research method.

There was a total of eight sessions, including one session with one participant, four sessions with two participants, one session with three participants, and two sessions with four participants. The inconsistency in numbers of participants per session was primarily due to non-attendance or scheduling concerns among participants. While some of these 
sessions were individual interviews or dyads, the terminology "focus group" will be used throughout.

For each focus group session, both the PI and a research collaborator (hereby referred to as "research team") were present. Each focus group session was audio-recorded with both the Zoom audio-record feature and a back-up digital audio recorder. The PI facilitated the session and the research assistant took notes and supported participants with technical difficulties. The PI followed a focus group protocol (Appendix I) to ensure consistency of questions.

The protocol, which was developed by the PI with support of three faculty advisors, included an introductory script to explain the process of focus groups and provided semistructured questions in accordance with stages of implementation (Bertram, Blasé, \& Fixen, 2015). Some of these broad questions included:

- What are your beliefs of using physical activity as a means to support student mental health?

- You know I'm interested in physical activity as a means to support student mental health. Does that resonate with you as a school psychologist? If so, why?

- What are your thoughts of incorporating physical activity as a part of supporting mental health?

- What would need to be in place for such an idea to be rolled out?

- What would it be like initially to implement this in a school? What would your role be in that?

- How do we know it is helping kids' mental health? How do we keep it going? How do you know we are doing it well? 
Participants were asked to reflect upon an actual experience or imagine a physical activity and mental health program. This reflection time allowed participants to embrace and think deeply about the content at hand. During the focus group, participants were encouraged to answer questions "popcorn style," or in a sporadic manner, providing responses in a non-ordered sequence.

At the conclusion of the session, the PI sent participants a \$35 Amazon gift card. While research has shown that cash incentives are more effective than gift certificates, it is important to note that gift cards do indeed increase participation (e.g., Birnholz, Horn, Finholt, \& Bae, 2004). Additionally, informing potential participants of a cash drawing can increase response rates for survey research (Morgan, Rapee, \& Bayer, 2017), which suggests that knowledge of an incentive could potentially increase participation in a focus group study.

The research team engaged in independent notetaking across all focus groups. They indicated technical glitches, observations of the participants (e.g., most or least vocal, level of optimism, etc.), recurring points, possible themes, and questions that required clarification or repeating. After each session, both members of the research team wrote a narrative report of their session reflections. They met after each focus group session to overview these notes, share perspectives, and debrief about the conversation.

The audio was sent to professional transcribers using Rev.com. Following the completion of transcription, the research assistant replaced all first names with a unique identifier to maintain anonymity of the participants. The research collaborator imported the de-identified transcripts into a secure, Health Insurance Portability and Accountability Act (HIPPA) compliant Box.com folder. Once the focus groups were successfully 
transcribed, the audio was erased. Additionally, all identifying information (e.g., participants' first names and email addresses) was stored in a password protected Qualtrics account.

\section{Sample}

A total of 20 individuals participated in the entirety of the study. It is noteworthy that 73 individuals attempted the Qualtrics survey, however they were eventually excluded from the sample. Specifically, 22 individuals either did not fully complete the survey or did not indicate that they agreed to the focus group consent form. Further, 6 individuals were disqualified due to meeting exclusion criteria (e.g., individuals that served the middle school level) or providing data that was inconsistent with the role of a school psychologist (e.g., only serving 1 grade), and subsequently did not respond to an e-mail from the PI inquiring about these inconsistencies. Further, nine individuals that were signed up for focus groups eventually decided to cancel or not enter into the focus group. Further, 16 individuals did not complete the Sign-up genius page after follow-up prompts from the PI.

The 20 participants were from the Midwestern (10\%), Northeastern (15\%), Southern (45\%) and Western (30\%) regions of the U.S. Participants were either Certificate of Advanced Graduate Study (CAGS) or specialist-level school psychologists $(60 \%)$, or doctoral-level school psychologists $(40 \%)$ that had been working in that role approximately seven years, on average $(M=6.7, S D=6.7$, Range $1-27)$ and working in their current school for approximately five years, on average $(M=5.2, S D=4.6$, Range 1-19). All participants identified racially and ethnically as White and non-Hispanic 
(100\%). Participants identified as female (90\%) or male (10\%) and no participants identified as transgender, non-binary, genderfluid, or gender queer.

Table 3.1 Personal Demographics

\begin{tabular}{lcc}
\hline \multicolumn{1}{c}{ Demographic Item } & \multicolumn{2}{c}{ Sample } \\
\cline { 2 - 3 } & $n$ & $\%$ \\
\hline Gender & 18 & 90 \\
Female & 2 & 10 \\
Male & 0 & 0 \\
Non-binary/third gender & 0 & 0 \\
Prefer to self-describe: & & \\
Prefer not to say & & \\
Transgender & 0 & 0 \\
Yes & 20 & 100 \\
No & & \\
Race/Ethnicity & 0 & 0 \\
American Indian or other Native American & 0 & 0 \\
Asian, Asian American, or Pacific Islander & 0 & 0 \\
Black or African American & 20 & 100 \\
White (Non-Hispanic) & 0 & 0 \\
Mexican or Mexican American & 0 & 0 \\
Puerto Rican & 0 & 0 \\
Other Hispanic or Latino & 0 & 0 \\
Multiracial & 0 & 0 \\
Other: & 0 & 0 \\
I prefer not to respond & & \\
School Psychology Level & & \\
Specialists Level & 8 & 60 \\
Doctoral Level & & 40
\end{tabular}

As this study focused on the elementary context (kindergarten through fifth grade), all participants worked in elementary schools that housed kindergarten, with $90 \%$ working in schools that housed kindergarten through at least fifth grade and 10\% working in schools that housed kindergarten through fourth grade. Participants worked in suburban (55\%), rural (30\%), and urban (15\%) schools. Half of the sample either did not indicate the percentage of students receiving free or reduced lunch or provided uninterpretable data. There were 10 participants that served schools with $61 \%$ or more 
students received free or reduced lunch. Most participants (75\%) indicated that students in their schools generally receive over 30 minutes of physical education weekly.

Table 3.2 School Demographics

\begin{tabular}{|c|c|c|}
\hline \multirow[t]{2}{*}{ Demographic Item } & \multicolumn{2}{|c|}{ Sample } \\
\hline & $n$ & $\%$ \\
\hline \multicolumn{3}{|l|}{ U.S. Region } \\
\hline Midwestern & 2 & 10 \\
\hline Northeastern & 3 & 15 \\
\hline Southern & 9 & 45 \\
\hline Western & 6 & 30 \\
\hline \multicolumn{3}{|l|}{ Grades } \\
\hline K-4 & 2 & 10 \\
\hline $\mathrm{K}-5$ & 15 & 75 \\
\hline K-6 & 3 & 15 \\
\hline \multicolumn{3}{|l|}{ Setting } \\
\hline Rural & 6 & 30 \\
\hline Suburban & 11 & 55 \\
\hline Urban & 3 & 15 \\
\hline \multicolumn{3}{|l|}{$\begin{array}{l}\text { Percent of students in school receiving free and } \\
\text { reduced lunch }\end{array}$} \\
\hline $0 \%-20 \%$ & 0 & 0 \\
\hline $21 \%-40 \%$ & 2 & 10 \\
\hline $41 \%-60 \%$ & 3 & 15 \\
\hline $61 \%-79 \%$ & 2 & 10 \\
\hline $80 \%-100 \%$ & 3 & 15 \\
\hline $\begin{array}{l}\text { Excluded due to uninterpretable data or no } \\
\text { response }\end{array}$ & 10 & 50 \\
\hline \multicolumn{3}{|l|}{ Recess Time } \\
\hline 0 mins -15 mins & 2 & 10 \\
\hline 16 mins -30 mins & 13 & 65 \\
\hline 31 mins -45 mins & 2 & 10 \\
\hline $46 \operatorname{mins}-60$ mins & 2 & 10 \\
\hline $\begin{array}{l}\text { Excluded due to uninterpretable data or no } \\
\text { response }\end{array}$ & 1 & 5 \\
\hline \multicolumn{3}{|l|}{ Physical Education Time } \\
\hline 0 mins -30 mins & 2 & 10 \\
\hline
\end{tabular}


31 mins -60 mins

61 mins - 90 mins

91 mins - 120 mins

525

Excluded due to uninterpretable data or no

4

20

response

Participants reported that they were athletes or fitness participants in high school (70\%) or college (50\%). Participants indicated on the Brunel Lifestyle Physical Activity Questionnaire Pre-Planned Lifestyle Physical Activity questionnaire (Karageorghis, Vancato, Chatzisarantis, \& Carron, 2005) that they engaged in physical activity for about 21 to 30 minutes daily $(\mathrm{M}=4.35, \mathrm{SD}=1.040)$, one to two hours per week $(\mathrm{M}=3.45, \mathrm{SD}$ $=1.146)$, about two to three times per week $(\mathrm{M}=2.85, \mathrm{SD}=.98)$, and have been engaging in this physical activity for about four to six months $(\mathrm{M}=4.15, \mathrm{SD}=1.4)$. Participants indicated that they generally engage in pre-planned physical activity programs for about up to six months before they give up $(\mathrm{M}=4.45, \mathrm{SD}=1.050)$. Participants indicated that they generally engage in physically activity moderately hard $(\mathrm{M}=3.2, \mathrm{SD}=1)$. A descriptive mean analysis of all items suggests that participants engage in a moderate amount of planned physical activity (Karageorghis, Vancato,

Chatzisarantis, \& Carron, 2005; $\alpha=.909 ; \mathrm{M}=3.7417, \mathrm{SD}=.91)$.

Table 3.3 Physical Activity Engagement of Sample

\begin{tabular}{lcc}
\hline \multicolumn{1}{c}{ Demographic Item } & \multicolumn{2}{c}{ Sample } \\
\cline { 2 - 3 } & $n$ & $\%$ \\
\hline High School Athlete/ Involvement in Fitness & 6 & 30 \\
$\quad$ No & 14 & 70 \\
$\quad$ Yes & & \\
College Athlete / Involvement in Fitness & 10 & 50 \\
$\quad$ No & 10 & 50 \\
$\quad$ Yes & $M$ & $S D$ \\
Brunel Lifestyle Physical Activity Questionnaire & & \\
Planned Exercise Sub-Test (1 = no engagement or & & \\
not relevant; 5= high ranking of frequency or & &
\end{tabular}


intensity)

How many times in a normal week do you

engage in pre-planned physical activity?

How long have you been engaging in pre

4.15

1.387

planned physical activity at this weekly rate?

In general, what is the duration of each session

4.35

1.040

of pre-planned physical activity?

If you add together each session of pre-planned

1.146

physical activity that you engage in during a

normal week, how much time would you

estimate that you spend in total?

In the past, how long have you generally

1.050

persisted with a pre-planned physical activity

program before giving up?

How vigorously do you engage in pre-planned

physical activity?

Sub-Scale Mean Aggregate

\section{Analysis}

All focus groups were transcribed and imported into NVivo software for qualitative analysis. Focus group data were analyzed in three unique stages proposed by Corbin and Strauss (2015), including open coding, axial coding, and selective coding. The research team met throughout the coding process to obtain consensus pertaining to their codes and subsequent themes. The research team developed coding rules that would support a consistent structure to this process. If the research team could not come to consensus on a code, they would refer to the coding rules document. If their differences could not be reconciled, they would bring in an external reviewer (a faculty member with expertise in qualitative methodology) to facilitate a decision-making conversation while providing their expertise. 


\section{Open Coding}

In open coding, the research team read through the transcripts and, through lineby-line reading, assigned code names. This provided a familiarity with the transcript and allowed the researchers to see how unique codes shared similarities. For example, several codes entitled "yoga" may begin to reveal patterns about this activity.

Following, the research team engaged in microanalysis, wherein brief memos were written about the codes derived. Memoing is intended to be detailed and selfreflective, while highlighting repetitive and specific words of interest, or perhaps noting emphases on particular words and understandings of concepts (Corbin \& Strauss, 2015). For example, through this process, a researcher may indicate several meanings of yoga, in that it could help children with anxiety symptoms or that school psychologists feel they do not have the resources to employ yoga interventions. Obtaining this higher-level understanding allows for distinctions among the codes and further allows the researcher to group together categories, including higher-order, broader phenomena (e.g., yoga for anxiety reduction) and sub-categories (more specific aspects relating to the higher-order concepts; e.g., difficulty with implementing yoga for anxiety). The two members of the research team independently coded the first two transcripts and came together to develop consensus. Following, they took turns, with one coding the subsequent transcript while the other checked it, and they then met to establish agreement and consensus. As opencoding culminated, a robust codebook was formed. After all transcripts were coded, the research team re-read through each transcript to ensure the codes were updated and accurate. 


\begin{abstract}
Axial Coding
While open coding allows for these elements of the theory to become derived, axial coding (Strauss \& Corbin, 2015) is employed to systematically connect categories and sub-categories. Rather than asking what the data say, researchers conceptualize underlying meanings of the data and their relationships to higher-level constructs. Strauss and Corbin state that "when analysts code axially, they look for answers to questions such as why or how come, where, when, how, and with what results," and in doing so they uncover relationships among categories (Strauss \& Corbin, 1998, pg. 127). In this process, the PI and research assistant employed diagraming techniques (Strauss \& Corbin, 2015) to visually depict relationships between the concepts. For example, such a relationship might indicate that if MTSS are in place there is a higher likelihood of increased sustainability of physical activity interventions. In doing so, each researcher independently engages in this process before coming together to reconcile differences and develop consensus.
\end{abstract}

\title{
Selective Coding
}

In the third analytical component, selective coding, the research team distilled the theory into relatable components that were threaded together to illuminate the theory (Corbin \& Strauss, 2015). Within this stage, researchers typically learn how categories are threaded through relationships, formulating a cohesive and comprehensive phenomenon. These coding processes allow for the iterative culmination of theory development. Both members of the research team met to determine the central theme and 
meaning culminating throughout the axial themes. This process encompassed both independent work and collaboration between the research team members.

Throughout the process, as data accumulated, the research team engaged in a constant comparative process (e.g., Corbin \& Strauss, 2015) where codes and themes derived from transcripts were compared with one another to inform the holistic culmination of themes. This iterative coding process supports the development of a theory (e.g., to illuminate school psychologists' perspectives of systemic mental health promotion through physical activity, and specifically a general understanding of potential facilitators and barriers to implementation). 


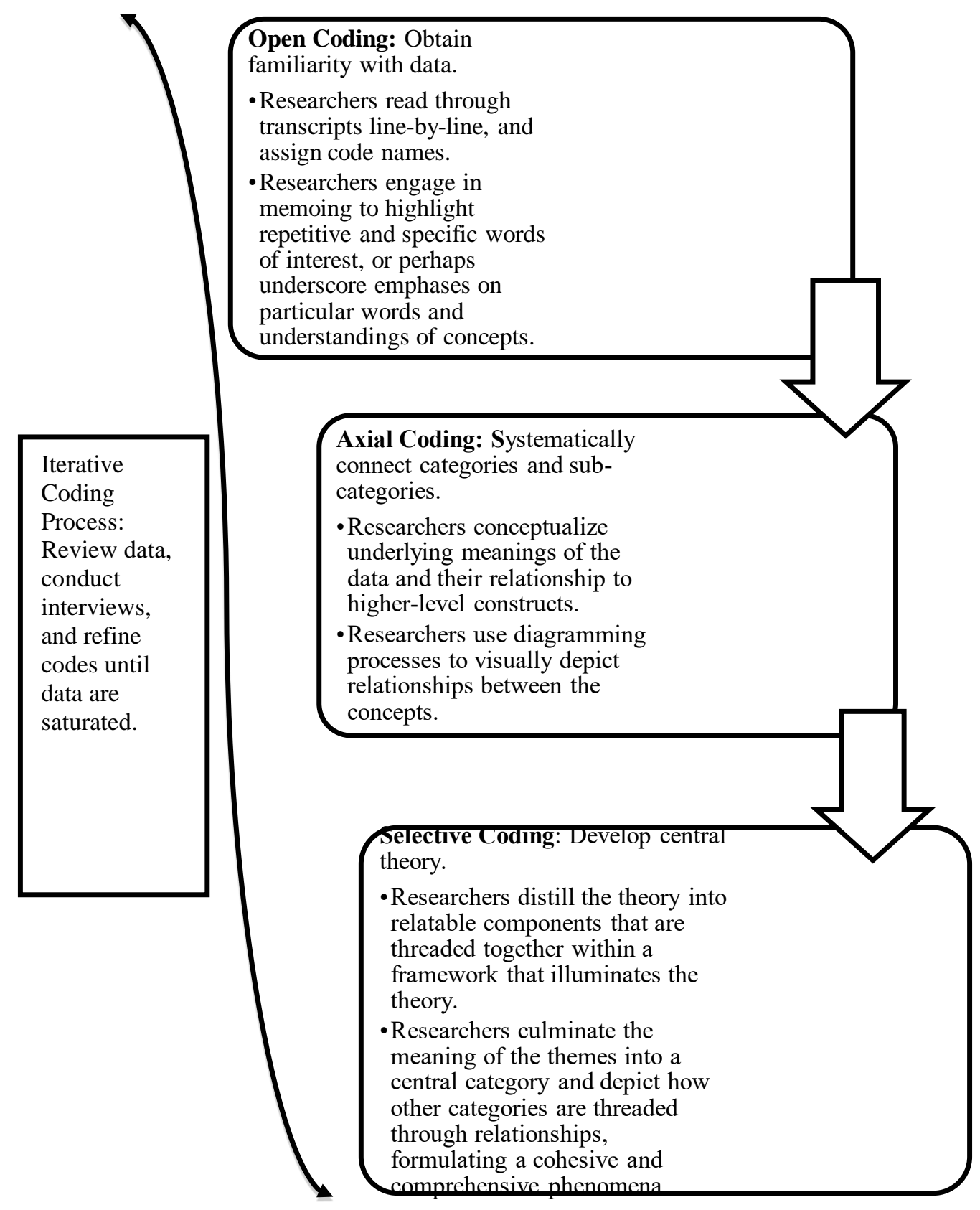

Figure 3.1 Iterative Coding Process 


\section{Trustworthiness}

As a measure to ensure trustworthiness (e.g., Corbin \& Strauss, 2015), researchers employed strategies that included: 1) utilizing an external reviewer, 2) providing a rich, thick description of the themes, 2) describing discrepant information to a theme, and 3) using an external reviewer to provide objective feedback about the research process. As discussed previously, the research team members also engaged in a comprehensive process to illuminate the positionalities that influence the ways in which they approached this research. Detailed positionality statements were written by the research team members, who also engaged in consistent conversations about their world views, identities, and perspectives as they relate to this research. Furthermore, an external reviewer (a faculty member in Special Education with expertise in grounded theory) met with the peer coders during a consensus meeting to provide feedback to ensure objectivity, including discussion on potential bias. Additionally, another faculty member (a faculty member in Counseling and School Psychology with expertise in qualitative research methods) was available to answer questions about this process.

Before beginning data analysis, members of the research team wrote separate positionality statements and engaged in consistent conversations about this topic to understand how their unique experiences could impact the data analysis process. Positionality is described as the extent to which the worldviews of the investigators of the study are aligned with the subject of investigation (Herr \& Anderson, 2005). The worldviews, experiences, and social identities of researchers can impact the data analytic process (Bourke, 2014; Creswell, 2014; Herr \& Anderson, 2005). For example, for this particular study, a researcher who was a sport coach might view physical activity more 
favorably than a researcher who preferred art to sport. Thus, such an experience can impact the way in which the researcher is viewing the data.

\section{Positionality Statements}

The PI of this study is a fifth-year candidate in the School Psychology doctoral program at the University of Massachusetts Amherst and is conducting this current study for his dissertation. He identifies as a white cisgender male and as part of the LGBTQ+ community. He is an avid exerciser and promotor of cultivating safe, supportive, and socially just school climates that infuse wellness practices, including physical activity. He conducts research on a) using sport and physical activity as vehicles to foster positive mental health outcomes for youth populations and b) affirming school-based practices for LGBTQ+ youth.

The research collaborator on this study is a second-year student in the School Psychology doctoral program at the University of Massachusetts Amherst. She identifies as a multiracial-ethnic, cisgender female and as a member of the LGBTQ+ community. As an active individual, she supports the use of physical activity interventions as a method for improving youth mental health outcomes within school settings. Her research interests include cultivating socially just and culturally inclusive initiatives to support atrisk students in alternative school placements.

The research team members engaged in a meeting preceding focus group data collection and analysis. They discussed their worldviews, social identities, and where these facets intersected with the scope of the study. Both individuals underscored that they view physical activity as a positive outlet for supporting youth mental health. They further discussed that other interventions (behavioral, social-emotional, and prescribed 
medication) could also foster positive outcomes, either in tandem with or in lieu of physical activity. The members of the research team also agreed that structural barriers could deter the effective implementation of physical activity, such as if physical activitybased interventions are quickly prescribed and lack follow-up, sustainment, and substantial data collection and analysis efforts.

Both team members identify as former youth athletes, and both currently engage in regular physical activity. One of the members associated school physical activity with feelings of vulnerability when proper support and structures were not in place. Notably, having supportive and diverse school stakeholders (i.e., physical education teachers) fostered more positive experiences for one of the research team members. The other member associated school physical activity settings with pervasive masculine stereotypes (e.g., aggression, dominance, and belittling others through showing anger), generating feelings of discomfort and subsequent avoidance of physical activity in school. As youths, both team members preferred to engage in physical activity and sports outside of the school context. Further, both researchers are committed to fostering school contexts that promote positive outcomes and acknowledge the social identities and needs of all youth.

The team members affirmed that regardless of their own worldviews, experiences, and perspectives, they would be open to all perspectives presented during the focus groups and continuously engage in open and honest conversations and intrapersonal selfreflections to prevent their perspectives from influencing data. Both research team members have academic training in bias awareness and sensitivity, and used this knowledge base to further protect against incorporating biases into analyses. 


\section{CHAPTER 4}

\section{RESULTS}

Using in-session notes, debrief notes, and transcripts, the researchers engaged in a rigorous data analysis process. The researchers independently read through each of the eight transcripts, assigning unique codes to the text of the transcripts (e.g., labelling meaning derived from the text). After independent analysis of each transcript, the researchers collaboratively discussed their coding, reconciled differences, and developed a master dataset. It is noteworthy that according to narrative reflection notes and conversations of the research team, after the seventh transcript the codes were consistently repeating and new information was scant, suggesting that the data were nearing saturation (e.g., Baum, 1998; Corbin \& Strauss, 2015; Fusch \& Ness, 2015; Glaser \& Strauss, 1967; MacDougall \& Fudge, 2001). Following coding of the eighth transcript, it was confirmed that data were saturated. The researchers then engaged in open coding, axial coding, and selective coding individually and then together to develop consensus.

\section{Open Coding}

The open coding process illuminated a diversity of content focusing on tense of perspective (e.g., if the school psychologist was discussing something hypothetically, from personal experience, or something their school engages in), programmatic perspectives (e.g., a type of physical activity modality, stakeholders who could be involved), theoretical leanings (e.g., behaviorism, systems), and the question they were answering (e.g., "what would it look like to implement this?”). Codes also underscored 
broad value systems (e.g., "kids need more physical activity" or "kids need more recess"). The initial coding involved categorizing the concrete nature of the meaning of text segments. As researchers engaged in coding throughout the transcripts, codes began to form as text segments fit into these categories. A total of 853 codes were derived from the dataset. Presented below is a table of the highest frequency codes in the dataset.

\section{Table 4.1 Open Coding}

\begin{tabular}{lcc}
\multicolumn{1}{c}{ Code Names } & $\begin{array}{c}\text { Number of } \\
\text { Codes }\end{array}$ & $\begin{array}{c}\text { Number of } \\
\text { Transcripts }\end{array}$ \\
hypothetical & 526 & 8 \\
What schools do & 236 & 8 \\
SP role & 166 & 8 \\
Barrier & 158 & 8 \\
What PA and MH could look like & 124 & 8 \\
Who would be involved & 110 & 8 \\
Teachers & 89 & 8 \\
Initial implementation & 88 & 8 \\
Team & 76 & 8 \\
Mental health & 65 & 7 \\
Time & 63 & 8 \\
Buy-in & 60 & 8 \\
What SP needs & 55 & 8 \\
Fidelity & 53 & 8 \\
Needs to be in place & 52 & 7 \\
Initial implementation challenges & 51 & 8 \\
How we know it is helping & 50 & 8 \\
How do we keep it going & 49 & 7 \\
Beliefs of PA as SP & 45 & 8 \\
Data & 45 & 7 \\
Measurement & 45 & 8 \\
Administration & 44 & 8 \\
Beliefs of PA & 42 & 7 \\
Intervention length of time & 39 & 7 \\
PE teacher & 39 & 7 \\
Movinglmovement & 37 & \\
& & 7 \\
& &
\end{tabular}


Professional development

Recess

Research and curriculum to support intervention ideasไResearch

Implementer

Elementary school

In-classroom PA

Staff

What schools need

Outside

Principal

Initial implementation benefits

Leadership

MTSS_Question

Walking

OT

Adjustments

Linking to needs

26

26

Schools value

26

Drawing on experience

Anxiety

24

Direct service work

District

24

Movement breaks

\section{Axial Coding}

Once the list of codes was developed, the research team independently engaged in axial coding, where they each considered categories and sub-categories. Both research team members considered questions about the categories (e.g., why, where, when, how, with what results) and in so doing uncovered relationships among categories (Strauss \& Corbin, 1998, pg. 127). During this process, the research team members employed diagramming processes (Strauss \& Corbin, 2015) and themed the codes together. Given 
the magnitude of codes, the research team employed several methods to ensure accurate depictions of the data. They used NVivo software to analyze overlap between codes (e.g., indicating that "resources" is linked with "administration") and printed out paper copies of the data and physically grouped them based on patterns (e.g., running and walking were coded as "physical activity modality"). The research team members engaged in independent coding over the course of several weeks and then met collaboratively to develop consensus and share perspectives and visualizations.

Three themes emerged that explain elementary-level school psychologists' perspectives of implementing physical activity: 1) components, 2) data-based decision making in implementation, and 3) treatment. These three themes operate in an ordered progression and barriers within any stage can impede implementation. Importantly, participants spoke more frequently about hypothetical situations rather than existing practices.

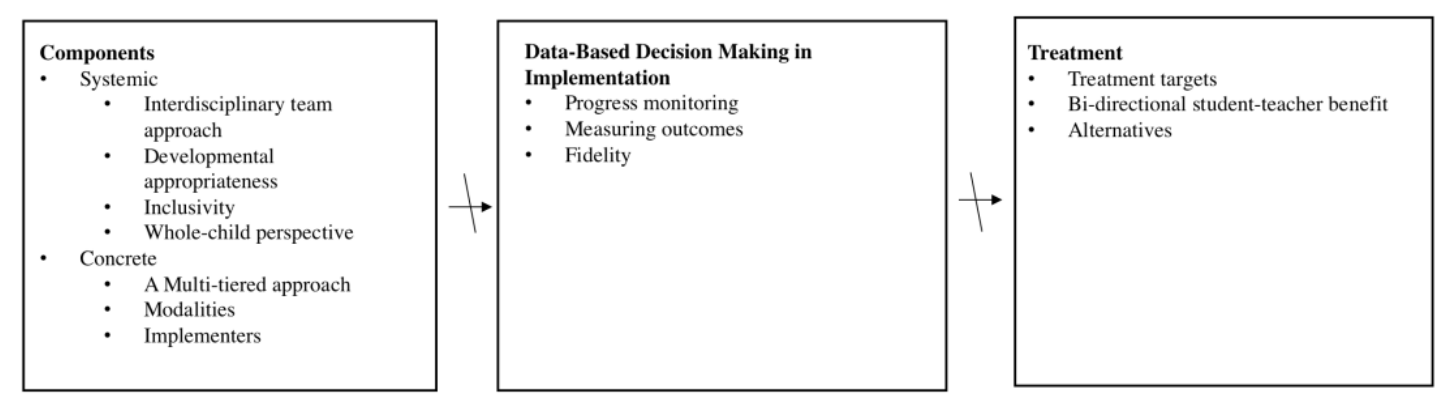

Figure 4.1 Axial Coding

Note: These three themes operate in an ordered progression and barriers within any stage can impede implementation. Slashes indicate possible barriers impeding the process. 


\section{Theme \#1: Components}

This theme highlights the building blocks or key factors that are needed to foster a structure, framework, or intervention encompassing mental health and physical activity. Components is broken up into two sub-themes: 1) systemic and 2) concrete.

\section{Systemic Components}

The systemic sub-theme refers to components that are needed on a macro level to harness practices on the ground level. For example, participants discussed that a systemic approach would be needed to set the appropriate infrastructure for implementation. One participant stated:

So I think having somebody who thinks that way is really helpful from the get go because getting something like this off the ground is a lot of work, there's a lot of moving parts and I think you have to kind of really be able to zoom out and say okay what's everything that we need and then learn how to prioritize and say okay, this is where we need to start with this. This is who needs to do that and kind of move from that way.

Systemic components involved four sub-themes: 1) interdisciplinary team approach, 2)

developmental appropriateness, 3) inclusivity, and 4) whole-child perspective.

\section{Interdisciplinary Team Approach}

Participants indicated the necessity of a team of diverse stakeholders working together to plan and support the implementation of a physical activity and mental health framework (76 mentions, eight transcripts). Specifically, this would involve a team of invested stakeholders that focus their efforts on physical activity and mental health initiatives. These stakeholders would engage in check-in meetings throughout the school year to plan for physical activity and mental health interventions, discuss initiatives, 
review data, and make data-based adjustments if warranted. A participant highlighted the value of having invested stakeholders on the team:

I mean, your school psych hopefully, maybe PE teacher, you could have your nurse, you could have your OT, your principal. It really could be I think anybody in the building who is invested in this idea.

Participants reported that both the skillsets and personalities of these stakeholders are crucial components to enact such an initiative. For example, participants indicated that the individual spearheading such an initiative should be respected and well liked among the school community, while also willing to contribute beyond their actual role to support such an initiative. Participants also highlighted that the team would require an administrator to uphold power and clout and to employ a "top-down" approach to infuse this work in the system. For example, participants indicated that new initiatives could be stalled or poorly implemented without administrative support. With this said, participants also reported that some administrators want to "guard instructional time" in light of state testing pressures and could view physical activity as a threat to instructional time.

... I know our administrators really guard instructional time. They're very big on a child's role in the classroom and making sure they're getting the instructional time that they need to. And they kind of have to sign off to allow us to do [these] physical activities because the child is missing instructional time within their classroom. So just signing off and saying, "Okay this is worth doing to make sure they're getting what they need."

Participants perceived greater administrator leniency with physical activity embedded in the classroom than individual physical activity plans that might take students outside of the classroom. Participants indicated that administrators could be charged as the stakeholders responsible for fidelity checks, advocacy, and navigation of the bureaucratic, logistical, and fiscal components. However, participants reported that 
administrators' lack training in mental health, which could further limit their commitment to this work.

Participants indicated that physical therapists and occupational therapists could serve as experts on physical activity and body mechanics. Physical therapists were regarded as a resource for consultation pertaining to creative ways to implement physical activity. However, the data indicate that having close proximity to a physical therapist allows for connections to be formed. A participant stated:

And one thing that she did that I absolutely loved, was [the physical therapist] came up with basically a choice board of different types of activities that the student could do. And they were all geared to what the student could do, and what the student would want to do.

Participants mentioned that physical therapists are often charged with large caseloads of students with documented disabilities, so to conduct whole-school initiatives would surpass their role. Occupational therapists were underscored as notable consultants and experts in sensory modalities for children needing a sensory diet, and could be of further support in targeting movements for specific needs.

Physical education teachers were positioned as stakeholders who know just about every student in the building and have an understanding of body mechanics. Participants indicated that physical education teachers have helped with interventions and have been approachable in collaborating with school psychologists. A participant stated:

I think if we were to implement anything [The P.E. teacher] role would be knowing the students because he does know the students. He sees every student in this school at least twice a week, and because of that he knows what they like, he knows their personalities. It's a valuable resource to have someone who actually, truly knows the kids as well as having a true and deep understanding of how the body works and how the body moves. 
With this said, some participants mentioned that some physical education teachers have lacked patience with students presenting with behavioral health challenges, and thus, more training is warranted for these stakeholders to support their implementation efforts. For example, participants discussed that P.E. teachers have "set off" students by "pushing buttons" and arguing. There was also a participant that discussed a P.E. teacher that tried to exclude students with Autism Spectrum Disorders and behavioral concerns from accessing gym time as a reward.

Teachers were viewed as primary implementers of physical activity within their classrooms. They are seen as stakeholders who can also communicate with their leadership team about what is working within the system. Participants also mentioned that such an initiative at the school level could increase teachers' physical activity as well. For example, a participant stated:

I think a secondary benefit might be connection with the students, like if you really are out there playing with students at recess and trying to get them engaged in games or incorporating more movements within your classroom activity, kids are going to be more lively and more engaged and hopefully more connected to what they're learning or their teacher or each other, which hopefully would ideally spread amongst the classroom.

Teachers might also be well positioned to recommend physical activity depending on students' needs and likes. School nurses were indicated as another professional that could support such efforts, but their role was not well defined.

Participants suggested that older students could support such initiatives (i.e., older elementary schoolers might select activities for high schoolers to facilitate). Further, some participants indicated the utility of including families on such a team. However, the role of families was more clearly discussed in terms of communicating school-based physical activity efforts to families as a means to inform them about such initiatives. 
School counselors and school psychologists were positioned as stakeholders who provide mental health expertise, which is viewed a valuable component of a team-based approach. Participants indicated that school counselors typically engage in more direct work, so they might be better equipped to engage in the implementation aspects of the physical activity program. Participants positioned school psychologists as stakeholders that could analyze school-wide and individual data obtained from a physical activity and mental health program, while also engaging in consultation and professional development initiatives with staff. A participant stated:

Well I guess it would be looking at data to see if the intervention you're putting in place is actually working. You're not going to give a kid physical activity if he comes back to the classroom more wired than he was when he left. You're not going to want to do that. And we're good data people, so I would I imagine that's where that's... At least what I do in my school, we crunch the data, and we look to see what's working and what's not working.

School psychologists indicated that their expertise in sharing information and data with school stakeholders would be valuable in both promoting the research underpinnings of physical activity and mental health while also advocating for its efficacy, especially at a tier 1 level. For example, this could take shape as having scheduled professional development times with school psychologists meeting with groups of school personnel to highlight the explicit link between physical activity and mental health benefits. Bringing in research studies would be critical to substantiate these linkages. Further, school psychologists can support work on the front-end of the initiative to foster increased sustainment.

School psychologists were more willing to provide direct service in tier 2 service delivery (e.g., group counseling with physical activity) than in tier 1 service delivery. Notably, school psychologists were more willing to engage in indirect service delivery 
roles involving data collection and analysis, consultation, and professional development. School psychologists also upheld an interest in administering research, such as translating the research base to practice. One participant discussed how this skillset could be highlighted:

Well I guess it would be looking at data to see if the intervention you're putting in place is actually working... And we're good data people, so I would I imagine that's where that's... At least what I do in my school, we crunch the data, and we look to see what's working and what's not working.

\section{Developmental Appropriateness}

Participants spoke of the concept of developmental appropriateness, or the necessity for physical activity to be enacted in such a way that meets the developmental needs of youth. For example, they discussed that physical activity should be accessible depending on the age of students, and that there should be physical activity that considers the learning needs and developmental levels of students. Participants provided examples of teaching children specific language and key words to use, that supports the notion of using a physical activity strategy to calm down their bodies.

Another example involved older students engaging in "ambassador" roles to choose physical activities for the school community. Foundationally, participants discussed the importance of students engaging in physical activity with same-aged peers to foster a comfortable environment and support appropriate skill acquisition. A participant discussed that "keeping similar-age kids together makes life easier, because when you have five-year-olds playing at the same time as twelve-year-olds, they play very differently." 


\section{Inclusivity}

Participants reported on the importance of physical activity as a universal intervention that would serve all students. The notion of diversity in physical activity was discussed, and particularly, how students should be exposed to enjoyable physical activity. Some students might have proclivities to less structured physical activities, while others may have proclivities to more structured games. Thus, it is important to link physical activity to students' likes and needs.

In addition to considering students' preferences, participants also highlighted themes of cultural inclusion through physical activity. One participant discussed that physical activity might seem non-threatening to families in comparison to therapy and medication, which often holds stigma and controversy among families. Furthermore, a participant also delineated the risks of sport culture generating toxic masculinity and mentally or emotionally unhealthy environments. This participant stated:

I would think it's more just about in how things are rolled out or kind of, thinking of toxic masculinity and that type of sports culture can be I think very problematic. And I think that can actually can cause some very unhealthy environments as far as mental health goes. But I think that if you're intentioned in the way you structure programs so that doesn't become part of it, I think you're okay.

Participants also indicated the importance of accommodating students with physical limitations, motor issues, and social-emotional needs to ensure they can achieve the benefits of physical activity. Participants suggested using specialists in the school (e.g., audiologists, occupational therapists) to provide consultation around effective differentiation of instruction. 


\section{Whole-Child Perspective}

The Whole-Child Perspective sub-theme positions physical activity as a factor that promotes overall health and well-being and is connected with other factors that promote child development (e.g., academic learning, nutrition). Participants discussed a well-rounded approach to physical activity. For example, some participants highlighted the importance of meeting the holistic health needs of students, stating that "you need to look at the whole child," and "I see it all very connected to each other... the foods we eat, the activities we do," and "addressing whole needs of a student instead of just those academic needs." A participant also provided examples of a school that operates a clinic with medical and dental services, and underscored the importance of education reaching beyond a solely academic approach. As participants stated, physical activity should be linked to education and health domains, and not stand as a fragmented aspect of care. Participants also indicated multi-modal ways of teaching students about physical activity while further fostering opportunities for engagement. Further, a participant described the link between physical activity and learning outcomes, advocating for a paradigm shift toward increased physical activity in schools:

For me it's a primary belief. If you're looking at a pyramid, that's a foundational component. You have to be stimulated, oxygen has to be moving to learn, and just sitting down and sitting in a desk all day, to me, does not correlate very strongly with maximizing potential. To me, exercise and any kind of physical movement has to happen to really get the full benefit of school. I'm probably more on that extreme. I'd be for like three recesses a day, physical education every day, and less time, definitely, in a desk.

Notably, participants connected physical activity and motor development, indicating how engaging in consistent and targeted physical activity can impact gross and fine motor skills. As such, it was discussed that consultation with an occupational 
therapist would provide targeted instruction to students that need increased skills in this area.

\section{Concrete Components}

This sub-theme refers to the key ingredients of this physical activity framework, and how it could be implemented. Concrete components include three sub-themes: 1) multi-tiered approach, 2) modalities, and 3) implementers.

\section{A Multi-Tiered Approach}

Participants conceptualized physical activity within a multi-tiered service delivery model. They indicated that tier 1 would involve standard recess with opportunities throughout the day to engage in physical activity as part of their routines (e.g., movement breaks in the classroom).

Tier 2 would involve extra morning recess with increased breaks, as well as the incorporation of physical activity within group counseling. Tier 3 would provide both individual skill-building (e.g., calming through yoga) and crisis response (e.g., students that are behaviorally dysregulated will be coached through physical activity) to students that need a higher level of care. Participants discussed supporting students through a multi-tiered lens and used language such as all tiers (8 mentions, five transcripts), universal ( 8 mentions, three transcripts), tier 1 (22 mentions, seven transcripts), prevention (13 mentions, five transcripts), tier 2 (15 mentions, six transcripts), individualized to students ( 5 mentions, four transcripts), tier 2 and tier 3 (4 mentions, three transcripts), and tier 3 (18 mentions, seven transcripts). 
Participants conceptualized ways to link mental health promotion and socialemotional learning within the physical activity context at a tier 1 level. Ideas included countering high-energy physical activity skills and also calming activities such as yoga, deep breathing, and mindfulness; teaching students about how exercise can impact their mental health; and allowing students to form their own teams and engage in experiences to foster cooperation skills.

Participants discussed the utility of movement breaks (24 mentions, six transcripts) as a general tier 1 intervention. Specific types of movement breaks discussed included brain breaks ( 8 mentions, two transcripts), Go Noodle (5 mentions, four transcripts), and YouTube videos (4 mentions, two transcripts). There was a general theme of infusing physical activity within the school day, such as exercise videos during class or engaging in more vigorous movement during transition times. Further, a participant provided an example pertaining to incorporating physical activity within academic content:

We had one student this year that we evaluated, and one of the things that became really clear is this kid needed to move in order to answer questions. His body was so wiggly. To make the long story short, one of the things that we recommended was for his intervention he was receiving and instruction to be movement based, so he was learning to read by jumping to these words in the room. We worked to make his lessons be really movement based, which was helping him so much not only to be engaged, but to learn the material as well.

Participants also indicated that programs and interventions with well-outlined procedures and guidelines could be helpful as a means to promote fidelity. Participants also discussed using existing packaged programs (e.g., Girls on The Run [5 mentions, three transcripts]; Playworks [two mentions, one transcript], or Liink [1 mention, one transcript]) to link explicit social-emotional instruction with physical activity (e.g., 
teaching students how to cooperate with others or engage in competitive skills).

Interestingly, one of the participants discussed that using physical activity to promote mental health could be a way of "disguising social-emotional supports."

Participants proposed that physical activity may be implemented at specific times of the day. Focus group participants discussed the utility of having universal classroombased physical activity before starting the day, which could include students walking around the school building or rotating between different physical activity "stations." Another participant discussed the implementation of a before-school physical activity routine in the classroom:

I think if you're being proactive, you could introduce it almost, say, schoolwide for five minutes a day right after the morning announcements. 'This morning we're going to work on this... 25 jumping jacks or something... and then you're going to stretch up, stretch to the left, stretch to the right.' You're going to start there, so universal for your tier 1, but then it's still a little proactive.

For students that need a higher level of support to target needs, participants indicated that it would be important for the leadership team to meet together and consider what supports would target the needs of the student. Students on Individualized Education Programs (IEPs) and 504 plans may already have goals that can be effectively met through physical activity (e.g., taking effective breaks to regulate).

For tier 2 interventions, participants indicated methods such as morning yoga in substantially separate settings for students with emotional and behavioral concerns, a morning run-club for children with behavioral concerns, and a breakfast club with physical activity to support children with getting settled in for the day. Participants also discussed that tier 2 and tier 3 supports can infuse physical activity within group and 
individual counseling. A participant recommended a group counseling intervention that would bring forth a multitude of benefits:

...Purposely creating a group that's got a common goal. One of the benefits hopefully would be, obviously the mental health benefits, but also friendships, creating more social support and friendships among the participants.

It is noteworthy that tier 3 recommendations generally referred to a structured program that considers the presenting needs of a student. For example, participants discussed that physical activity could be used to meet students' Individual Educational Plan (IEP) goals (e.g., taking effective breaks to support behavioral regulation). Further, tier 3 also includes crisis intervention to help students behaviorally regulate by taking a break and engaging in vigorous physical activity (e.g., jump rope, running).

\section{Modalities}

Notably, the most frequently mentioned modalities involved walking (30 mentions, eight transcripts; e.g. going for a walk in the hallway), movement breaks (24 mentions, six transcripts), yoga (20 mentions, five transcripts) or mindfulness (13 mentions, six transcripts), and running (16 mentions, six transcripts). Participants indicated the importance of having students choose activities and offering a diversity of activities to enhance students' perceptions and engagement in physical activity and allow them to find an activity that they enjoy and want to continue with. Indeed, developing a physical activity routine at a young age may support lifelong mental health functioning. A participant stated:

I also think that exercise in schools could be a way to help kids, especially kids who might not be team sport players or kids who are not naturally athletic, help them find something they really like to do for their life, for a lifetime, that maybe traditional physical education wouldn't expose them to. 
The data highlight that walking serves as a distraction or mechanism to separate from a stressful situation. Walking was often connoted with allowing students to take breaks from stressful situations or to enhance therapeutic engagement. For example, walking was described in the focus groups as a way for students to "blow off steam" or take a break from a stressful situation. However, it was also described as an opportunity for school psychologists to walk with students to engage in problem-solving discussions and counseling. One participant further discussed literature suggesting some evidence in using walking during the course of therapy.

Yoga was indicated as a unique modality that could be used to calm students that might be behaviorally dysregulated or at risk of becoming behaviorally dysregulated. Yoga and mindfulness collectively were also generally perceived as calming (participants suggested yoga as a way to decompress), and as such, were indicated to counteract physical activities that might be more vigorous and energizing to students.

Participants also indicated running as a modality, though this was less descriptive than other modalities. Specifically, participants indicated that children need to "run around," while it was also discussed that students could engage in a morning running club at school or incorporate running in-place into existing classroom-based physical activity. Other modalities that were deemed more traditional sports (e,g., basketball, baseball) were more likely to be discussed in the confines of physical education class, while more individual activities (e.g., walking, running, obstacle courses) were indicated as modalities that could support individual mental health needs. 


\section{Implementers}

Given the structured, tiered approach that was delineated (e.g., tier 1 as standard recess with opportunities throughout the day to engage in physical activity as part of students' routines; tier 2 as extra morning recess with increased breaks; and tier 3 as targeting individual skill development and crisis response). Participants largely see teachers and recess staff as implementers of school-based physical activity interventions at a tier 1 level, as they work with children in their classrooms and at recess on a regular basis and can incorporate physical activity in the classroom routine. With this said, participants also recommended that teachers serve as a communication link to the interdisciplinary leadership team to offer information on how initiatives are working on the ground, and reciprocally, to learn alternative perspectives from the team.

Of note, some participants mentioned community volunteers also helping with implementation of such initiatives. At a tier 2 or tier 3 level, school counselors and school psychologists were largely charged with implementation within their direct service work, or had a large role in direct consultation with the teacher, who would likely be the primary implementer. School psychologists indicated their interest in serving in a consultative role to support implementation. Such efforts involve full-staff professional development (e.g., teaching about benefits of physical activity for mental health) as well as technical assistance to teachers about the interventions they employ, and consistently sharing school data to highlight effectiveness of interventions. 


\section{Theme \#2: Data-Based Decision Making}

This theme includes three sub-themes: 1) progress monitoring, 2) measuring outcomes, and 3) fidelity. Overall, participants discussed using data to inform decisions about interventions, and thematically referenced steps of a problem-solving framework (e.g., Deno, 2002). The data-based decision-making theme was derived from a value that participants held around using data to inform practice. The code "data" had 45 mentions across seven transcripts. For example, participants spoke of the role of school psychologists in supporting the leadership team in using data to identify school- or student-based need, target an intervention accordingly, measure the progress of an intervention, track formative progress, and assess outcomes. Participants relied on their skillsets in data-based decision-making and problem-solving to approach any domain of practice, rather than just physical activity implementation. Participants compared such a process to navigating Response to Intervention (RTI):

And just really working out the nuts and bolts of who's going to do it, and what students are we going to put in place, and looking at the data, and what we're going to measure, and just having that discussion just like you would in a regular $R T I$ for reading, or a reading intervention, or a math intervention.

Participants emphasized asking behaviorally-rooted questions before considering an intervention, such as "what is our goal?," "how are you hoping to improve?," and “what are we hoping to improve?" Specific strategies were considered as pinpoints throughout the day when students would benefit from physical activity. Participants discussed the degree to which interventions benefitted students, and recommended appropriate adjustments. Specifically, the notion of "crunching data to see what is working and what is not working" was heavily emphasized. Participants discussed 
multiple ways of measuring behavior, including smiley face scales, norm-referenced measures, and behavioral observations. Throughout the focus groups, some participants referenced research studies pertaining to the link between physical activity and mental health, and further highlighted the utility of the research base to support implementation efforts in schools.

\section{Progress Monitoring}

Participants discussed the importance of monitoring progress throughout implementation of an intervention, including use of existing behavior management systems such as School-Wide Information System (SWIS) and Class Dojo. Participants discussed that they hope to see initial benefits in decreased office referrals, increased physical health, increased attention and concentration, and more days in school.

Participants further delineated the importance of using treatment integrity sheets and the value of formative data:

I think it's hugely beneficial, but Participant 008's right. There are going to be challenges when you implement anything, and you just kind of have to roll through those and make those minor adjustments so that things do work a little bit better, and to celebrate the successes that you do have and make sure you acknowledge those successes because we do tend to focus on things that aren't going right. But yeah, it's incredibly beneficial.

Related to progress monitoring, participants discussed the importance of incorporating teacher voice to relay concerns to leadership staff that can implement changes. Participants also suggested reviewing fidelity lists during team meetings to ensure effective implementation of the intervention. 


\section{Measuring Outcomes}

Participants indicated measuring outcomes by using pre-post data collection efforts (15 mentions, seven transcripts) to determine effectiveness, and by collecting anecdotal data from teachers and students with less consistency around employing longitudinal designs. Participants discussed measuring a host of outcomes using appropriately linked scales, including norm-referenced measures (e.g., a state-wide school climate inventory) and other self-report measures, such as behavioral rating scales.

Participants noted a variety of measures, including social-emotional competencies and weekly physical activity or television time to assess change over time. Participants also proposed reviewing increases in numbers of positive behavior incentives or rewards distributed. Participants also indicated that teachers could be evaluated based on the degree to which they incorporate wellness into their classrooms, emphasizing that this metric may increase wellness-oriented practices. Some participants underscored the importance of assessing progress on student's IEP goals and considered how teachers can implement these goals through physical activity. A participant stated:

The special education teachers, especially, I think would utilize it because they have even goals on their students' IEPs related to transitioning and different things that they could use physical activity as far as their measurement.

\section{Fidelity}

Participants accentuated the importance of measuring the fidelity (53 mentions, eight transcripts) of the intervention. However, in order to appropriately assess fidelity, the physical activity must be a routine and clearly defined component of the intervention. Participants indicated multiple methods to assess fidelity, such as observation with a supplemental checklist. Participants discussed that administrative leadership staff could 
conduct fidelity checks in the classroom, although their presence may be distracting. These fidelity checks could include an assessment of the frequency and execution of physical activity, as well as an address of implementation concerns. Of note, participants also commented throughout the focus group that "you can't do it wrong" and kids need to "go run." This lack of structure seemingly contradicts the aforementioned fidelity efforts and may hinder effective measurement of the intervention.

\section{Theme \#3: Treatment}

Participants positioned physical activity as a form of treatment to support students in developing skills or remediating mental health symptoms. Specifically, three sub-themes emerged, including 1) treatment targets, 2) bi-directional student-teacher benefit, and 3) alternatives.

\section{Treatment Targets}

Participants discussed that physical activity can impact student outcomes across academic, behavioral, and social-emotional domains. Participants upheld a philosophical belief that "children [are] not getting enough physical activity" and "[children are] not getting outside enough.” Thus, providing these opportunities in school can support healthy development and address targeted outcomes.

Participants highlighted that the act of taking a physical activity break can foster more quality instructional time. For example, children "getting their wiggles out" by taking a break could promote improved work completion. Participants stated that students need to "get out and be themselves" and enjoy time without structure, indicating that 
physical activity can "help kids do their best learning and feel safe and healthy and happy in the classrooms."

Participants collectively mentioned use of physical activity to support a host of mental health concerns, specifically ADHD (10 mentions, five transcripts), depression (20 mentions, six transcripts), and anxiety (24 mentions, seven transcripts). Notably, a thematic question arose pertaining to the connection between physical activity modality and a target symptom area (e.g., running for inattentiveness versus yoga for anxiety). Throughout conversations, participants identified mediating factors, such as physical activity for promotion of social connection, which could decrease depressive symptoms, and physical activity to provide a break, which could support regulation. Participants further indicated the difficulty of identifying and measuring internalizing symptoms and, subsequently, intervening appropriately. One participant considered how an exercise or group counseling session might be structured differently depending on targeted concerns:

I could see, for example, students with ADHD maybe being a group of targeted students who could benefit from that, I think maybe all students would benefit from some more exercise... if you're talking about [anxiety or depression], I would think maybe the smaller groups would be better because you're talking about some of that sensitive stuff, and you need to build the relationships in the group for the kids to be able to share some of that personal stuff before they'd be really diving into that and find some help.

For children presenting with mental health symptoms, school might be one of the only places where they can obtain physical activity. Participants indicated the importance of targeting physical activity to students' needs and preferences to successfully enhance outcomes. For example, some discussed the importance of referencing research to consider what types of physical activities target certain needs, so as to provide those particular interventions for students. 
In considering effective treatment targets, participants focused on the importance

of both using research as a guide to support evidence-based implementation, and sharing research with the school community to enhance buy-in and demonstrate the link between research and practice. A participant stated:

I just want to harp on that evidence support again. Having the support behind it to say that it's valuable and that it's necessary, and then having it easily accessible, like what works clearinghouse-level, easily accessible.

\section{Bi-Directional Teacher-Student Benefit}

Participants discussed considerably that intentional implementation of schoolwide physical activity could benefit both students and teachers. For example, some suggested that teachers could serve as role models in sharing their physical activity endeavors (e.g., running races, etc.), and that teachers could be provided with physical activity breaks along with their students. Participants expressed that in a school-wide effort, adult stakeholders should be engaged to model desired behaviors. Interestingly, participants also considered incentivizing adults for their physical activity (e.g., by having step competitions), which could enhance the social-emotional well-being of teachers and subsequently provide a more positive learning environment for students. A participant stated:

I think even it could have a component for teachers, maybe, just because I feel like everybody in the school's stressed out, and it would help a lot of people to have some balance or some exercise in their day-to-day... because I know everybody wants to be healthier and happier.

Participants delineated that such a framework may be better suited for teachers that have a personal interest and investment in physical activity, and that teachers should be engaged in physical activity in a manner that is responsive to their needs. One participant shared an anecdote about a physical education teacher who oriented both 
students and faculty to exercise equipment to increase engagement. Another suggested that staff collaboratively engage in physical activity outside of school hours as a means to support a well-rounded school health movement:

There are plenty of small-scale things where maybe there's a group that meets after school and walks together, or something else, but getting a larger-scale thing available for teachers beyond just offering a discount on a gym membership... you've got to differentiate across staff members, age, and ability.

\section{Alternatives}

Participants proposed that physical activity could be viewed as a more palatable alternative to traditional types of mental health treatment. For example, due to stigma surrounding therapy and medication, families might be more accepting of students learning physical activity skills.

I also think cross-culturally, exercise and movement is generally understood across a variety of cultures... exercise, a lot of times, is less threatening. We're not saying anything about necessarily counseling or medication. It's not something they have to sweep under the rug. The exercise gives them a way to really enact something that could be beneficial without threatening their core beliefs and their systems. I think that's part of it that cannot be overlooked, the power that can have.

Furthermore, participants indicated that physical activity could also serve to disguise social-emotional support for children by supporting them in engaging in creative ways to regulate their emotions. A participant stated:

You could play it off, 'ugh, I need to get my steps in, so let's just walk.' You can play it off or just check in with kids more, get them out. They're having a rough day, having a rough morning, and it's just something that anybody can really do and that can give them the extra movement break... move their feet, [or] what not. 


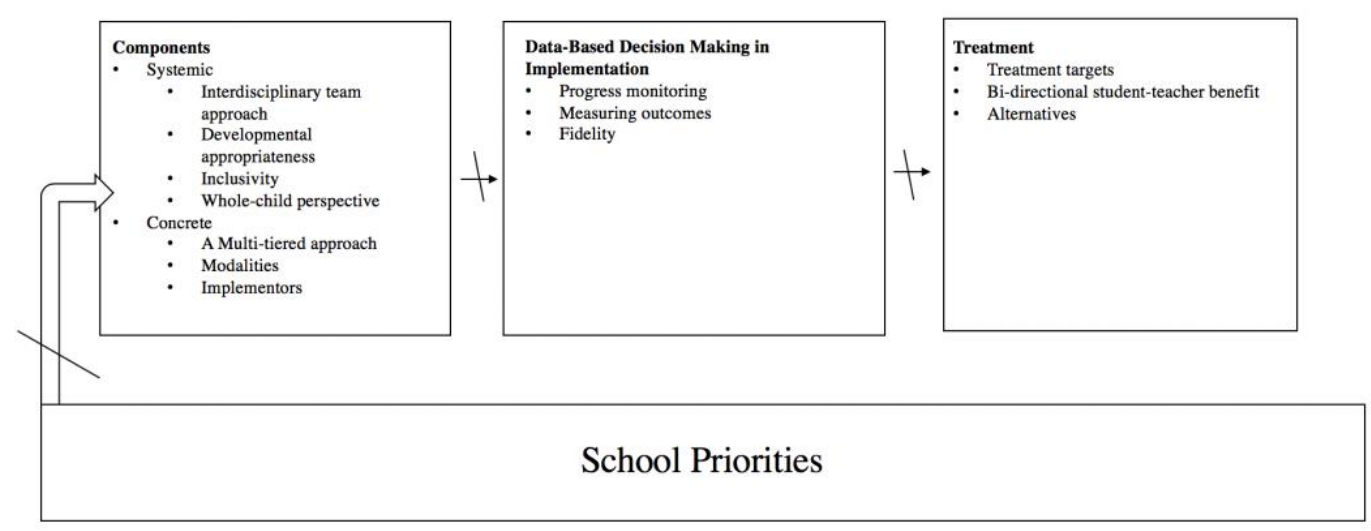

Note: These three themes work in an ordered progression, and barriers within any stage can impede implementation. School priorities that are geared toward these efforts facilitate progression. School priorities that are resistant of these efforts serve as barriers. Slashes indicate possible barriers impeding the process.

Figure 4.2 Selective Coding

\section{Selective Coding}

Three themes emerged from the data: 1) components, 2) data-based decisionmaking, and 3) treatment. In selective coding, researchers consider the central thread among themes to facilitate the emergence of a cohesive theory. To illuminate the core theoretical underpinnings of this statement, the research team engaged in independent work and collaborative meetings. They agreed that the three unique themes cannot exist in isolation or be grouped together without school priorities, which refer to the values of the school as a whole, particularly the administration and district. For example, participants discussed that a successful initiative would necessitate both a clear school mission statement surrounding mental health, and support from executive leadership to foster a comfortable change environment. A participant stated:

I think it has to be a team, and I think it has to be administration connecting it to the values in the building or the annual goals that your building has, or 
incorporating into instructional practices that teachers are already using, or a problem or concern that teachers have really expressed.

Additionally, participants also discussed that top-down policy can also shift the culture of the school. For example, while teachers or school psychologists uphold priorities to incorporate physical activity within mental health intervention service delivery, administrative buy-in enables reciprocity and collaboration between on-the-ground staff and leadership.

\section{Barriers}

Participants shared a host of barriers that could hinder physical activity promotion. Notably, time stood out as a substantial barrier. For example, school psychologists discussed that their busy schedules could impede their ability to engage in an initiative, though if their personal interest was high enough, they would participate in such efforts.

Administrators' desire to guard instructional time emerged as another challenge. A participant stated that "they're very big on a child's role in the classroom and making sure they're getting the instructional time that they need to." Participants also cited lack of staff resources and being overextended as barriers.

Participants further suggested that students might be more behaviorally dysregulated in the beginning of an intervention and it might be difficult for them to adjust to the new routine. With this said, teaching students about physiological changes in their body during physical activity, and subsequently, coaching them through the sensations would be a useful skill for them to obtain. 
I could see kids maybe acting more silly at first, maybe acting out more because they're not sure how to utilize the things correctly... I mean I think at first it might heighten some of the impulsivity and hyperactivity until they learn the correct way to use it.

Notably, participants highlighted how the time of their professional training may impact how they interface with this work. For example, as the field has evolved, school psychologists that were trained long ago may feel less equipped or may have engaged in additional mental health-related professional development outside of school.

The concept of sustainment arose as an additional concern. If teachers do not buy in or foresee the initiative working, they may become de-motivated and sustainment is likely to fall short. Thus, another noteworthy barrier is managing expectations of stakeholders during interventions that take time to implement and produce outcomes. A participant stated:

I mean, for us, if we have a way to show it's working, it's going to keep going. And that's why a lot of our interventions fall off, because the teachers don't perceive that it's working... It really just comes down to whether or not our teachers feel like it's working, and if we can show the principals that it is working.

Participants also discussed the cost of implementing a physical activity program, particularly of necessary supplies and resources. Without both available funding and administrative approval, it would be difficult to roll out such an initiative. With this said, participants were willing to make use of minimal supplies. However, to diversify activities and meet the interests and needs of students, it is likely that ample resources will be needed. A participant stated:

I think just about any program that's implemented is going to be criticized for costing money or taking kids out of reading interventions, or whatever else is being the priority of the moment, and so I think that's one of the big challenges, is the public opinion. 
Relatedly, participants highlighted that space can be a concern, both in terms of identifying locations in the school for children to engage in physical activity, as well as ensuring children's safety. A participant noted that many schools in urban areas may not have the means to support such an effort outside.

Well, I've heard of schools in the cities that have a small, tiny patch of pavement, and that's where the kids have their recess. It makes me really sad to think that kids in our country and all the world might not have access to green space and outdoor space that's safe and not have toxic fumes... Ideally, a school would have a lawn or a playground or some beautiful woods, some place that's outside where a lot of this could take place.

When considering the relationships among each of the axial codes, these barriers can impede the progression of components, modalities, and treatment. Thus, participants suggest that schools engage in extensive pre-planning to consider and strategically address barriers that may hinder the intervention's progress and implementation. 


\section{CHAPTER 5}

\section{DISCUSSION}

\section{Statement of Theory}

This study explored a sample of elementary level school psychologists' perspectives of incorporating physical activity within mental health intervention service delivery. Results underscore the necessity of administrative priorities that support interventions that fuse physical activity and mental health. When school administrators, such as principals, prioritize and buy in to such service delivery models, it can lead to the formation and effective sustainment of both systemic (e.g., interdisciplinary team approach, developmentally appropriate practice, inclusivity, a whole-child approach) and concrete (delivery of multi-tiered interventions, specific physical activity modalities, and implementers) components. Such components, in turn, facilitate comprehensive and consistent data collection efforts that can allow school psychologists to plan interventions. Following, such data efforts can promote treatment targets for students, teachers, and the school community. Of note, barriers (e.g., lack of priorities, fragmented structure, minimal data efforts) can impede effective implementation progress and hinder sustainable practices. 


\section{School Health Models}

The results of this study suggest that school psychologists see the overall benefit in using physical activity as a mechanism to promote and enhance social-emotional and mental health outcomes. With this said, they indicated the structural facilitators and barriers that could promote or impede such processes, respectively. Much of what participants indicated was in line with the conceptualization of the Comprehensive School Physical Activity Program (CSPAP; CDC, 2013) of the Whole School, Whole Community, Whole Child Model. For example, the CSPAP (CDC, 2013) specifies that physical activity is provided within schools for 60 minutes per day through a multicomponent approach, including before- and after-school physical activity, quality physical education, and movement breaks throughout the day. While it suggests that teachers and physical education teachers can be implementers, it positions the physical education teacher as the leader of such an initiative. Differences, however, between the results derived from this current study and the CSPAP largely involve the way in which stakeholders are involved with physical activity efforts, and also the explicit treatment targets that participants spoke of in the focus groups. For example, the CSPAP indicates that physical education teachers are well-positioned to lead a school-wide physical activity effort. However, to provide a seamless service delivery that effectively uses data to drive decisions while also targeting specific mental health variables, school psychologists may be well-positioned to work alongside the physical education teacher in these efforts.

The CSPAP provides broad indicators of the roles of particular stakeholders in the school. For example, it indicates that teachers and staff promote, teach, and integrate 
concepts. However, participants in the focus groups discussed how the unique skills of various school stakeholders would be necessary to utilize when considering physical activity integration within school mental health service delivery. For instance, occupational therapists could provide sensory support, while school counselors and school psychologists could promote the mental health benefits of such efforts and implement tier 2 and tier 3 supports. Employing the expertise of diverse stakeholders in these efforts can ensure that students' various needs are met as they access physical activity interventions.

The WSCC considers topics such as physical education and physical activity; counseling, psychological, and social services; social and emotional climate; and employee wellness as distinct components of a healthy school. However, participants in this study indicated physical activity as a mechanism that can bridge these facets together. Rather than existing in siloes, these components can overlap to influence systemic health change in schools. For example, participants discussed the notion of employing group counseling that infuses physical activity. These activities would encompass both physical education and physical activity; and counseling, psychological, and social services. Additionally, participants discussed that a whole school effort toward physical activity promotion could also enhance teacher physical activity and subsequent outcomes, thus bridging social and emotional climate with employee wellness.

Participants also reinforced the importance of a multi-tiered approach to intervention, where physical activity would be used in well-planned and targeted ways to meet the unique needs of students. This concept aligns with Adelman and Taylor's (1999) and Sugai and Horner's (2006) call for coordinated models of intervention, rather than 
considering a fragmented approach. At tier 1, participants conceptualized all students having access to structured or non-structured recess that is linked with social-emotional learning. Structured recess would allow for students to obtain explicit instruction in developing skills in cooperation and teamwork. Non-structured physical activity would allow students to autonomously navigate interpersonal experiences. Participants also discussed that all students would receive movement breaks throughout the day. At tier 2, notably, participants would engage in structured before-school physical activity and structured group counseling that targets specific needs. At tier 3, students would use physical activity within the confines of individual therapy or in crisis situations.

Indeed, the conceptualization provided by the participants both converges and diverges with literature from Fedewa et al. (2013), who delineate how physical activity could be delivered within a three-tiered model. For example, at tier 1, these researchers discussed that all students would receive one hour of physical activity through movement breaks, recess, and physical education. Tier 2 interventions for students needing additional physical activity (for which the authors list a host of reasons, including academic, mental health, and socio-economic) would involve before- or after-school programs, and additional physical activity breaks which might be implemented during transition times. Students that receive tier 3 supports may benefit from individualized instruction from a physical education teacher to foster cardiovascular or strength and resistance exercise. Students receiving tier 3 services might also use a stability ball or migrate to a separate area of the classroom to obtain a quick session of physical activity. The authors suggest that tier 3 supports are also infused in the home setting as well. 
The greatest differences among these two models involves the targeting of outcomes across domains by Fedewa et al. (2013), while this current study focused specifically on the mental health domain. Also, Fedewa and colleagues (2013) position the physical education teacher as a key implementer for tier 3 interventions. Within this current study, the school mental health professional is positioned as a key leader for tier 3 interventions, given their skillset and competency to intervene in crisis situations and provide targeted therapeutic supports. Again, this could also be attributed to this current study's focus on mental health outcomes, naturally positioning a school mental health professional as a more appropriate stakeholder. Of note, both the results of this current study and Fedewa and colleagues' (2013) study position teachers as implementers of tier 1 practices.

Participants in this current study discussed providing students with physical activity modalities that align with their needs and preferences. Participants commented in the focus groups that some children might be more inclined to participate in yoga, while others might enjoy running. With this said, this multi-component approach (e.g., using a variety of physical activity modalities) aligns with public health research and recommendations (Lavizzo-Mourey et al., 2012; PAGC, 2018) to engage youth in physical activity.

\section{Implementation}

When considering the broad stages of implementation, which include 1) exploration, 2) installation, 3) initial implementation, and 4) full implementation (Fixsen et al., 2005), it is noteworthy that participants also considered the necessity of these 
stages in their discussions. As discussed, exploration refers to assessing needs, considering the match of the intervention with the target population, identifying facilitators and barriers (e.g., resources, personnel) that could promote or hinder implementation, and ensuring feasibility of the intervention. Aligning with this stage, participants were able to identify the need for such a framework or intervention. For example, participants indicated that "kids need to move," or "they aren't getting enough physical activity." Participants were also able to point to literature suggesting the importance of physical activity in improving social-emotional and mental health outcomes. Participants further indicated how a physical activity campaign could diffuse into the system to promote a healthier school community. This concords with Rogers' (1983) Diffusion of Innovations model, which considers how over time through communication channels within the school, physical activity can become embedded and, in turn, adopted. While school administrators are identified as stakeholders, laying the groundwork and vision, school psychologists can serve to advocate and communicate these initiatives, thus promoting diffusion.

Participants' personal beliefs around physical activity converged with their professional beliefs around its utility in schools. Participants reflected on their personal experiences of physical activity supporting their own or their child's social-emotional and mental health functioning. For example, there were instances where participants discussed how they feel better after exercising or noticed a positive change in their child's behavior after they engaged in physical activity. For example, a participant stated:

I mean I would say I'm pretty positive I wouldn't have gotten through my training program if I didn't engage in physical activity myself. It's definitely a great way to relieve stress and our students definitely experience a lot of stress. So I think a 
positive outlet for them to help cope with that is a really great thing and it's something they can continue to use and have for the rest of their life.

The second phase, installation, refers to obtaining resources, preparing the organization for the new intervention, and ensuring elements to support implementation. Participants indicated implementation drivers on both individual and systemic levels, including school priorities, data structures, teacher buy-in, staff commitment, financial support, and equipment. Further, school psychologists were willing to engage in staff training and follow-up consultation to further ensure healthy implementation and sustainment.

The third stage, initial implementation, involves rolling out an intervention while iteratively adjusting the drivers of implementation and navigating concerns of stakeholders. Regarding this stage, participants indicated the importance of presenting data to stakeholders and managing expectations around "something going wrong." For example, participants discussed that students are likely to have difficulty regulating their behaviors during the process of adjusting to a new physical activity routine, and teachers may become frustrated if they perceive the intervention not immediately benefitting students. Thus, school psychologists play an important role in supporting implementers during this process.

The final phase, full implementation, suggests that the intervention is executed with strong data systems and implementation drivers that foster desired effects and sustainability. Regarding this stage, participants discussed that consistently seeing positive change can lead to increased buy-in and subsequent continued implementation. Further, providing praise to implementers and sharing success data can help sustain these efforts. 
Participants discussed the need for a leader or champion to enact this work within schools, ideally someone with an interest in physical activity. While participants indicated that the school system needs to prioritize such an initiative, the champion could be an existing school stakeholder willing to go above and beyond their current role. This converges with research conducted by Goodman and Steckler (1989), who found that champions for organizational health change were typically "middle officials." A teacher or school psychologist may be well suited for a champion role. However, these stakeholders are notoriously busy, and taking on additional time-sensitive work in addition to their roles could lead to increased risk of burn-out (Schilling, Randolph, \& Boan-Lenzo, 2017; Skaalvik \& Skaalvik, 2017). Thus, schools must prioritize adequate systems to support these stakeholders.

Fixsen and colleagues (2015) conceptualize the components serving as building blocks of implementation. These include a) a source, or program that is intended to be implemented; b) a destination, which involves the person or entity that takes on the program; c) a communication link, or individual that represents the program and engages in efforts to support its fidelity; d) consistent feedback about the program; and e) its influence on the individual or systemic level. Based upon the data gleaned from the study, the source is noted as a physical activity or mental health framework; and the destination is a committee consisting of a champion with support from school administration. The communication link involves the implementers (e.g., teachers) with their teams, while the influence involves the priorities of the school. Relatedly, this study illuminates that data-based decision making is critical to understand the progress and efficacy of using physical activity in schools to foster increased mental health outcomes. 


\section{Therapeutic Outcomes of Physical Activity}

Participants discussed a host of therapeutic outcomes of physical activity. As discussed, the most frequently mentioned modalities involved walking (30 mentions, eight transcripts; e.g., going for a walk in the hallway), movement breaks (24 mentions, six transcripts), yoga (20 mentions, five transcripts) and mindfulness (13 mentions, six transcripts), and running (16 mentions, six transcripts). Participants indicated that specific physical activities uphold unique purposes; for example, walking serves to distract and separate students from stressful situations. This is supported by literature on exercise serving as a distraction coping skill (e.g., Stathapolou et al., 2006; Craft \& Perna, 2004).

As discussed, yoga was indicated as a unique modality that could be used to calm students that might be behaviorally dysregulated or at risk of becoming behaviorally dysregulated. This is supported by literature suggesting that yoga with guided meditation can decrease involuntary stress response (Frank et al., 2014). Participants' anecdotes about physical activity are also supported by the literature. That is, participants discussed using physical activity movement breaks to increase on-task behavior (Mahar, Murphy, Rowe, Golden, Shields, \& Raedek; Lowden, Powney, Davidson, \& James, 2001), while engaging in general levels of physical activity to support their feelings of mastery and confidence (Craft \& Perna, 2004; Zahl, Steinsbekk, \& Wichstrøm, 2016; Voskuil \& Robbins, 2015). Participants underscored the importance of recess time as a mechanism to support students in developing problem-solving skills, which is well-supported by the literature (London et al., 2014; Madsen et al., 2011; Mayfield et al., 2010). School psychologists also indicated the importance of structured group counseling sessions to target mental health concerns, although the literature on this topic is scarce. 


\section{The Role of the School Psychologist}

Fedewa and Clarke (2010) identified school psychologists as change agents that can incorporate physical activity within school-wide practices to support a host of student outcomes by advocating across classroom, school, and district levels. This study uniquely positions school psychologists as data analysts, mental health consultants, and tier 2 and tier 3 interventionists in efforts to promote physical activity and mental health. Further, this study identifies school psychologists as advocates and key stakeholders in implementing interventions.

School psychologists consider themselves key stakeholders in supporting schools in linking physical activity with mental health. School psychologists also uphold a role in locating resources and literature to support these efforts. With this said, some participants indicated that they would like more training around use of physical activity to support mental health. Participants' perspectives of their roles within this work are in line with recommendations from Greenspan et al. (2019), who discuss that school psychologists should consult and collaborate with teachers about physical activity, engage in progress monitoring of physical activity-based interventions, and implement physical activity within their service delivery.

While participants in the study were able to brainstorm specific ways that physical activity could be used as a modality, they often relied on their broad training in school psychology to guide their decision-making around data collection efforts. For example, participants often referenced using a problem-solving model to identify problems and link interventions accordingly (Deno, 2002), while also considering MTSS teams as a way to support physical activity efforts. This suggests that participants were generally 
guided by strong theoretical heuristics that are essential to school psychology. This positions school psychologists as upholding the training to incorporate physical activity within sound problem solving and intervention frameworks to effectively link physical activity interventions to support mental health. Specifically, using a problem-solving model allows school psychologists to consider the magnitude of the target problem and generate effective solutions that target the problem area. Using MTSS allows school psychologists to deliver interventions in a population-based approach that takes into account the needs of all students. These important facets of school psychological service delivery lend themselves to the incorporation of physical activity to foster increased mental health outcomes.

\section{Limitations}

This study presents notable limitations. In grounded theory, researchers often engage in theoretical sampling to continue to collect data from other participants to make increased meaning of the concept. Given much of what participants indicated was hypothetical, it could have added further rigor to extend the interview outside of school psychologist population. For example, there was much discussion about the impact of administrator buy-in, decision-making power, and priorities, In theoretical sampling (e.g., Corbin \& Strauss, 2015), the researcher would then interview administrators to gain a greater understanding of their perspectives to answer lingering questions. As another example, participants discussed movement breaks as a modality. As that theme became saturated, the researcher could have explored additional detail on types of movement breaks that would be most feasible. 
While the data highlighted from this current study are strong, its ability to generalize to elementary school populations and school psychological service delivery should be considered with caution for a multitude of reasons. Firstly, this is a newer area of work focused on a heterogenous population. Further, within grounded theory, it is noteworthy that the data obtained can provide a foundation to quantitively test the model developed (e.g., Taber, 2000). Thus, collecting increased qualitative data to glean other school stakeholders' perspectives of this work may then lead to a testable model that can be more appropriately generalized to wider context.

Another notable limitation includes the heterogeneity of the sample. All participants in the study identified as White, Non-Hispanic, cisgender, and mostly (90\%) female. According to the 2015 NASP membership survey (Walcott \& Hyson, 2015), the racial make-up of school psychologists was $86.3 \%$ White, 5.5\% Black or African American, 2.9\% Asian, and 4.0\% other or multiracial. Also, $84.2 \%$ were female and $15.3 \%$ were male. In light of the more recent push toward increased diversity in the field (Grapin, Bocanegra, Green, Lee, \& Jaafar, 2016; Walcott \& Hyson, 2015), it is likely that some diverse identities were not represented in this survey. Given the heterogeneity of the sample, the voices of perspectives of diverse groups were not represented in this study. Relatedly, questions were not centered around diversity issues within physical activity. Thus, this study did not successfully illuminate a breadth of strong social justice themes pertaining to physical activity interventions in schools.

Online synchronous focus groups using video chat was selected as a feasible and inexpensive way to collect data from participants located in various geographic locations (e.g., Kenny, 2005). As discussed, there is minimal literature on the use of online focus 
groups in research (e.g., Kenny, 2005; Stewart \& William, 2005; Williams et al., 2012), and less literature on using real-time video chat (e.g., Han et al., 2019; Kite \& Phongsavan, 2017; Tuttas, 2015) and while it is a promising modality, its lack of research support serves as a limitation to this study. This study, given the rich data derived, serves as a strong indicator of online focus group research, particularly its capacity to increase access to research participants.

Relatedly, as this study used online technology to conduct focus groups, some technical errors arose. For example, at times there were audio delays that caused participants to speak over one another. Further, since many participants called in from home, it was evident that they may have been distracted during the focus groups (e.g., possibly looking at social media, playing with pets). At times, participants' audio was not clear and their statements were at times difficult to decipher. This made it difficult for the research team to interpret the data and for other participants to respond.

This study could present selection bias (e.g., Frey, 2018). It is likely that school psychologists who engage in a study in this topic area have a personal interest in physical activity or health promotion. This is indicated by the above average scores on the Brunel Lifestyle Physical Activity Questionnaire (Karageorghis, Vancato, Chatzisarantis, \& Carron, 2005) as well as participants reporting that they were athletes or fitness participants in high school or college (70\% and 50\%, respectively). Of note, research from unpublished data (Greenspan, Whitcomb, Fefer, \& Hayden, 2017) suggested that $57.1 \%$ of school mental health professionals were high school athletes or frequent participants in fitness activities while $39.3 \%$ were college athletes or frequent participants in fitness activities. This suggests that this current study may have included participants 
that are generally more enthusiastic about fitness and physical activity which could have skewed the data in a more positive direction.

Further, as the focus group leader was also the PI of this study, it is possible that his bias may have impacted results. At times during the focus groups, the PI responded with praise (e.g., "that's great!") when participants indicated certain physical activity modalities. Such statements could cause participants to feel pressured to respond in a certain way. In light of the topic, participants may have answered questions in an overly positive manner to appease the PI. To this point, social desirability (e.g., Lavrakas, 2018) could have played a role in the data as participants may have reflected on the positives of physical activity to be perceived positively by themselves, the other participants, and the researcher.

\section{Implications for Research}

This study offers rich implications for future research. Firstly, future convergent studies that underscore the intersections between physical activity and school-based mental health supports will add to this foundational research. While this study sheds light on school psychologists' perspectives and conceptualization of physical activity embedded in mental health service delivery, it is underscored form the data that school priorities largely impact such interventions. Participants indicated that school administrators' perceptions of physical activity were dependent upon the severity of the need and amount of class time a student may miss. There was a perception illuminated in the data that administrators may be more willing to support tier 1 interventions, rather than tier 2 or tier 3. An important next step will be to explore administrators' perspectives 
of physical activity interventions across the tiers. Specifically, it will be critical to delineate common factors that are viewed as facilitators and barriers to physical activity interventions.

This study focused on elementary schools to consider the unique developmental needs of a particular population. Further, considering implementation of physical activity supports for younger children, offers increased opportunities for preventative supports. Future research should consider the utility of physical activity interventions for secondary schools. Understanding the unique needs and conceptualization of middle school and high school physical activity supports would offer an important continuum of care throughout schooling that generalize to using physical activity as a daily mental health support throughout adulthood.

Of note, participants discussed the potential utility of incorporating physical activity within group counseling sessions for internalizing symptoms. There is a current dearth of literature on such an intervention; thus, future research may explore integrating physical activity within a group that employs cognitive behavioral therapy. Of note, physical activity could serve as a behavioral activation intervention (Cuijpers, van Straten, \& Warmerdam, 2007) while also providing youth with the well documented psychological and neurobiological causal and mediating benefits.

Concepts of social justice were seldomly addressed by the participants in the study. As discussed, certain student populations, including students with physical disabilities (Goodwin \& Watkinson, 2000) and sexual minority and gender diverse students (Greenspan, Griffith, Hayes, \& Murtagh, 2019; Kosciw, Greytak, Zongrone, Clark, \& Truong, 2018), frequently experience discriminatory, hostile, and non-equitable 
physical activity environments. Further, dominant gender and racial discourses exist within the physical activity context (Azzarito \& Solomon, 2005). Further, socioeconomic resources can likely propel access to physical activity while financial limitations might deter access. These topics warrant further exploration. Future research should consider the school psychologist's role in infusing social justice and equitable practice within school physical activity and health practices. Further, a more diverse participant sample would illuminate wider worldviews and allow researchers to consider how diverse roles intersect with this critical work.

There is a need for increased research exploring the benefits and challenges of conducting online focus groups. This current study adds to the literature suggesting its utility in obtaining rich data from participants that may be traditionally difficult to interview due to time restrictions and travel costs.

\section{Implications for Practice}

This study positions school psychologists as key stakeholders in Implementing physical activity interventions within schools to support the mental health of students. The data gleaned from this study illuminate that school psychologists perceive physical activity as an important vehicle to strengthen the social-emotional and mental health outcomes of youth. However, school psychologists would benefit from increased education to bridge their training in mental health and implementation science with physical activity. Specifically, school psychologists would benefit from increased training on the connections between physical activity engagement and mental health 
outcomes, and further, how physical activity can be delivered within existing intervention frameworks (e.g., PBIS).

School psychology graduate programs would benefit from focusing on the utility of physical activity in coursework, research, and program-wide learning activities. Indeed, collaborating with physical education and kinesiology departments at the university level could enhance school psychology research and training to more deeply consider intersections between physical activity and mental health. Conversely, this effort could also support physical education teacher in obtaining increased understandings of child mental health and the role of the school psychologist. Such collaborations at the graduate training level could further bridge increased future professional collaborations between school psychologists and physical education teachers, which would serve to strengthen efforts to integrate mental health interventions and physical activity.

This study also illuminated that school psychologists would benefit from increased resources pertaining to physical activity interventions. Indeed, there is a burgeoning literature base on physical activity interventions (e.g., CDC, 2010; PAGC, 2018; Greenspan et al., 2019). As such, it is important that school psychology advocacy organizations such as NASP and APA-Division 16 as well as physical activity scholars to disseminate empirically supported resources to link this research into practice materials School Psychologists understand the importance of physical activity to support mental health outcomes of youth, and many uphold the motivation to support such efforts. With this said, administrative priorities are upheld as the primary gatekeeper to including a continuum of physical activity interventions within schools. School psychologists may consider consulting with administrators about the burgeoning research 
base linking physical activity and mental health. Subsequently, school psychologists may consider using their skills in consultation and implementation as they work with a multidisciplinary team of committed stakeholders to build readiness and capacity and support the implement physical activity within school to promote mental health outcomes of youth. 


\section{APPENDIX A}

\section{FACEBOOK RECRUITMENT}

$\mathrm{Hi}$, School Psychologists! I invite you to participate in a 90-minute focus group (maximum time) to learn about your perspectives of using physical activity to support mental health outcomes for youth in elementary school settings. You will receive a \$35

Amazon gift card for participating. Please click the link below for a 10-15 minute questionnaire and to learn more! (Link directs to Qualtrics survey.) 


\section{APPENDIX B}

\section{TWITTER RECRUITMENT}

Hi, School Psychologists - I invite you to participate in a 90-min. focus group (max. time) to talk about using \#physicalactivity in elementary school settings. \$35 Amazon card for participating! Link below for 10-15 min. questionnaire and to learn more. (Link directs to Qualtrics survey.) 


\section{APPENDIX C \\ E-MAIL RECRUITMENT}

\section{Dear Colleague,}

I hope this email finds you well! I am working on my dissertation study to learn more about school psychologists' perspectives of using physical activity to promote mental health outcomes for elementary school students.

I invite you to participate in a focus group, which will take at most 90 minutes. Within this group, school psychologists will be encouraged to respond to a series of semistructured questions and share their thoughts and perspectives on this topic.

The information gleaned from these focus groups will help inform directions for future interventions.

Participants that complete the focus groups will receive a \$35 Amazon gift card.

Please click this link to complete a screener and questionnaire before registering for the focus group! The questionnaire is expected to take no more than 15 minutes.

(Link directs to Qualtrics survey.)

Please let me know if you have any questions!

Best,

Scott Greenspan

Doctoral Candidate, School Psychology

University of Massachusetts Amherst

sgreenspan@umass.edu 


\section{APPENDIX D ONLINE CONSENT FORM}

Thank you for your interest in this focus group study about physical activity in school psychology! Focus groups will be held online via Zoom chat with School Psychologists working in elementary schools in the United States. We look forward to hearing about your perspectives. We just need to ask you some questions to learn more about you!

This survey process will take approximately 15 minutes at most. Following, the researcher will be in touch to schedule a focus group time. If you decide to participate, at the completion of the focus group, you will receive at \$35 Amazon gift card.

\section{Online Survey Consent Form}

You are being invited to participate in a focus group research study titled Physical Activity in School Psychology. This study is being conducted by Scott Greenspan, M.S., a Doctoral Candidate in School Psychology at the University of Massachusetts Amherst. This current form is two-fold and serves as (1) a screener to ensure your eligibility to participate in the focus groups and (2) a questionnaire form about yourself and your school. You were selected to participate in this study because you are a school psychologist.

The data yielded from this screener/demographic will allow for the researchers to analyze demographic data of the eligible participants, which is important in understanding the diverse characteristics of participants. For example, it is important to know the percentage of participants that identify with a certain demographic item. Also, these data may bring forth important patterns and research insights. For example, it might also be important if most participants identifying with a particular demographic item respond a similar way to a question that is asked. If you are deemed ineligible for this study, the data that you provide will be discarded.

\section{Why are we doing this research study?}

The screener is intended to allow the researchers to develop a pool of eligible participants to engage in a focus group study. The purpose of the demographic form is to understand the demographics of participants and their schools.

\section{Who can participate in this research study?}

Anyone may engage in the screener. However, only those individuals that are involved with systems change work (e.g., MTSS, PBIS, RTI, school climate efforts, systems consultation, etc.) and are employed within a public school/district and work within the elementary context will be eligible to participate.

Elementary schools could involve K-5 schools that also include pre-school, pre-K, 6th grade, 7th grade, and/or 8th grade. If you are unsure if your school would qualify this can be indicated in the screener and, the PI can follow up with you. 
Participants will also be required to provide an email address for the PI to contact them about scheduling a focus group session.

\section{What will I be asked to do and how much time will it take?}

This screener will ask you for your first name, email address, if you are willing to be contacted for focus group scheduling purposes, if you work in a public school context, and if you engage in systems change work, and specifically within an elementary school context.

If you agree to take part in this study, you will be asked to complete an online survey/questionnaire. This survey/questionnaire will ask about your personal demographics (e.g., years in the field, state that you are employed, gender, race/ethnicity), school demographics (e.g., urban/rural/suburban location, free and reduced lunch percentage) as well as questions about your exercise (e.g., athletic involvement, current physical activity) and questions about physical activity in your school (e.g., time allotted for recess and physical education).

\section{Will being in this research study help me in any way?}

Participating in this questionnaire will allow for the researchers to have a pool of participants to engage in the focus groups. You may not directly benefit from the study, but it is our hope that we can obtain a large number of participants to engage in the focus group which will then inform future research regarding the feasibility of using physical activity to support students' mental health.

\section{What are my risks of being in this research study?}

We believe there are minimal risks associated with this research study; however, a risk of breach of confidentiality always exists and we have taken the steps to minimize this risk as outlined in a section below.

\section{How will my personal information be protected?}

For the demographic form, participants will indicate their first name, which will be manually replaced with their unique ID number and uploaded to Box.com. The original form in Qualtrics.com will be erased at the end of the study. All information in Box will be de-identified.

Will I be given any money or other compensation for being in this research study? Participants will not receive compensation for completing this screener/questionnaire. However, if you are eligible for the study and attend the entire focus group, you will be provided with a \$35 Amazon gift card.

\section{What happens if I say yes, but I change my mind later?}

You do not have to be in this study if you do not want to. If you agree to be in the study, but later change your mind, you may drop out at any time. There are no penalties or consequences of any kind if you decide that you do not want to participate. 


\section{Who can I talk to if I have questions?}

If you have questions about this project or if you have a research-related problem, you may contact the researcher(s), Scott Greenspan, M.S. at sgreenspan@ umass.edu or (781) 801-2543 or Sara Whitcomb, Ph.D. at swhitcomb@educ.umass.edu or (413) 545-6904. If you have any questions concerning your rights as a research subject, you may contact the University of Massachusetts Amherst Human Research Protection Office (HRPO) at humansubjects@ ora.umass.edu or (413) 545-3428.

By clicking "I agree" below you are indicating that you are at least 18 years old, have read this consent form and agree to participate in this research study. You are free to skip any question that you choose.

Please print a copy of this page for your records.

I agree.

I disagree. 


\section{APPENDIX E SCREENER QUESTIONS}

Are you currently working as a school psychologist?

Yes No

Do you work within a public school context in the United States?

Yes No

Within your role do you engage in systems change work?

Such work includes supporting school-wide initiatives, which may include, but is not limited to:

- Positive Behavior Interventions and Supports (PBIS)

- Response to Intervention (RTI)

- Multi-tiered systems of support (MTSS)

- School-wide social-emotional learning School climate efforts

- School data collection and/or data analysis efforts

- Systems-level consultation

Yes No

Do you engage in systems change work (e.g., PBIS, RTI, MTSS, school-wide SEL, etc.) within the elementary school context?

Elementary schools could involve k-5 schools that also include pre-school, pre-K, 6th grade, 7 th grade, and/or 8th grade. If you are unsure if your school would qualify please click "other" and explain.

Yes No

Other (please explain)

What is your first name?

What is your email address that you check most often?

\section{Confirm Email}

If you are selected for this study, we will contact you at the above e-mail address to schedule a time. Do we have your permission to contact you at the above listed email address?

Yes No 
(If Yes is selected for all prompts) You meet the eligibility criteria to participate in this study! We have some more questions to ask you, which will take approximately 12 minutes or less.

(If No is selected for 1 prompt) You have indicated that you are either unwilling to provide consent to participate in this study, not involved in systems change work at the elementary level in the United States, are not employed with a public school, or do not grant the researcher to contact you via e-mail. Therefore, you are not eligible to participate in this study.

If you have selected one of these fields in error, please feel free to complete the survey again. Thank you for your interest in this work! 


\section{APPENDIX F \\ PHYSICAL ACTIVITY INVOLVEMENT}

Were you a high school athlete or frequent participant in fitness activities?

Yes No

Were you a college athlete or frequent participant in fitness activities?

Yes No

The Brunel Lifestyle Physical Activity Questionnaire Pre-Planned Physical Activity Sub-Scale

How many times in a normal week do you engage in pre-planned physical activity? Never

$1-2$ times

3-4 times

5-6 times

7 or more times

How long have you been engaging in pre-planned physical activity at this weekly rate?

Not relevant to me

Less than 1 month

1-3 months

4-6 months

More than 7 months

In general, what is the duration of each session of pre-planned physical activity?

Not relevant to me

Less than $10 \mathrm{~min}$.

10-20 min.

21-30 min.

More than $30 \mathrm{~min}$.

If you add together each session of pre-planned physical activity that you engage in during a normal week, how much time would you estimate that you spend in total? Not relevant to me

Less than 1 hour

$1-2$ hours

3-5 hours

More than 5 hours

In the past, how long have you generally persisted with a pre-planned physical activity program before giving up?

Not relevant to me as I have never persisted 
Up to 1 month

Up to 3 months

Up to 6 months

More than 6 months or I have never given up

How vigorously do you engage in pre-planned physical activity?

Not relevant to me

Very light (hardly out of breath)

Moderately hard

Hard

Very hard (breathing deeply) 


\section{APPENDIX G \\ SCHOOL INVOLVEMENT}

What grades are housed in the elementary school setting that you work in? (Check all that apply)

Pre-School / Pre-K 1

2

3

4

5

6

7

8

Is there anything else that you would like us to know about the grades housed in the elementary setting you work in?

Which of these settings best describes your school's location? Urban Suburban Rural

Approximately what percent of students receive free or reduced price lunch in your district?

If you are unsure, you can keep this field blank.

In the school your primarily serve, how many minutes per week on average do most students in your school have physical education class?

If you are unsure, you can keep this field blank.

In the school you primarily serve, how many minutes per day on average do most students have recess?

If you are unsure, you can keep this field blank. 


\section{APPENDIX H \\ PERSONAL DEMOGRAPHICS}

In which state are you currently employed?

What is your racial or ethnic identification?

American Indian or other Native American

Asian, Asian American, or Pacific Islander

Black or African American

White (Non-Hispanic)

Mexican or Mexican American

Puerto Rican

Other Hispanic or Latino

Multiracial

Other:

I prefer not to respond

What is your gender?

Female

Male

Non-binary / third gender

Prefer to self-describe

Prefer not to say

Transgender is an umbrella term that refers to people whose gender identity, expression or behavior is different from those typically associated with their assigned sex at birth. Other identities considered to fall under this umbrella can include non-binary, gender fluid, and genderqueer - as well as many more.

Do you identify as transgender?

Yes

No

Prefer not to say

What is the highest degree that you hold?

Bachelor's degree

Master's degree

CAGS or Specialist degree Doctoral degree

How many years have you been working as a school psychologist?

How many years have you been working as a school psychologist in your current district? 


\section{APPENDIX I \\ FOCUS GROUP CONSENT FORM AND CONFIRMATION}

\section{Thank you for participating in the screener/questionnaire!}

We just ask for approximately three more minutes of your time to complete the focus group study registration process!

Specifically, the next step in this process involves completing the focus group consent form. Please read this content and if you agree, please click "I agree." If you have any questions please contact Scott Greenspan, sgreenspan@umass.edu. Please keep a copy of this consent form and print for your records. It will also be e-mailed to you.

\section{Focus Group Consent Form for Participation in a Research Study University of Massachusetts Amherst \\ Researcher: Scott Greenspan, M.S. Faculty Advisor: Sara Whitcomb, Ph.D. Study Title: Physical Activity in School Psychology - Focus Group Study}

\section{What is this form?}

This form is called a Consent Form. It will give you information about the study so you can make an informed decision about participation in this research. We encourage you to take some time to think this over and ask questions now and at any other time. If you decide to participate, you will be asked to click "I agree." The primary investigator (PI) will email you with a copy of this form.

\section{What are some of the important aspects of this research study that I should be aware of?}

The purpose of this study is to understand school psychologists' perspective of implementing physical activity to support youth mental health. This study will be held via Zoom video chat. Participating in this research study is voluntary. If you agree to participate, you will be contacted by the primary investigator to schedule a time to engage in a 90-minute (maximum time) focus group with other school psychologists. Participants will answer a series of questions, which will help inform future intervention development.

After you schedule a focus group time, the PI will also send two reminder emails. One email will be sent once the date/time is confirmed. The other email will be sent within 24 hours of the start of the group.

While we do not foresee risks in participating in the study, one concern might surround privacy and confidentiality, especially in the context of a group. The PI is engaging in several steps to ensure your privacy. For example, while the group will be audio recorded, the audio will be uploaded into a password protected Box.com account. 
Additionally, it will be sent for transcription to Rev.com, which has transcribers sign nondisclosure agreements and abide by confidentiality standards. The PI will also remind the group to keep the information revealed in the group private. Of note, this cannot be guaranteed.

\section{Why are we doing this study?}

The purpose of this study is to understand school psychologists' perspective of implementing physical activity to support youth mental health. While there is research showing this physical activity can support mental health outcomes for youth, little is known about school psychologists' input and perspectives about this topic. Developing such an understanding could support future intervention implementation efforts.

\section{Who can participate in this research study?}

School psychologists that work in a public school/district and engage in systems change work at the elementary school level are welcome to join. Also, participants must be willing to provide their email address for contact with the researcher to schedule a focus group time. Also, participants must be willing to provide their first name and email address so the researcher can be in email contact to schedule a focus group time.

Where will this research study take place and how many people will participate? The research study will take place online via Zoom video chat. There will be no more than 7 people per group. While it is unknown at this current time, we expect that approximately 30 school psychologists in total will participate.

\section{What will I be asked to do and how much time will it take?}

If you agree to take part in this study, you will be asked a series of semi-structured questions and potential follow-up questions. The questions pertain to implementation of physical activity interventions to support youth mental health. The session will be at most 90 minutes. After the session, you will not be contacted by the researcher for more information. However, you are welcome to contact him with any questions.

\section{Will being in this research study help me in any way?}

You may not directly benefit from this research; however, we hope that your participation in the study may inform future initiatives to promote youth mental health through physical activity.

\section{What are my risks of being in this research study?}

We believe there are minimal risks associated with this research study; however, a risk of breach of confidentiality always exists and we have taken the steps to minimize this risk as outlined in the section below

\section{How will my personal information be protected?}

Privacy and confidentiality are important to us. The following procedures will be used to protect the confidentiality of your study records. 
To protect confidentiality, all participants will be assigned a unique ID number that will be used so they can be identified in the transcript. Audio will be uploaded to Box.com (in a folder that just the PI and his faculty advisor have access to) and deleted by the conclusion of the study. All back-up audio (which will be used in case the Zoom recorder doesn't work) will be erased after confirmation that one audio file of the group was successfully uploaded to Box.com. All audio will be deleted at the remainder of the study.

The audio files will be uploaded to Box.com, and back-up copies will be erased. The audio files will also be uploaded to Rev.com for transcription. Before the transcript is downloaded from the Rev.com server, the PI and/or research assistant will use the Rev.com editing feature to replace names with ID numbers to further protect personal information.

The screener and demographic forms will be in a password protected Qualtrics account that only the PI and his faculty advisor will have access to. At the conclusion of this study, the researchers may publish their findings. You will not be identified in any publications or presentations.

Please be advised that although the researchers will take every precaution to maintain confidentiality of the data, the nature of focus groups prevents the researchers from guaranteeing confidentiality. The researchers would like to remind participants to respect the privacy of your fellow participants and not repeat what is said in the focus group to others.

Will I be given any money or other compensation for being in this research study? Participants that complete the focus group study will be provided with a \$35 Amazon gift card. This will be sent to the email that they provided.

\section{Who can I talk to if I have questions?}

Take as long as you like before you make a decision. We will be happy to answer any question you have about this study. If you have further questions about this project or if you have a research-related problem, you may contact the researchers: Scott Greenspan at sgreenspan@umass.edu or (781) 801-2543, or Sara Whitcomb, Ph.D., at (413) 545-6904, or swhitcomb@educ.umass.edu. If you have any questions concerning your rights as a research subject, you may contact the University of Massachusetts Amherst Human Research Protection Office (HRPO) at humansubjects@ora.umass.edu or (413) 545-3428

\section{What happens if I say yes but I change my mind later?}

You do not have to be in this study if you do not want to. If you agree to be in the study, but later change your mind, you may drop out at any time. There are no penalties or consequences of any kind if you decide that you do not want to participate.

\section{What if I am injured?}


The University of Massachusetts does not have a program for compensating subjects for injury or complications related to human subjects research, but the study personnel will assist you in getting treatment.

\section{Subject statement of voluntary consent}

Upon clicking "I agree," I am agreeing to voluntarily enter this study. I have had a chance to read this consent form. If I am not sure about something, I will click "I am not sure yet" and the researcher, Scott Greenspan will reach out to answer questions I have. I can also contact the researcher, Scott Greenspan (sgreenspan@umass.edu , 781-801-2543), or his faculty advisor (Sara Whitcomb, Ph.D. swhitcomb@educ.umass.edu, 413-545-6904) with any questions before signing. I have been informed that I can withdraw at any time. A copy of this signed Informed Consent Form has been provided for me.

I agree.

I'm not sure I disagree.

Thank you for participating in this survey. We will be in touch with you shortly to schedule a time for your participation in a focus group. As a reminder, upon completion of the focus group, you will be sent a \$35 Amazon gift card.

If there is anything else that you would like to let us know, please feel free to indicate this information in the box below, or e-mail the primary investigator, Scott Greenspan sgreenspan@umass.edu 


\section{APPENDIX J FOCUS GROUP PROTOCOL}

Thank you for participating in this study! My name is Scott Greenspan, and I am a Doctoral Candidate in the School Psychology program at UMass Amherst.

Today I am hoping to learn about school psychologists' perspectives about using physical activity as a means to support student mental health. While there is research showing that physical activity can support mental health outcomes, little is known about school psychologists' input and perspectives about this topic.

Within this process, I will ask you several questions. Feel free to answer popcorn style and you can just jump in if nobody is talking. I want to make sure everyone's voice is heard. If you have any questions about the study during the conversation, feel free to let me know and/or send a message to my colleague Kelsey Gordon who will be helping out with the study.

The chat feature is on the bottom of the screen (explain where)

Research collaborator introduces herself to the group

I do ask that you all please keep private what is said here. While I know this cannot be guaranteed, I do respectfully request that from everyone here.

This focus group will take at most 90-minutes. At the end of the focus group you will be sent a $\$ 35$ Amazon gift card.

Please feel free to take a moment to review the consent form. Please let me know if you have any questions.

Are you all ready to begin the focus group discussion?

First, can we please go around and say your first name, what state you are calling in from, Type of school/schools, and what does your role look like?

- Can you also please say if kindergarten in housed in your elementary school setting?

\section{OPEN QUESTION/ EXPLORATION}

You know I'm interested in physical activity as a means to support student mental health.

- What are your beliefs of using PA to support youth mental health?

- Does using PA to support youth mental health resonate with you as a school psychologist? If so, why? If not, why not?

Potential/possible clarifying/follow-up questions

- What are your thoughts of incorporating physical activity as a part of supporting mental health?

- Note: If it does not resonate, follow-up about why and bring this up throughout the focus group

Let's imagine (or reflect on actual experience if applicable) that we are implementing physical activity in the schools to promote mental health (summarize some of what was said previously). What would it look like? 


\section{INSTALLATION}

What would need to be in place for such an idea to be rolled out?

Potential/possible clarifying/follow-up questions:

- What would you need to be a part of this?

- What would the school need?

- Who would be involved?

If it does not resonate......

- If the conversation goes in the direction in which participants do not resonate with focus on incorporating physical activity for improving mental health, here are some of my initial thoughts for additional follow up questions that could steer the conversation: Should physical activity be a focus within school settings? Why or why not? Who should be responsible for these programs? What are the challenges \& barriers to doing so? If the implementation barriers could be tackled then how could we make this possible (leading into installation/implementation questions).

\section{INITIAL IMPLEMENTATION:}

We have imagined what physical activity in schools could look like and we have also thought of resources that might be needed.

What would it look like initially to implement this in a school? What would your role be in that?

Potential/possible clarifying/follow-up questions:

- Do you see any benefits or challenges?

- Worthwhile?

FULL IMPLEMENTATION:

We've imagined this PA and MH program, we have implemented it and figured out your role.

- How do we know it is helping kids' mental health?

- How do we keep it going?

- How do you know we are doing it well?

Follow-up questions:

- How do we assess that it is working?

- How do we make adjustments?

- How do we know it is implemented with fidelity?

- Where does PA fit into a multi-tiered model? (if not answered throughout)

Do you have any questions or comments about this that you would like to share before we end today?

Thank you very much for your participation! I will e-mail you a \$35 Amazon gift card. If you have any questions, feel free to send me an e-mail at sgreenspan@umass.edu. 


\section{BIBLIOGRAPHY}

Ahn, S., \& Fedewa, A. L. (2011). A meta-analysis of the relationship between children's physical activity and mental health. Journal of Pediatric Psychology, 36(4), 385-397. doi:10.1093/jpepsy/jsq107.

Algozzine, B., Barrett, S., Eber, L., George, H., Horner, R., Lewis, T., Putnam, B., Swain-Bradway, J., McIntosh, K., \& Sugai, G (2014). School-wide PBIS Tiered Fidelity Inventory. OSEP Technical Assistance Center on Positive Behavioral Interventions and Supports. www.pbis.org

Allensworth, D. D., \& Kolbe, L. J. (1987). The comprehensive school health program: exploring an expanded concept. Journal of School Health, 57(10), 409-412. doi: 10.1111/j.1746-1561.1987.tb03183.x

Annesi, J. J. (2005). Correlations of depression and total mood disturbance with physical activity and self-concept in preadolescents enrolled in an after-school exercise program. Psychological Reports, 96(3_suppl), 891-898. doi: 10.2466/pr0.96.3c.891-898

Azzarito, L., \& Solomon, M. A. (2005). A reconceptualization of physical education:

The intersection of gender/race/social class. Sport, Education and Society, 10(1), 2547. doi: $10.1080 / 135733205200028794$

Barker, D. (2019). In defense of white privilege: physical education teachers' understandings of their work in culturally diverse schools. Sport, Education and Society, 24(2), 134-146. doi: 10.1080/13573322.2017.1344123

Barros, R. M., Silver, E. J., \& Stein, R. E. (2009). School recess and group 
classroom behavior. Pediatrics, 123(2), 431. doi: 10.1542/peds.2007-2825

Bertram, R. M., Blase, K. A., \& Fixsen, D. L. (2015). Improving programs and outcomes: Implementation frameworks and organization change. Research on Social Work Practice, 25(4), 477-487. doi: https://doi.org/10.1177/1049731514537687

Biddle, S. J., Ciaccioni, S., Thomas, G., \& Vergeer, I. (2018). Physical activity and mental health in children and adolescents: An updated review of reviews and an analysis of causality. Psychology of Sport and Exercise, 42. doi.org/10.1016/j.psychsport.2018.08.011

Birnholtz, J. P., Horn, D. B., Finholt, T. A., \& Bae, S. J. (2004). The effects of cash, electronic, and paper gift certificates as respondent incentives for a webbased survey of technologically sophisticated respondents. Social Science Computer Review, 22(3), 355-362. doi: 10.1177/0894439304263147

Bourke, B. (2014). Positionality: Reflecting on the research process. The Qualitative Report,19(33), 1-9. Retrieved from http://nsuworks.nova.edu/tqr/vol19/iss33/3

Bray, M. A., Sassu, K. A., Kapoor, V., Margiano, S., Peck, H. L., Kehle, T. J., \& Bertuglia, R. (2012). Yoga as an Intervention for Asthma. School Psychology Forum, 6(2), 39-49.

BrckaLorenz, A., Zilvinskis, J., \& Haeger, H. (2014). Categorizing identities: Race, gender, disability, and sexual orientation. Air Annual Forum. Retrieved 
from

http://cpr.indiana.edu/uploads/Categorizing\%20Identities\%20Handout\%20FINAL \%202.pdf on May 16, 2019

Bronfenbrenner, U. (1979). The ecology of human development. Harvard university press.

Brown, M. B., Holcombe, D. C., Bolen, L. M., \& Thomson, W. S. (2006). Role function and job satisfaction of school psychologists practicing in an expanded role model. Psychological Reports, 98(2), 486-496. doi: 10.2466/pr0.98.2.486496

Brown, H. E., Pearson, N., Braithwaite, R. E., Brown, W. J., \& Biddle, S. J. (2013). Physical activity interventions and depression in children and adolescents. Sports medicine, 43(3), 195-206. Doi: 10.1007/s40279-012-0015-8.

Bundy, A., Engelen, L., Wyver, S., Tranter, P., Ragen, J., Bauman, A., ... \& Perry, G. (2017). Sydney Playground Project: A Cluster-Randomized Trial to Increase Physical Activity, Play, and Social Skills. Journal of School Health, 87(10), 751759. doi: $10.1111 /$ josh. 12550

Cannella-Malone, H. I., Tullis, C. A., \& Kazee, A. R. (2011). Using antecedent exercise to decrease challenging behavior in boys with developmental disabilities and an emotional disorder. Journal of Positive Behavior Interventions, 13(4), 230239. doi.org/10.1177/1098300711406122

Carey, M.A. \& Asbury, J. (2012). Focus group research. Walnut Creek, CA: Left Coast Press, Inc.

Carless, D., \& Douglas, K. (2016). Promoting mental health in youth sport. In N. 
L. Holt (Ed.), Positive youth development through sport (pp. 216-226). New

York, NY, US: Routledge/Taylor \& Francis Group.

http://dx.doi.org/10.4324/9781315709499-18

CASEL (2017). Framework for systemic social and emotional learning. Retrieved from https://casel.org/wp-content/uploads/2017/01/CASEL-Wheel-2.pdf

Castillo, J. M., Arroyo-Plaza, J., Tan, S. Y., Sabnis, S., \& Mattison, A. (2017). Facilitators of and barriers to model school psychological services. Psychology in the Schools, 54(2), 152-168. doi: 10.1002/pits.21991

Castillo, J. M., Wolgemuth, J. R., Barclay, C., Mattison, A., Tan, S. Y., Sabnis, S., ... \& Marshall, L. (2016). A qualitative study of facilitators and barriers related to comprehensive and integrated school psychological services. Psychology in the Schools, 53(6), 641-658. doi: 10.1002/pits.21932

Centers for Disease Control and Prevention. (2018) CDC healthy Schools.

Retrieved from https://www.cdc.gov/healthyschools/wscc/index.htm

Centers for Disease Control and Prevention (2015). Results from the school health policies and practices study 2014. Retrieved from https://www.cdc.gov/healthyyouth/data/shpps/pdf/shpps-508-final_101315.pdf

Center for Disease Control and Prevention (2013). Comprehensive school physical activity programs: A guide for schools. Atlanta, GA: Authors Centers for Disease Control and Prevention (2010). The association between school based physical activity, including physical education, and academic performance. Atlanta, GA: U.S. Department of Health and Human Services

Choy, L. B., McGurk, M.D., Tamashiro, R.,Nett B., \& Maddock, J. (2008). 
Increasing access to places for physical activity through a joint use agreement: a case study in urban Honolulu. Preventing Chronic Disease, 5(3). Retrieved from www.cdc.gov/pcd/issues/2008/jul/07_0117.htm

Corbin, J., Strauss, A., \& Strauss, A. L. (2015). Basics of qualitative research. (4th ed.). Sage Publications.

Collaborative for Academic, Social, and Emotional Learning. (2017). Core SEL competencies. Retrieved from https://casel.org/core-competencies/

Conners, C. K., Sitarenios, G., Parker, J. D. \& Epstein, J. N. (1998) The Revised Conners' Teacher Rating Scale (CTRS-R): factor structure, reliability, and criterion validity, Journal of Abnormal Child Psychology, 26(4), 279-291.

Cook, C. R., Frye, M., Slemrod, T., Lyon, A. R., Renshaw, T. L., \& Zhang, Y. (2015). An integrated approach to universal prevention: Independent and combined effects of PBIS and SEL on youths' mental health. School Psychology Quarterly, 30(2), 166. doi: 10.1037/spq0000102

Côté, J., Strachan, L., \& Fraser-Thomas (2006) Participation, personal development, and performance through youth sport. In Holt, N.L. Positive Youth Development Through Sport (34-45). Routledge: London and New York

Cornelius, C., Fedewa, A. L., \& Ahn, S. (2017). The effect of physical activity on children with ADHD: a quantitative review of the literature. Journal of Applied School Psychology, 33(2), 136-170. doi: 10.1080/15377903.2016.1265622

Costello, E. J., Mustillo, S., Erkanli, A., Keeler, G., \& Angold, A. (2003). 
Prevalence and development of psychiatric disorders in childhood and adolescence. Archives of General Psychiatry, 60(8), 837-844. doi:

10.1001/archpsyc.60.8.837

Couturier, L., Chepko, S., \& Holt/Hale, S. (2014). National standards \& gradelevel outcomes for K-12 physical education. Reston, VA: Human Kinetics.

Creswell (2014). Research design: Qualitative, quantitative, and mixed methods approaches. (4th ed.). Sage Publications.

Creswell, J. W., \& Creswell, J. D. (2018). Research design: Qualitative, quantitative, and mixed methods approaches. (5th ed.). Sage Publications.

Cronin, L. D., \& Allen, J. (2018). Examining the relationships among the coaching climate, life skills development and well-being in sport. International Journal of Sports Science \& Coaching, 13(6), 815-827. doi:

$10.1177 / 1747954118787949$

Craft, L. L., \& Perna, F. M. (2004). The benefits of exercise for the clinically depressed. Primary care companion to the Journal of clinical psychiatry, 6(3), 104.

Crews, D. J., Lochbaum, M. R., \& Landers, D. M. (2004). Aerobic physical activity effects on psychological well-being in low-income Hispanic children. Perceptual and Motor Skills, 98(1), 319-324.

Cuijpers, P., van Straten, A., \& Warmerdam, E. H. (2007). Behavioral treatment of depression: A meta-analysis of activity scheduling. Clinical Psychology Review, 27(3), 318-326. doi: 10.1016/j.cpr.2006.11.001 
Dale, L. P., Vanderloo, L., Moore, S., \& Faulkner, G. (2018). Physical activity and depression, anxiety, and self-esteem in children and youth: An umbrella systematic review. Mental Health and Physical Activity. doi:

10.1016/j.mhpa.2018.12.001

Danielson, M. L., Bitsko, R. H., Ghandour, R. M., Holbrook, J. R., Kogan, M. D., \& Blumberg, S. J. (2018). Prevalence of parent-reported ADHD diagnosis and associated treatment among US children and adolescents, 2016. Journal of Clinical Child \& Adolescent Psychology, 47(2), 199-212. doi:

$10.1080 / 15374416.2017 .1417860$

DeBate, R. D., \& Thompson, S. H. (2005). Girls on the Run: improvements in self-esteem, body size satisfaction and eating attitudes/behaviors. Eating and Weight Disorders-Studies on Anorexia, Bulimia and Obesity, 10(1), 25-32. doi:10.1007/BF0335

DeBoer, L. B., Powers, M. B., Utschig, A. C., Otto, M. W., \& Smits, J. A. (2012). Exploring exercise as an avenue for the treatment of anxiety disorders. Expert review of neurotherapeutics, 12(8), 1011-1022. doi: 10.1586/ern.12.73

DeVries, H. A., Beckmann, P., Huber, H., \& Dieckmeir, L. (1968). Electromyographic evaluation of the effects of sauna on the neuromuscular system. The Journal of sports medicine and physical fitness, 8(2), 61-69.

DeVries, H. A. (1981). Tranquilizer effect of exercise: A critical review. The Physician and sports medicine, 9(11), 46-55.doi: 10.1080/00913847.1981.11711206

Deno, S. L. (2002). Problem Solving as "Best Practice" In A. Thomas \& J. Grimes 
(Eds.), Best practices in school psychology IV (p. 37-55). National Association of School Psychologists.

Dewey, J. (1997). Experience and Education. New York: Simon and Shuster.

Dinoff, A., Herrmann, N., Swardfager, W., Liu, C. S., Sherman, C., Chan, S., \& Lanctôt, K. L. (2016). The effect of exercise training on resting concentrations of peripheral brain-derived neurotrophic factor (BDNF): a meta-analysis. PLoS One, 11(9), e0163037. Doi: 10.1371/journal.pone.0163037

Dishman, R. K., \& O'Connor, P. J. (2009). Lessons in exercise neurobiology: The case of endorphins. Mental Health and Physical Activity, 2(1), 4-9.

Doll, B. \& Cummings, J. A. (2008). Transforming school mental health services: Population based approaches to promoting the competency and wellness of children. Thousand Oaks, CA: Corwin Press.

Dudley, D. A., Pearson, P., Okely, A. D., \& Cotton, W. G. (2015).

Recommendations for policy and practice of physical education in culturally and linguistically diverse Australian secondary schools based on a two-year prospective cohort study. School Psychology International, 36(2), 172-188. doi: $10.1177 / 0143034314566489$

Dunlop, B. W., \& Nemeroff, C. B. (2007). The role of dopamine in the pathophysiology of depression. Archives of general psychiatry, 64(3), 327-337. doi:10.1001/archpsyc.64.3.327

Durant, N., Harris, S. K., Doyle, S., Person, S., Saelens, B. E., Kerr, J., ... \& 
Sallis, J. F. (2009). Relation of school environment and policy to adolescent physical activity. Journal of School Health, 79(4), 153-159. doi: 10.1111/j.17461561.2008.00384.x

Dusenbury, L., \& Weissberg, R. P. (2017). State Efforts to Promote Social and Emotional Learning in Students. A Status Report. Collaborative for Academic, Social, and Emotional Learning.

Eccles, M. P., \& Mittman, B. S. (2006). Welcome to implementation Science. Implementation Science, 1(1). doi: 10.1186/17485908-1-1.

Ericsson, I. (2008). Motor skills, attention and academic achievements. An intervention study in school years 1-3. British Educational Research Journal, 34(3), 301-313. Doi: 10.1080/01411920701609299

Fedewa, A. L., Ahn, S., Erwin, H., \& Davis, M. C. (2015). A randomized controlled design investigating the effects of classroom-based physical activity on children's fluid intelligence and achievement. School Psychology International, 36(2), 135-153.

Fedewa, A. L., Candelaria, A., Erwin, H. E., \& Clark, T. P. (2013). Incorporating physical activity into the schools using a 3-tiered approach. Journal of School Health, 83(4), 290-297. doi: 10.1111/josh.12029

Fedewa, A. L., \& Clark, T. P. (2010). Let's move! School psychologists as change agents in the domain of school-based physical activity. Communique, 38(6).

Felver, J. C., Butzer, B., Olson, K. J., Smith, I. M., \& Khalsa, S. B. S. (2015). 
Yoga in public school improves adolescent mood and affect. Contemporary School Psychology, 19(3),184-192. doi: 10.1007/s40688-014-0031-9

Fixsen, D. L., Naoom, S. F., Blase, K. A., Friedman, R. M., \& Wallace, F. (2005). Implementation research: A synthesis of the literature (Louis de la Parte Florida Mental Health Institute Publication\# 231). Tampa, FL: University of South Florida, Louis de la Parte Florida Mental Health Institute, The National Implementation Research Network.

Flynn, S. V., Korcuska, J. S., Brady, N. V., \& Hays, D. G. (2019). A 15-year content analysis of three qualitative research traditions. Counselor Education and Supervision, 58(1), 49-63. doi: 10.1002/ceas. 12123

Folino, A., Ducharme, J. M., \& Greenwald, N. (2014). Temporal effects of antecedent exercise on students' disruptive behaviors: An exploratory study. Journal of School Psychology, 52(5), 447-462. doi:10.1016/j.jsp.2014.07.002

Frank, J. L., Bose, B., \& Schrobenhauser-Clonan, A. (2014). Effectiveness of a school-based yoga program on adolescent mental health, stress coping strategies, and attitudes toward violence: findings from a high-risk sample. Journal of Applied School Psychology, 30(1), 29-49. doi: 10.1080/15377903.2013.863259

Frey, B. (2018). The SAGE encyclopedia of educational research, measurement, and evaluation. Thousand Oaks, CA: SAGE Publications, Inc. doi: $10.4135 / 9781506326139$

Fry, M. D., Guivernau, M., Kim, M. S., Newton, M., Gano-Overway, L. A., \& 
Magyar, T. M. (2012). Youth perceptions of a caring climate, emotional regulation, and psychological well-being. Sport, Exercise, and Performance Psychology, 1(1), 44. doi: 10.1037/a0025454

Fusch, P. I., \& Ness, L. R. (2015). Are we there yet? Data saturation in qualitative research. The Qualitative Report, 20(9), 1408-1416.

Ghandour, R. M., Sherman, L. J., Vladutiu, C. J., Ali, M. M., Lynch, S. E., Bitsko, R. H., \& Blumberg, S. J. (2018). Prevalence and treatment of depression, anxiety, and conduct problems in US children. The Journal of Pediatrics. doi: 10.1016/j.jpeds.2018.09.021

Glaser, B.G., \& Strauss, A.L. (1967). The Discovery of Grounded Theory: Strategies for Qualitative Research. Chicago: Aldine.

Goldfield, G. S., Mallory, R., Parker, T., Cunningham, T., Legg, C., Lumb, A., ... \& Adamo, K. B. (2007). Effects of modifying physical activity and sedentary behavior on psychosocial adjustment in overweight/obese children. Journal of pediatric psychology, 32(7), 783-793. 10.1093/jpepsy/jsm017

Goodwin, D. L. \& Watkinson, E. J. (2000). Inclusive physical education from the perspective of students with physical disabilities. Adapted Physical Activity Quarterly, 17(2), 144-160.

Grapin, S. L., Bocanegra, J. O., Green, T. D., Lee, E. T., \& Jaafar, D. (2016). Increasing diversity in school psychology: Uniting the efforts of institutions, faculty, students, and practitioners. Contemporary School Psychology, 20(4), 345-355. doi: $10.1007 / \mathrm{s} 40688-016-0092-\mathrm{z}$

Greenberg, M. T., Weissberg, R. P., O'Brien, M. U., Zins, J. E., Fredericks, L., Resnik, 
H., \& Elias, M. J. (2003). Enhancing school-based prevention and youth development through coordinated social, emotional, and academic learning. American Psychologist, 58(6-7), 466. doi: 10.1037/0003-066X.58.67.466

Gorham, L. S., Jernigan, T., Hudziak, J., \& Barch, D. M. (2019). Involvement in sports, hippocampal volume, and depressive symptoms in children. Biological Psychiatry: Cognitive Neuroscience and Neuroimaging, 4(5), 484-492. doi: 10.1016/j.bpsc.2019.01.011

Greenspan, S.B., Fefer, S., Whitcomb, S., \& Kemp, J.M. (2019). Incorporating physical activity in interventions: A systematic review in school psychology journals. Psychology in the Schools, 56(6), 907-927. doi: 10.1002/pits.22246

Greenspan, S.B., Griffith, C., Hayes, C.R., Murtagh, E.F. (2019). LGBTQ+ and ally youths' school athletics perspectives: A mixed-method analysis. Journal of LGBT Youth, 16(4), 403-434. doi: 10.1080/19361653.2019.1595988

Greenspan, S. (2017). From report writing to running: Combatting job stress with physical activity. Communique. 46 (4) p. 14.

Greenspan, S.B., Whitcomb, S., Fefer, S., \& Hayden, L. (2017). School mental health professionals' and physical educators' perspectives of collaborating and integrating social-emotional learning and physical activity. Unpublished raw data.

Harvey, S. P., Lambourne, K., Greene, J. L., Gibson, C. A., Lee, J., \& Donnelly, J. E. (2018). The effects of physical activity on learning behaviors in elementary school children: A randomized controlled trial. Contemporary School Psychology, 22(3), 303-312. doi: /10.1007/s40688 
Helmich, I., Latini, A., Sigwalt, A., Carta, M. G., Machado, S., Velasques, B., ... \& Budde, H. (2010). Neurobiological alterations induced by exercise and their impact on depressive disorders. Clinical practice and epidemiology in mental health: Clinical Practice \& Epidemiological Mental Health, 6, 115. doi: $10.2174 / 1745017901006010115$

Herr, K. \& Anderson, G. L. (2005). The continuum of positionality in action research. In Herr, K., \& Anderson, G. L. (Eds.), The Action Research Dissertation: A Guide for Students and Faculty (pp. 29-48). Thousand Oaks, CA: SAGE Publications Ltd. doi: 10.4135/9781452226644

Hilt, L. M., \& Pollak, S. D. (2012). Getting out of rumination: Comparison of three brief interventions in a sample of youth. Journal of abnormal child psychology, 40(7), 1157-1165. doi: 10.1007/s10802-012-9638-3

Holt, N. L. (Ed.). (2016). Positive Youth Development Through Sport. New York: Routledge.

Horner, R. H., \& Sugai, G. (2015). School-wide PBIS: An example of applied behavior analysis implemented at a scale of social importance. Behavior Analysis in Practice, 8(1), 80-85. Doi: 10.1007/s40617-015-0045-4

Hosker, D. K., Elkins, R. M., \& Potter, M. P. (2019). Promoting Mental Health and Wellness in Youth Through Physical Activity, Nutrition, and Sleep. Child and Adolescent Psychiatric Clinics, 28(2), 171-193. doi: 10.1016/j.chc.2018.11.010

Human Rights Campaign (2015). Collecting transgender-inclusive gender data in 
workplace and other surveys. Retrieved from

https://www.hrc.org/resources/collecting-transgender-inclusive-gender-data-inworkplace-and-other-surveys on may 16, 2019

Iannotti, R. J., Kogan, M. D., Janssen, I., \& Boyce, W. F. (2009). Patterns of adolescent physical activity, screen-based media use, and positive and negative health Indicators in the US and Canada. Journal of Adolescent Health, 44(5), 493-499. 10.1016/j.jadohealth.2008.10.142

Janson, J., \& Rohleder, N. (2017). Distraction coping predicts better cortisol recovery after acute psychosocial stress. Biological psychology, 128, 117-124. doi: 10.1016/j.biopsycho.2017.07.014

Jarrett, O. S., Maxwell, D. M., Dickerson, C., Hoge, P., Davies, G., \& Yetley, A. (1998). Impact of recess on classroom behavior: Group effects and individual differences. The Journal of Educational Research, 92(2), 121-126. doi: $10.1080 / 00220679809597584$

Jones, D. E., Greenberg, M., \& Crowley, M. (2015). Early social-emotional functioning and public health: The relationship between kindergarten social competence and future wellness. American Journal of Public Health, 105(11), 2283-2290. doi: 10.2105/AJPH.2015.302630S

Käll, L.B., Malmgren, H., Olsson, E., Lindén, T., \& Nilsson, M. (2015). Effects of a curricular physical activity intervention on children's school performance, wellness, and brain development. Journal of School Health, 85(10), 704-713. doi: 10.1111/josh.12303.

Käll, L. B., Nilsson, M., \& Lindén, T. (2014). The impact of a physical activity 
intervention program on academic achievement in a Swedish elementary school setting. Journal of School Health, 84(8), 473-480. doi: 10.1111/josh.12179

Kann, L., McManus, T., Harris, W., Shanklin, S.L., Flint, K.H., Queen, B.,... \& Ethier, K.A. Youth risk behavior surveillance - United States, 2017 (2018). Morbidity and Mortality Weekly Report Surveillance Summaries, 67(8): 1-114. https://dx.doi.org/10.15585/mmwr.ss6708a1

Karageorghis, C. I., Vencato, M. M., Chatzisarantis, N. L. D., \& Carron, A. V. (2005). Development and initial validation of the Brunel lifestyle physical activity questionnaire. British Journal of Sports Medicine, 39(5), e23-e23. doi: 10.1136/bjsm.2004.014258

Kenny, A. J. (2005). Interaction in cyberspace: an online focus group. Journal of Advanced Nursing, 49(4), 414-422. Doi: 10.1111/j.1365-2648.2004.03305.x

Kiluk, B. D., Weden, S., \& Culotta, V. P. (2009). Sport participation and anxiety in children with ADHD. Journal of Attention Disorders, 12(6), 499-506. doi: $10.1177 / 1087054708320400$

Kite, J., \& Phongsavan, P. (2017). Insights for conducting real-time focus groups online using a web conferencing service. F1000Research, 1-12. doi: 10.12688/f1000research.10427.1

Kremer, P., Elshaug, C., Leslie, E., Toumbourou, J. W., Patton, G. C., \& Williams, J. (2014). Physical activity, leisure-time screen use and depression among children and young adolescents. Journal of Science and Medicine in Sport, 17(2), 183-187. doi: 10.1016/j.jsams.2013.03.012

Kuusinen, J., \& Heinonen, M. (1972). Immediate aftereffects of the Finnish sauna 
on psychomotor performance and mood. Journal of Applied Psychology, 56(4), 336-340.

http://dx.doi.org/10.1037/h0032942

Kolbe, L. J., Collins, J., \& Cortese, P. (1997). Building the capacity of schools to improve the health of the nation: A call for assistance from psychologists. American Psychologist, 52(3), 256. doi: 10.1037/0003066X.52.3.256

Kosciw, J. G., Greytak, E. A., Zongrone, A. D., Clark, C. M., \& Truong, N. L. (2018). The 2017 National School Climate Survey: The experiences of lesbian, gay, bisexual, transgender, and queer youth in our nation's schools. New York: GLSEN.

Kuusinen, J., \& Heinonen, M. (1972). Immediate aftereffects of the Finnish sauna on psychomotor performance and mood. Journal of Applied Psychology, 56(4), 336 - 340. doi: 10.1037/h0032942

Lavizzo-Mourey, R., Dorn, J. M., Fulton, J. E., Janz, K. F., Lee, S. M., McKinnon, R., ... \& Troiano, R. P. (2012). Physical Activity Guidelines for Americans Mid-Course Report: Strategies to Increase Physical Activity Among Youth. Department of Health and Human Services: Washington, DC. Lavrakas, P. J. (2008). Encyclopedia of survey research methods. Thousand Oaks, CA: Sage Publications, Inc. doi: 10.4135/9781412963947

Lerner, R. M., Lemer, J. V, Almerigi, J., Theokas, C, Naudeau, S., Gestsdottir, S., et al. (2005). Positive youth development, participation in community youth development programs, and community contributions of fifth grade adolescents: 
Findings from the first wave of the 4-H Study of Positive Youth Development. Journal of Early Adolescence, 25,17-71. Doi:

London, R. A., Westrich, L., Stokes-Guinan, K., \& McLaughlin, M. (2015).

Playing Fair: The Contribution of High-Functioning Recess to Overall School Climate in Low-Income Elementary Schools. Journal of School Health, 85(1), 5360. doi.org/10.1111/josh.12216

Lowden, K., Powney, J., Davidson, J., \& James, C. (2001). The Class Moves!® Pilot in Scotland and Wales: An Evaluation. The Scottish Council for Research in Education.

Lubans, D., Richards, J., Hillman, C., Faulkner, G., Beauchamp, M., Nilsson, M., ... \& Biddle, S. (2016). Physical activity for cognitive and mental health in youth: a systematic review of mechanisms. Pediatrics, 138(3). doi: 10.1542/peds.20161642

MacDougall, C., \& Fudge, E. (2001). Planning and recruiting the sample for focus groups and in-depth interviews. Qualitative Health Research, 11(1), 117-126. doi.org/10.1177/104973201129118975

Madsen, K. A., Hicks, K., \& Thompson, H. (20101). Physical activity and positive youth development: Impact of a school-based program. Journal of School Health, 81(8), 462-470. doi: doi.org/10.1111/j.1746-1561.2011.00615.x

Martínez-Jurado, P. J., Moyano-Fuentes, J., \& Jerez-Gómez, P. (2014). Human resource management in lean production adoption and implementation processes: success factors in the aeronautics industry. BRQ Business Research Quarterly, 17(1), 47-68. doi: 10.1016/j.cede.2013.06.004 
Mahar, M. T., Murphy, S. K., Rowe, D. A., Golden, J., Shields, A. T., \& Raedeke, T. D. (2006). Effects of a classroom-based program on physical activity and ontask behavior. Medicine and science in sports and exercise, 38(12), 2086. doi: 10.1249/01.mss.0000235359.16685.a3

Mash, E.J. \& Barkley, R. A. (Eds) (2014) Child psychopathology, 3rd edition. New York: Guilford.

Mayfield, C. A., Child, S., Weaver, R. G., Zarrett, N., Beets, M. W., \& Moore, J. B. (2017). Effectiveness of a playground intervention for antisocial, prosocial, and physical activity behaviors. Journal of School Health, 87(5), 338-345. doi: doi.org/10.1111/josh.12506

McCormick, L. K., Steckler, A. B., \& McLeroy, K. R. (1995). Diffusion of innovations in schools: A study of adoption and implementation of school-based tobacco prevention curricula. American Journal of Health Promotion, 9(3), 210219. doi: $10.4278 / 0890-1171-9.3 .210$

Melnyk, B. M., Jacobson, D., Kelly, S. A., Belyea, M. J., Shaibi, G. Q., Small, L., ... \& Marsiglia, F. F. (2015). Twelve-Month Effects of the COPE Healthy Lifestyles TEEN Program on Overweight and Depressive Symptoms in High School Adolescents. Journal of School Health, 85(12), 861-870. doi: 10.1111/josh.12342

Melnyk, B. M., Jacobson, D., Kelly, S., O'Haver, J., Small, L., \& Mays, M. Z. (2009). Improving the mental health, healthy lifestyle choices, and physical health of Hispanic adolescents: A randomized controlled pilot study. Journal of School Health, 79(12), 575-584. doi: 10.1111/j.1746-1561.2009.00451.x 
Mendelsohn, T., Greenberg, M. T., Dariotis, J. K., Gould, L. F., Rhoades, B. L., \& Leaf, P. J. (2010). Feasibility and preliminary outcomes of a school-based mindfulness intervention for urban youth. Journal of Abnormal Child Psychology, 38(7), 985-994. Doi: 10.1007/s 10802-010-9418-х

Merrell, K. W., \& Buchanan, R. (2006). Using public health models to enhance systems capacity of schools. School Psychology Review, 35(2), 167-180.

Morgan, A. J., Rapee, R. M., \& Bayer, J. K. (2017). Increasing response rates to follow-up questionnaires in health intervention research: Randomized controlled trial of a gift card prize incentive. Clinical Trials, 14(4), 381-386. doi: $10.1177 / 1740774517703320$

Morgan, W. P. (Ed.). (1997). Series in health psychology and behavioral medicine. Physical activity and mental health. Philadelphia, PA, US: Taylor \& Francis.

Mullender-Wijnsma, M. J., Hartman, E., de Greeff, J. W., Bosker, R. J., Doolaard, S., \& Visscher, C. (2015). Improving academic performance of school-age children by physical activity in the classroom: 1-year program evaluation. Journal of School Health, 85(6), 365-371. doi: 10.1111/josh.12259

Napoli, M., Krech, P. R., \& Holley, L. C. (2005). Mindfulness training for elementary school students: The attention academy. Journal of Applied School Psychology, 21(1), 99-125. doi: 10.1300/J370v21n01_05

National Implementation Research Network (n.d.). Research on Implementation 
Stages. Retrieved from https://nirn.fpg.unc.edu/learnimplementation/implementation-stages/research on May 15, 2019

Nicholson, H., Kehle, T. J., Bray, M. A., \& Van Heest, J. (2011). The effects of antecedent physical activity on the academic engagement of children with autism spectrum disorder. Psychology in the Schools, 48(2), 198-213.

doi:10.1002/pits.20537

National Association of School Psychologists. (2015). The importance of mental and behavioral health services for children and adolescents (Position statement). Bethesda, MD: Author.

National Association of School Psychologists. (2010). Model for comprehensive and integrated school psychological services. Retrieved from https://www.nasponline.org/assets/Documents/Standards\%20and\%20Certification /Standards/2_PracticeModel.pdf

Newman, S.B., Rich, L., Reyna, V., Towne, L., Feuer, M.,...\& Wilson, L. (2002). The use of scientifically based research in education. Washington D.C.: United States of America Department of Education. Retrieved from https://www2.ed.gov/nclb/methods/whatworks/research/transcript.pdf O'callaghan, R. M., Ohle, R., \& Kelly, Á. M. (2007). The effects of forced exercise on hippocampal plasticity in the rat: A comparison of LTP, spatial-and non-spatial learning. Behavioural brain research, 176(2), 362-366.ß

Paluska, S. \& Schwenk, T. (2000). Physical activity and mental health: current concepts. Sports Medicine, 29(3), 167-180. Doi: 10.2165/00007256-20002903000003 
Panzano, P. C., Seffrin, B., Chaney-Jones, S., Roth, D., Crane-Ross, D., Massatti, R., \& Carstens, C. (2005). The innovation diffusion and adoption research project (IDARP): Moving from the diffusion of research results to promoting the adoption of evidence-based innovations in the Ohio mental health system. New Research in Mental Health, 16, 78-89.

Peck, H. L., Kehle, T. J., Bray, M. A., \& Theodore, L. A. (2005). Yoga as an intervention for children with attention problems. School Psychology Review, 34(3), 415-424.

Pepitas, A., Cornelius, A., \& Van Raalte, J. (2006) Youth development through sport. In Holt, N.L. Positive Youth Development Through Sport (61-70). Routledge: London and New York

Phillips, C. (2017). Brain-derived neurotrophic factor, depression, and physical activity: making the neuroplastic connection. Neural plasticity, 2017. doi:

$10.1155 / 2017 / 7260130$

Physical Activity Guidelines Advisory Committee (2018). 2018 Physical activity guidelines advisory committee scientific report. Washington D.C.: U.S. Department of Health and Human Services.

Physical Activity Guidelines Advisory Committee (2008). Physical activity guidelines advisory committee report, 2008. Washington D.C.: U.S. Department of Health and Human Services.

Reschley, D.J. (2008). School psychology paradigm shift. In Thomas, A. \& Grimes, J. (Eds.). Best Practices in School Psychology V. Bethesda, MD: National Association of School Psychologists. 
Rogers E. M. (1995). Diffusion of innovations. New York, N.Y.: The Free Press.

Rommel, A. S., Halperin, J. M., Mill, J., Asherson, P., \& Kuntsi, J. (2013).

Protection from genetic diathesis in attention-deficit/hyperactivity disorder: possible complementary roles of exercise. Journal of the American Academy of Child \& Adolescent Psychiatry, 52(9), 900-910. doi: 10.1016/j.jaac.2013.05.018

Ronsley, R., Lee, A. S., Kuzeljevic, B., \& Panagiotopoulos, C. (2013). Healthy Buddies $^{\mathrm{TM}}$ Reduces Body Mass Index Z-Score and Waist Circumference in Aboriginal Children Living in Remote Coastal Communities. Journal of School Health, 83(9), 605-613. doi: 10.1111/josh.12072

Speece, D. L., Case, L. P., \& Molloy, D. E. (2003). Responsiveness to general education instruction as the first gate to learning disabilities identification. Learning Disabilities Research \& Practice, 18(3), 147-156. doi: $10.1111 / 1540-5826.00071$

Strong, W. B., Malina, R. M., Blimkie, C. J., Daniels, S. R., Dishman, R. K., Gutin, B., ... \& Rowland, T. (2005). Evidence based physical activity for schoolage youth. The Journal of pediatrics, 146(6), 732-737. doi: 10.1016/j.jpeds.2005.01.055

Sugai, G., \& Horner, R. R. (2006). A promising approach for expanding and sustaining school-wide positive behavior support. School psychology review, 35(2), 245.

Saldaña, J. (2012). The coding manual for qualitative researchers (2nd edition). Sage.

Shriberg, D., Song, S. Y., Miranda, A. H., \& Radliff, K. (Eds.). (2013). School 
psychology and social justice: Conceptual foundations and tools for practice. Routledge.

Sugai, G., \& Horner, R. R. (2006). A promising approach for expanding and sustaining school-wide positive behavior support. School psychology Review, 35(2), 245.

Savina, E., Garrity, K., Kenny, P., \& Doerr, C. (2016). The benefits of movement for youth: A whole child approach. Contemporary School Psychology, 20(3), 282292. doi: 10.1007/s40688-016-0084-z

Schilling, E. J., Randolph, M., \& Boan-Lenzo, C. (2018). Job Burnout in School Psychology: How Big Is the Problem?. Contemporary School Psychology, 22(3), 324-331. doi: 10.1007/s40688-017-0138-x

Shoval, E., \& Shulruf, B. (2011). Who benefits from cooperative learning with movement activity?. School Psychology International, 32(1), 58-72. doi:10.1177/0143034310396806

Skaalvik, E. M., \& Skaalvik, S. (2017). Still motivated to teach? A study of school context variables, stress and job satisfaction among teachers in senior high school. Social Psychology of Education, 20(1), 15-37. doi: 10.1007/s11218-0169363-9

Smith, R. E., \& Smoll, F. L. (2005). Assessing psychosocial outcomes in coach training programs. Handbook of Research in Applied Sport and Exercise Psychology: International Perspectives, 293-316.

Stathopoulou, G., Powers, M. B., Berry, A. C., Smits, J. A., \& Otto, M. W. 
(2006). Exercise interventions for mental health: a quantitative and qualitative review. Clinical psychology: Science and practice, 13(2), 179-193. doi: 10.1111/j.1468-2850.2006.00021.x

Stewart, K., \& Williams, M. (2005). Researching online populations: the use of online focus groups for social research. Qualitative Research, 5(4), 395-416. Doi: $10.1177 / 1468794105056916$

Strong, W. B., Malina, R. M., Blimkie, C. J., Daniels, S. R., Dishman, R. K., Gutin, B., ... \& Rowland, T. (2005). Evidence based physical activity for schoolage youth. The Journal of pediatrics, 146(6), 732-737. doi:

10.1016/j.jpeds.2005.01.055

Taber, K. S. (2000). Case studies and generalizability: Grounded theory and research in science education. International journal of science education, 22(5), 469-487. doi: https://doi.org/10.1080/095006900289732

The Child \& Adolescent Health Measurement Initiative (2016). 2016-2017 National survey of children's health. Data resource center for child and adolescent health. Retrieved from http://www.childhealthdata.org/browse/survey/results?q=5283\&r=1

Tremarche, P. V., Robinson, E. M., \& Graham, L. B. (2007). Physical education and its effect on elementary testing results. Physical Educator, 64(2), 58.

Troiano, R. P., Berrigan, D., Dodd, K. W., Masse, L. C., Tilert, T., \& McDowell, 
M. (2008). Physical activity in the United States measured by accelerometer.

Medicine and Science in Sports and Exercise, 40(1), 181. doi:

0.1249/mss.0b013e31815a5lb3

Tsai, S. J. (2017). Role of neurotrophic factors in attention deficit hyperactivity disorder. Cytokine \& Growth Factor Reviews, 34, 35-41.

Tuttas, C. A. (2015). Lessons learned using web conference technology for online focus group interviews. Qualitative Health Research, 25(1), 122-133. doi: $10.1177 / 1049732314549602$

Twemlow, S. W., Biggs, B. K., Nelson, T. D., Vernberg, E. M., Fonagy, P., \& Twemlow, S. W. (2008). Effects of participation in a martial arts-based antibullying program in elementary schools. Psychology in the Schools, 45(10), 947959. doi: 10.1002/pits. 20344

Von Euler, C., \& Söderberg, U. (1957). The influence of hypothalamic thermoceptive structures on the electroencephalogram and gamma motor activity. Electroencephalography and clinical neurophysiology, 9(3), 391-408. Doi: 10.1016/0013-4694(57)90029-9

Walcott, C. M., \& Hyson, D. (2018). Results from the NASP 2015 membership survey, part one: Demographics and employment conditions [Research report]. Bethesda, MD: National Association of School Psychologists.

Williams, S., Clausen, M. G., Robertson, A., Peacock, S., \& McPherson, K. (2012). Methodological reflections on the use of asynchronous online focus groups in health research. International Journal of Qualitative Methods, 11(4), 368-383. doi: https://journals.sagepub.com/doi/full/10.1177/160940691201100405 
Wipfli, B., Landers, D., Nagoshi, C., \& Ringenbach, S. (2011). An examination of serotonin and psychological variables in the relationship between exercise and mental health. Scandinavian journal of medicine \& science in sports, 21(3), 474481. doi: doi.org/10.1111/j.1600-0838.2009.01049.x

Youth Sport Trust (2018). PE provision in secondary schools 2018. Survey

Research Report. Retrieved from https://www.youthsporttrust.org/system/files/resources/documents/PE\%20provisi on\%20in\%20secondary\%20schools $\% 202018 \% 20$ \%20Survey\%20Research\%20Report_0.pdf

Ysseldyke, J.E., Burns, M., Dawson, P., Kelley, B., Morrison, D., Ortiz, S... \& Telzrow, C. (2006). School Psychology: A blueprint for training and practice III. Bethesda, MD: National Association of School Psychologists.

Zahl, T., Steinsbekk, S., \& Wichstrøm, L. (2017). Physical activity, sedentary behavior, and symptoms of major depression in middle childhood. Pediatrics, 139 (2) doi: 10.1542/peds.2016-1711 